\title{
Shape-Selective C-HActivation of Aromatics to Biarylic Compounds Using Molecular Palladium in Zeolites
}

Jannick Vercammen ${ }^{1}$, Massimo Bocus ${ }^{2}$, Sam Neale $^{2}$, Aram Bugaev ${ }^{3}$, Sam Van Minnebruggen ${ }^{1}$, Julianna Hajek ${ }^{2}$, Patrick Tomkins ${ }^{1}$, Alexander Soldatov ${ }^{3}$, Andraž Krajnc ${ }^{4}$, Gregor Mali ${ }^{4}$, Véronique Van Speybroeck ${ }^{2 *}$, Dirk E. De Vos ${ }^{1 *}$

${ }^{1}$ Centre for Membrane Separations, Adsorption, Catalysis, and Spectroscopy for Sustainable Solutions (cMACS), KU Leuven, Leuven, Belgium

${ }^{2}$ Center for Molecular Modeling (CMM), Ghent University, Zwijnaarde, Belgium

${ }^{3}$ The Smart Materials Research Institute, Southern Federal University, Rostov-on-Don, Russia.

${ }^{4}$ Department of Inorganic Chemistry and Technology, National Institute of Chemistry, Ljubljana, Slovenia.

*Correspondence to: Veronique.vanspeybroeck@ugent.be (V.V.S.); dirk.devos@kuleuven.be (D.D.V.).

\section{Abstract}

The selective activation of inert $\mathrm{C}-\mathrm{H}$ bonds has emerged as a promising tool for avoiding wasteful traditional coupling reactions. Oxidative coupling of simple aromatics allows for a cost-effective synthesis of biaryls. The utilization of this technology is however severely hampered by a poor regioselectivity and by the limited stability of state of the art homogeneous Pd catalysts. Here we show that confinement of cationic $\mathrm{Pd}$ in the pores of a zeolite allows for a shape-selective $\mathrm{C}-\mathrm{H}$ activation of simple aromatics without functional handle or electronic bias. For instance, out of 6 possible isomers, 4,4'-bitolyl is produced with high shape-selectivity (80\%) in oxidative toluene coupling on Pd-Beta. Not only is a robust, heterogeneous catalytic system obtained; a concept is also set to control the selectivity in transition metal catalyzed arene $\mathrm{C}-\mathrm{H}$ activation by spatial confinement in zeolite pores.

\section{Main}

Biarylic bonds are important structural motifs in numerous organic chemicals. Their current industrial production relies on traditional coupling reactions (Suzuki, Ullmann etc.), which use pre-activated arenes (aryl halides, arylboronic acids etc.) ${ }^{1}$. The high cost of these intermediates and the associated waste generation usually direct their application towards high-end, specialty chemicals. Especially in the polymer industry there is a growing demand for biarylic monomers because of their superior chemical and physical stability, and their favorable health and safety profiles $^{2,3,4}$.

Direct functionalization of unreactive $\mathrm{C}-\mathrm{H}$ bonds via transition metal mediated $\mathrm{C}-\mathrm{H}$ activation has emerged as a promising alternative to traditional multi-step approaches ${ }^{1}$. C-H/C-H arene-arene couplings can in principle be used for the direct synthesis of biaryls from simple arenes, with e.g. $\mathrm{Pd}$ carboxylates as the catalysts ${ }^{6,7,8,9,10}$. If $\mathrm{O}_{2}$ is used as the oxidant, water is the only by-product ${ }^{11}$. Unfortunately, the multitude of $\mathrm{C}-\mathrm{H}$ bonds present in organic reactants, and the poor differentiation between them often result in poor regioselectivity. Consequently, reactions with simple arenes (e.g. toluene) lead to useless mixtures of many isomers ${ }^{12}$. Ortho-selectivity can be achieved if the existing substituent exerts a directing effect, as is typical for ketone groups, carbamates, amides 
etc ${ }^{13}$. Complex schemes have to be adopted to achieve some meta-selectivity, e.g. by installing pendant groups on the ligand of the catalytic complex ${ }^{14}$. Finally, para-selectivity was realized recently via pre-functionalization with highly electrophilic radicals ${ }^{15,16}$ and by installing extreme steric bulk on the aromatic reactant, e.g. by using pivaloyl-derivatized reactants ${ }^{17}$. Clearly, these complex reactants are quite far from the simple, monosubstituted aromatics that one would desire to functionalize in a regioselective way.

A so far unexplored option is to implement the molecular mechanisms of transition-metal catalyzed $\mathrm{C}-\mathrm{H}$ activation in the shape-selective confinement of a porous material like a zeolite. Zeolites are microporous, crystalline aluminosilicates; they are applied at large scale in industrial reactions because of their excellent activity and stability, and their low cost. The molecular dimensions and shape of the pores may direct the selectivity to particular products via the imposed steric constraints ${ }^{18}$. This shape-selectivity has been extensively studied for acid catalyzed reactions. However, zeolites have so far not been used to create a shape-selective environment around molecular catalysts that activate $\mathrm{C}-\mathrm{H}$ bonds of arenes to form more complex organics ${ }^{19}$.

Here we demonstrate that $\mathrm{Pd}(\mathrm{II})$ catalysts, site-isolated in the framework of zeolite Beta or some other 12-membered ring (MR) zeolites, uniquely allow to oxidatively couple toluene and other monosubstituted aromatics to biaryls, with exceptional selectivity for the $p, p$ '-dimer.

\section{$\underline{\text { Results }}$}

\section{Pd catalysts at work in zeolite hosts}

The most active homogeneous catalysts for oxidative coupling of arenes generally comprise a palladium salt, a strongly acidic additive (e.g. $p$-toluenesulfonic acid, TsOH) and acetic $\operatorname{acid}^{6,7,8,9,10}$. When applying such homogeneous catalysts to toluene (Fig. 1), an unbiased regioisomer distribution is obtained, with all $\mathrm{C}-\mathrm{H}$ bonds being activated by $\mathrm{Pd}$ to similar extents (Supplementary Figures 2-3; Supplementary Table 1). Furthermore, side products were identified, resulting from oxygenation, from benzylic coupling, and, especially at higher conversions, from consecutive coupling to trimers ( $4.8 \mathrm{~mol} \%$ trimer at $8.0 \%$ toluene conversion). We first set out to replace the strongly acidic additives by acid zeolites, initially without acetic acid to simplify the reaction mixture. At equal loadings of $\mathrm{Pd}(\mathrm{OAc})_{2}$, the bitolyl formation with addition of acid zeolites not only surpassed that with any other tested solid acid, but occasionally even the homogeneous catalyst tested in the same conditions (Fig. 1). Large pore zeolites (i.e. with 12membered rings) were required to offer sufficient space for toluene and other substituted arenes to react; medium pore zeolites such as H-ZSM-5 were only effective for the oxidative coupling of benzene. To our delight, zeolites not only with three-dimensional pores (H-Beta) but also with one-dimensional pores (H-MOR, H-ZSM-12 etc.), which are more susceptible to diffusion restrictions, could be used to boost the catalytic performance of $\mathrm{Pd}$ in this reaction.

The most remarkable feature of this disclosure is the regioselectivity in the biaryl product if zeolites are applied. Out of the 6 possible bitolyl regiomers, zeolites containing only 12-MR channels and no large cavities (H-MOR, H-ZSM-12, H-Beta) were highly selective for parasubstituted products. The combined selectivity for all products with at least one para-substituent reaches $97 \%$ in H-Beta, with a selectivity of $77 \%$ for $p, p$ '-bitolyl, compared to only $59 \%$ and $16 \%$ respectively for a homogeneous catalyst with TsOH. Zeolites with large cages (H-USY, H-MCM-22) showed a high combined selectivity for products with at least one ortho-substituent ( $72 \%$ for H-USY compared to $28 \%$ for TsOH). Furthermore, side-reactions, such as the coupling at the benzylic position or oxygenation reactions, were suppressed in 12-MR zeolites like H-Beta. 
On MCM-22, known for its surface activity ${ }^{20}$, some trimer formation was observed, but such consecutive coupling at higher conversions was inhibited in the microporous environment of the other tested 12-MR zeolites.

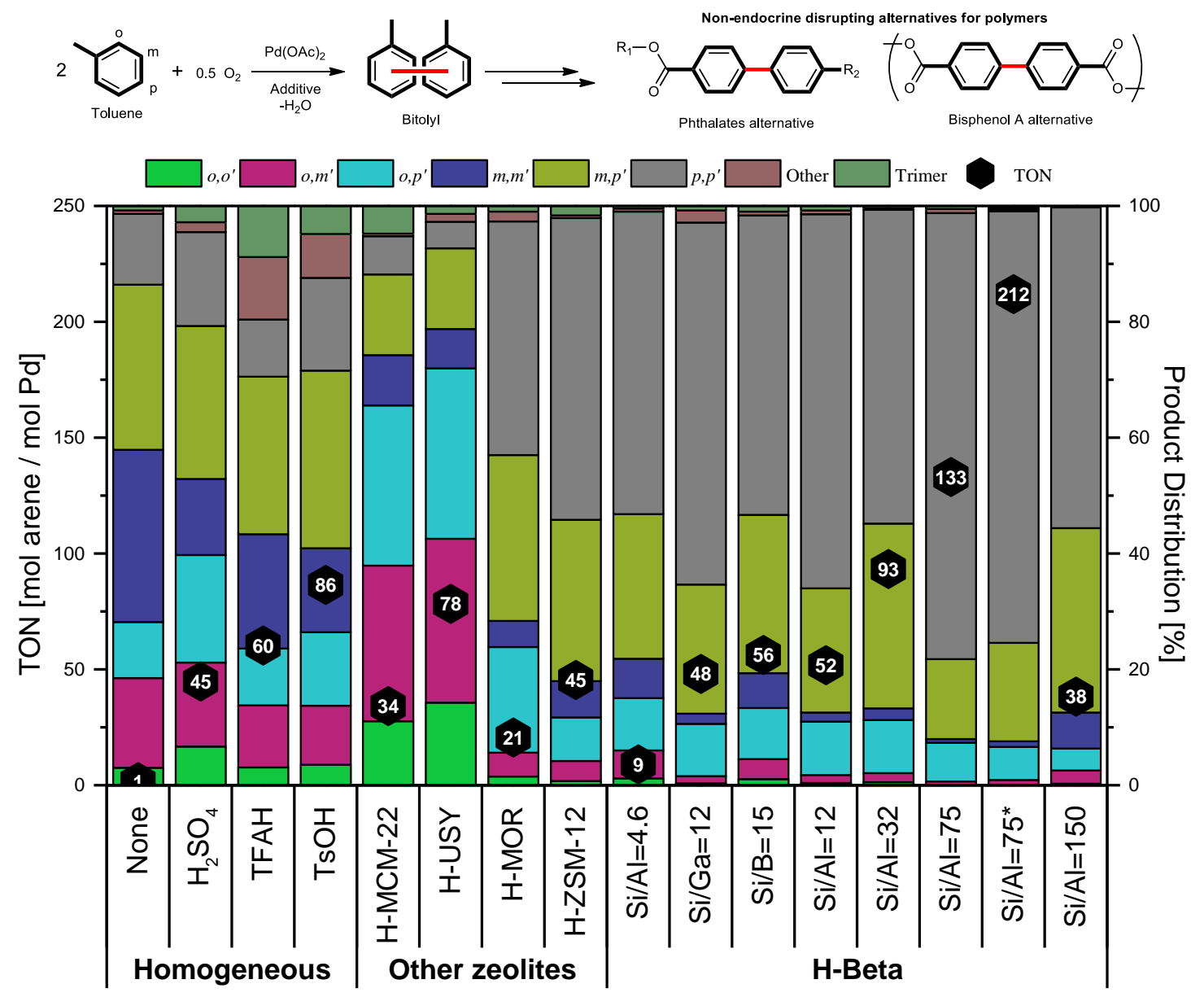

Fig. 1: Oxidative coupling of toluene with different additives. Reaction conditions: $15 \mu \mathrm{mol}$ $\mathrm{Pd}(\mathrm{OAc})_{2}, 2 \mathrm{ml}$ toluene, $90^{\circ} \mathrm{C}, 16$ bar $\mathrm{O}_{2}, 16 \mathrm{~h}$. Homogeneous reactions employed $0.3 \mathrm{mmol}$ of the additive and $1 \mathrm{ml}$ of acetic acid, while reaction with zeolites used $50 \mathrm{mg}$ at $\mathrm{Si} / \mathrm{Al}<50$ and 100 $\mathrm{mg}$ at a $\mathrm{Si} / \mathrm{Al}>50$. * Acetic acid (200 eq to $\mathrm{Pd}$ ) was added.

\section{Towards high activity and selectivity}

In view of the intriguing shape-selectivity for a double $\mathrm{C}-\mathrm{H}$ activation at the para-position combined with the exceptional activity of Pd-loaded H-Beta, we decided to further investigate this system (Supplementary Figures 4-11). Addition of small amounts of acetic acid (1 to 300 eq to $\mathrm{Pd}$ ) further boosted the performance to a turnover number (TON) of 212 or a yield of 16.8\%, while maintaining an identical product distribution (Supplementary Figure 12). High zeolite Si/Al ratios were required for obtaining higher TON values (Fig. 1). This is likely unrelated to acid strength, since similar results were obtained with Ga- and B-substituted Beta. Rather, the beneficial effect of the high $\mathrm{Si} / \mathrm{Al}$ ratio seems related to the more hydrophobic properties of such a zeolite (Fig. 1). A decline in regioselectivity during the reaction was observed at a Si/Al ratio of 32 (Supplementary Figure 6) while the regioselectivity remained constant and even improved initially at the higher $\mathrm{Si} / \mathrm{Al}$ ratio of 75 (Fig. 4b). This was attributed to a poisoning effect of the formed water ${ }^{21}$, and 
confirmed by spiking reactions with $100 \mu \mathrm{l}$ of water (370 eq to Pd), which decreased the TON drastically for a Si/Al of 32 from 93 to 2, but only slightly for the more hydrophobic zeolite Beta with a Si/Al of 75, from 133 to 96. The excellent catalytic stability of H-Beta is further highlighted by a doubling of the TON from 212 to 422 (yield of $34 \%$ bitolyl) upon increasing the reaction temperature from $90^{\circ} \mathrm{C}$ to $110^{\circ} \mathrm{C}$ (Fig. 2). High turnover numbers were obtained at $\mathrm{O}_{2}$ pressures of 16 bar or more; but addition of $\mathrm{Fe}(\mathrm{OTf})_{3}$ allows the Beta zeolite system to also reach significant TONs under only 1 bar of $\mathrm{O}_{2}$ (see Supplementary Table 2).

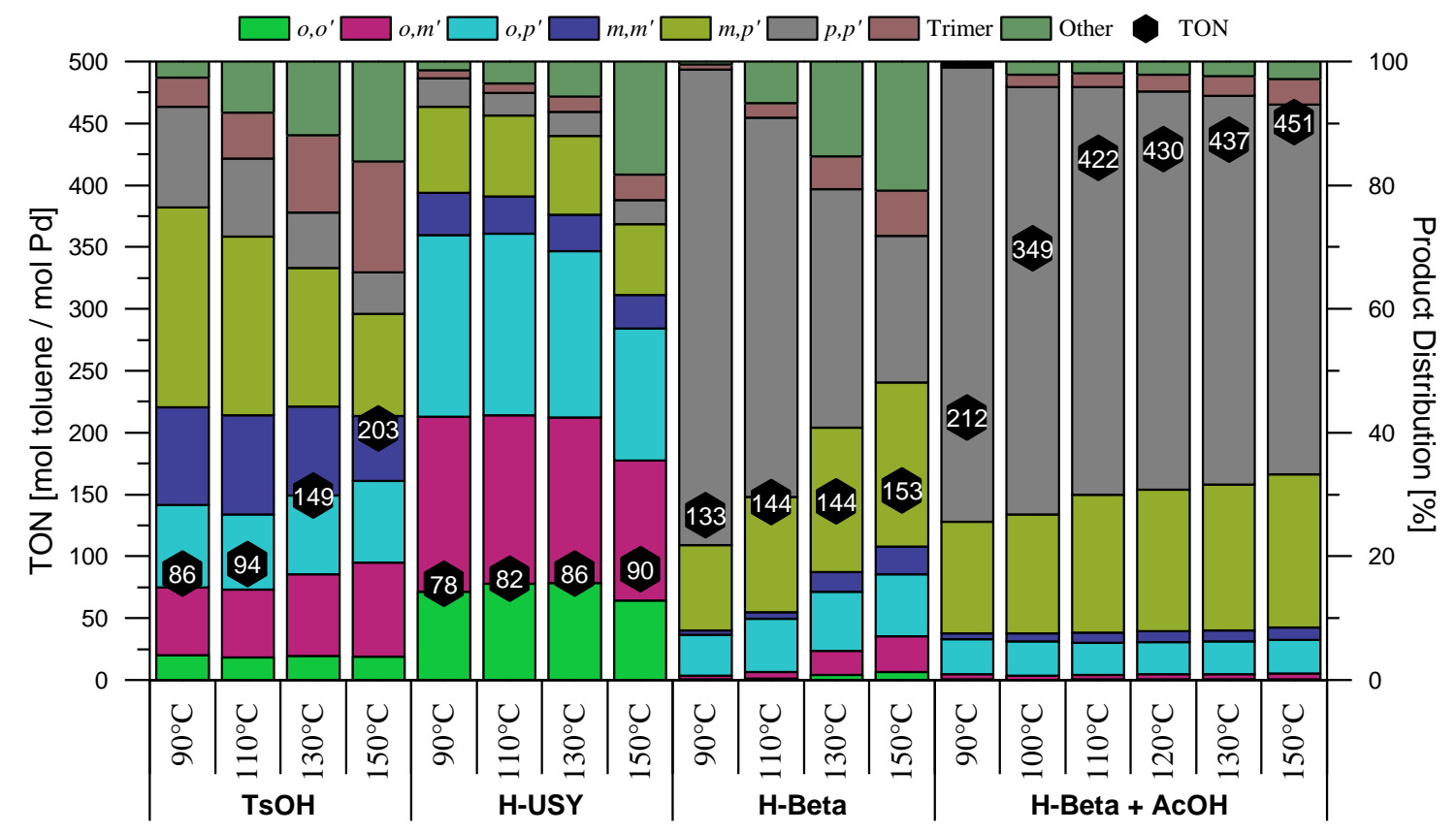

Fig. 2: Variation of the reaction temperature in the oxidative coupling of toluene. Reaction conditions: $15 \mu \mathrm{mol} \mathrm{Pd}(\mathrm{OAc})_{2}, 2 \mathrm{ml}$ toluene, 16 bar $\mathrm{O}_{2}, 16$ hours. Following amounts were employed: TsOH (0.3 mmol) and $1 \mathrm{ml} \mathrm{AcOH}, \mathrm{H}-\mathrm{USY}(\mathrm{Si} / \mathrm{Al}=40,50 \mathrm{mg}), \mathrm{H}-\mathrm{Beta}(\mathrm{Si} / \mathrm{Al}=75,100$ $\mathrm{mg}), \mathrm{H}-\mathrm{Beta}+\mathrm{AcOH}(200$ eq $\mathrm{AcOH}$ to $\mathrm{Pd})$.

\section{Nature of the active site}

The catalytic species formed upon loading the $\mathrm{H}$-Beta zeolite with $\mathrm{Pd}(\mathrm{OAc})_{2}$ was characterized in detail (Fig. 3). X-Ray absorption near edge structure (XANES) spectra are consistent with Pd(II), surrounded by 4 neighbouring oxygen atoms in a square planar coordination; Pd prevails in the +2 state, while the contribution of $\operatorname{Pd}(0)$ nanoparticles is only minor (Supplementary Figures 14-15, Supplementary Table 3). When the loading is performed in toluene, the spectral changes suggest that one of these oxygen atoms may be replaced by a nearby toluene molecule (Supplementary Figure 16). Extended X-ray absorption fine structure (EXAFS) spectra were successfully modelled with mononuclear Pd(II) with 4 oxygen neighbours; while there could be a small contribution of $\operatorname{Pd}(0)$ nanoparticles, the presence of di- or trinuclear Pd, like in the precursor Pd acetate, can be excluded. Again, upon loading in toluene, the best fit is obtained with 3 oxygen atoms from the zeolite and an acetate, together with a nearby toluene (Fig. 3a; Supplementary Figure 17; Supplementary Tables 4-6). Solid state ${ }^{13} \mathrm{C}$ magic-angle spinning (MAS) NMR of the acid Beta zeolite loaded with ${ }^{13} \mathrm{C}$ enriched $\mathrm{Pd}$ acetate proved that one acetate out of two reacts to form acetic acid moving freely in the pores, while a second acetate remains immobilized at a $\mathrm{Pd}$ centre (Supplementary Figure 21). The mutual proximity of acetate ligands was probed using $2 \mathrm{D}{ }^{13} \mathrm{C}-{ }^{13} \mathrm{C}$ 
spin-diffusion experiments and $1 \mathrm{D}{ }^{13} \mathrm{C}$ double-quantum (DQ)-filtered experiments (Fig. 3; Supplementary Figures 22-23); this proved that the individual acetates are spatially isolated from other acetate ligands. The combined information points to a molecular $\mathrm{Pd}(\mathrm{II})$ species that receives one charge compensation from the framework and one from a pendant acetate ligand. However, it does not rule out the possibility that a fraction of Pd is compensated by two anionic zeolite charges.

Such species can be formed in zeolite Beta either in-situ in toluene, or prior to the reaction (Supplementary Figure 13). The zeolite amount was varied at a fixed amount of Pd; the reaction rate linearly increases until a $\mathrm{Al} / \mathrm{Pd}$ ratio of 1 is reached. This supports the single charge compensation of each Pd centre by the zeolite (Fig. 4a). The crucial presence of the acetate ligand was shown by the absence of any reaction if a $\mathrm{Pd}(\mathrm{II})$-zeolite was prepared via classical ionexchange with $\mathrm{Pd}\left(\mathrm{NH}_{3}\right)_{4}^{2+}$ and subsequent calcination (Supplementary Figure 24). The activity could only be restored by addition of acetic acid. Palladium is strongly bound to the framework as shown by a successful filtration test, which evidences a fully heterogeneous Pd-zeolite catalyst (Fig. 4b; Supplementary Figures 25-26; Supplementary Table 7).

a

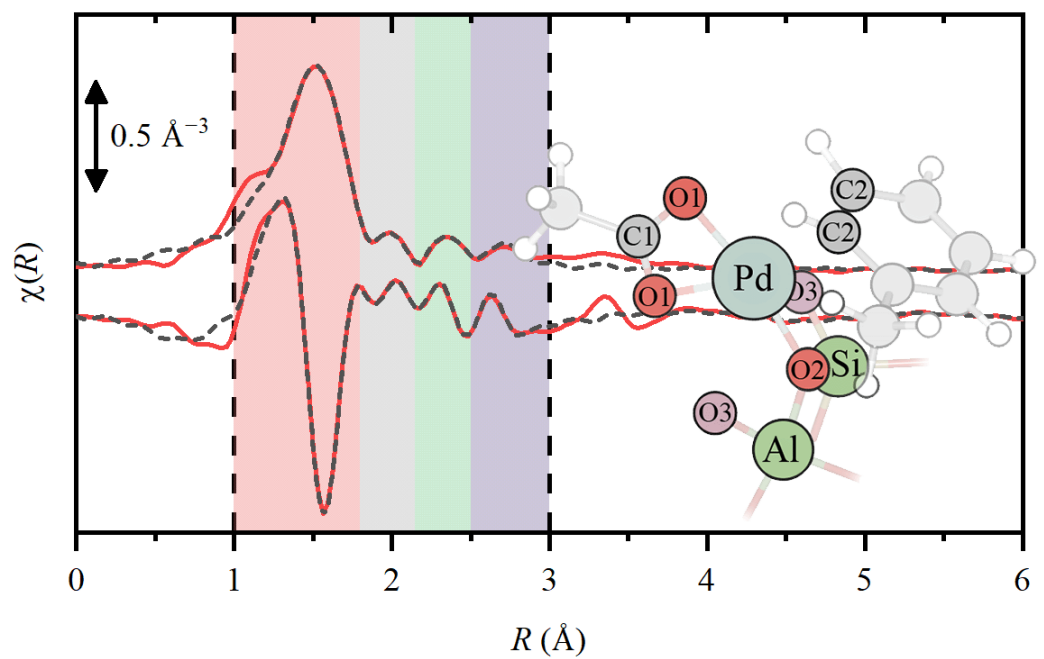



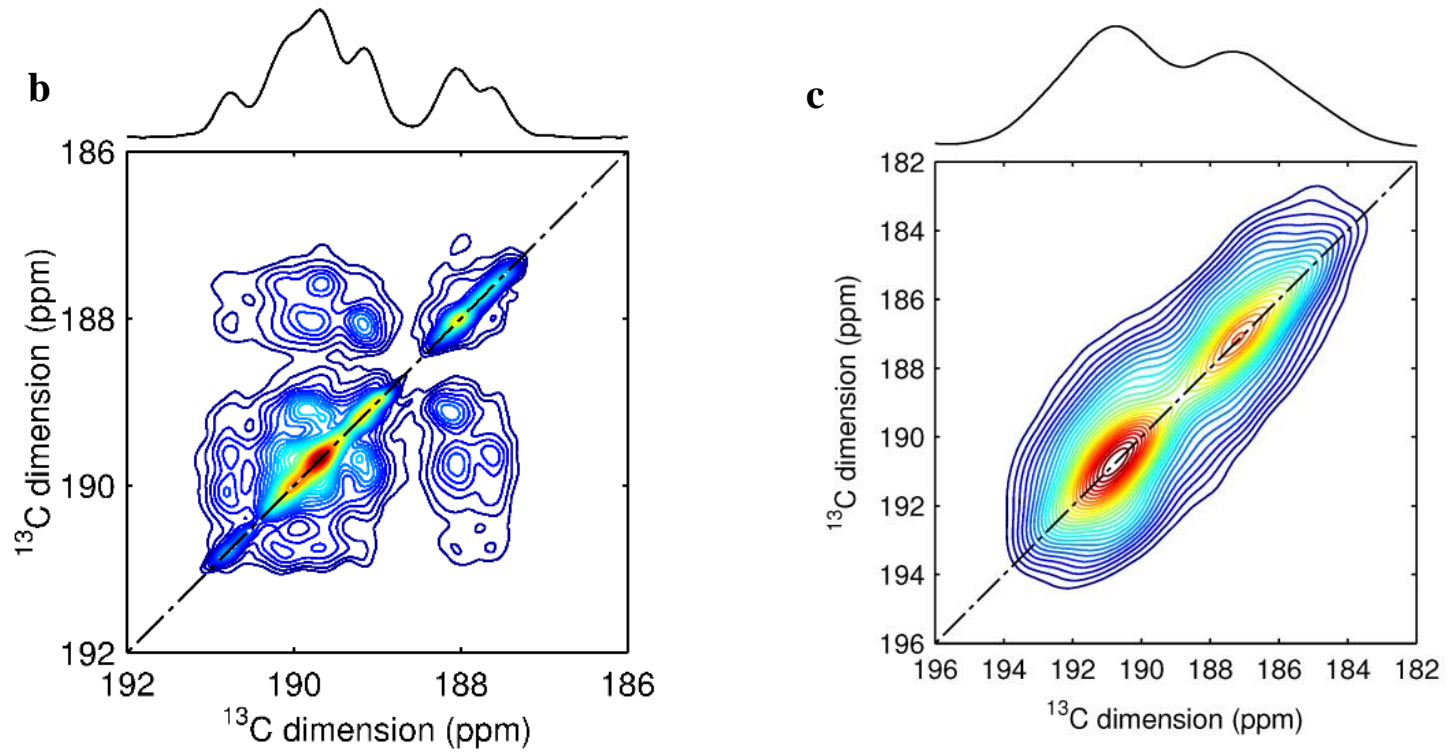

Fig. 3: Spectroscopic characterization of Pd-loaded Beta zeolite. a, Experimental (red) and fitted (dashed black) EXAFS spectra for Pd-Beta, pre-loaded in toluene. For the fit, the theoretically proposed intermediate $\mathbf{V}$ was used (Fig. 6b). The different background colors highlight the region with the major contribution from the atoms of the corresponding color. b,c, 2D ${ }^{13} \mathrm{C}-{ }^{13} \mathrm{C}$ spin-diffusion MAS NMR spectra of the ${ }^{13} \mathrm{C}$-enriched $\mathrm{Pd}(\mathrm{OAc})_{2}(\mathbf{b})$ and $\mathrm{Pd}-\mathrm{Beta}(\mathbf{c})$. The absence of cross-peaks in the latter spectrum proves that the acetate ligands are spatially isolated.

a

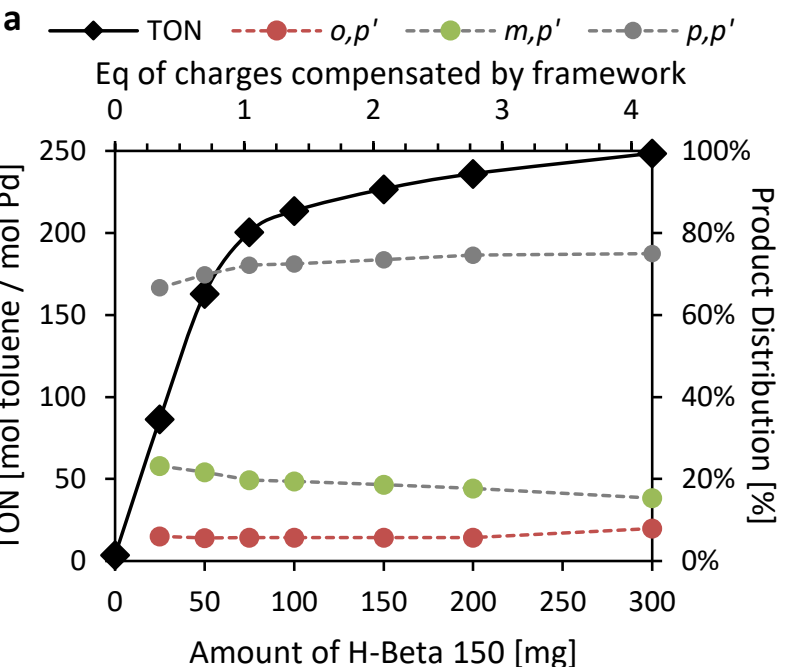

b

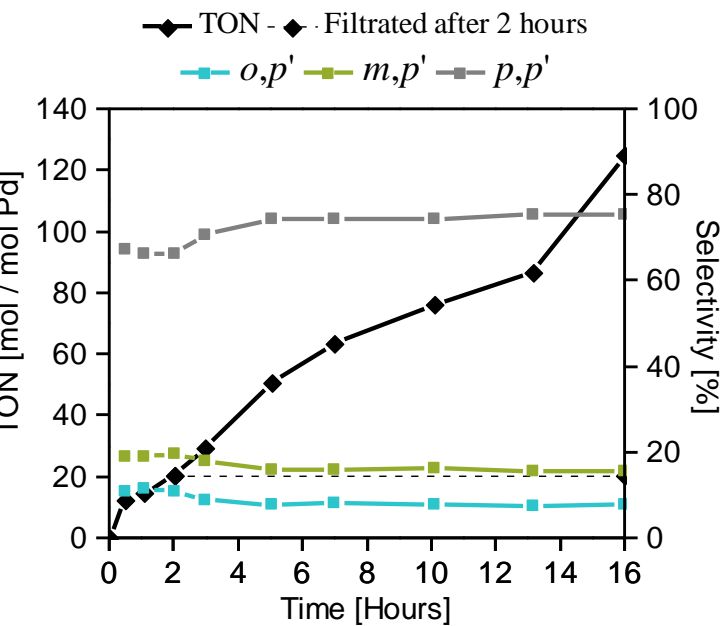

Fig. 4: Variation of the amount of H-Beta, kinetics and filtration test. a, Variation of the amount of $\mathrm{H}-\mathrm{Beta}(\mathrm{Si} / \mathrm{Al}=75)$ in the oxidative coupling of toluene $(2 \mathrm{ml})$ with $3 \mathrm{mmol}$ of acetic acid added and a reaction time of $16 \mathrm{~h}\left(15 \mu \mathrm{mol} \mathrm{Pd}(\mathrm{OAc})_{2}, 16\right.$ bar $\mathrm{O}_{2}, 16$ hours $)$. b, Time profile and filtration test for the oxidative coupling of toluene with $\mathrm{H}$ Beta $(100 \mathrm{mg}, \mathrm{Si} / \mathrm{Al}=75)$ without additional acetic acid. After 2 hours of reaction, the solids were removed by filtration, and the filtrate was reacted further with fresh $\mathrm{H}-\mathrm{Beta}(\mathrm{Si} / \mathrm{Al}=75,100 \mathrm{mg})$ for 14 hours (dashed line; see Supplementary Figure 26-27 for detailed description). Reaction conditions: $15 \mu$ mol Pd(OAc) 2,2 $\mathrm{ml}$ toluene, $90^{\circ} \mathrm{C}, 16$ bar $\mathrm{O}_{2}$. 


\section{Producing useful biarylic monomers}

The methodology could easily be expanded to the oxidative coupling of other simple arenes of interest in polymer chemistry. Oxidative coupling of anisole could lead to an alternative synthetic strategy for 4,4'-dihydroxybiphenyl, which is not only a starting material for heat-resistant materials, but also for replacements of the disputed bisphenol A derived polycarbonates ${ }^{22,23}$. A high activity (TON of 197) and selectivity of $77 \%$ for $p, p$ '-bianisyl were obtained in the oxidative homocoupling of anisole with H-Beta (Fig. 5a). While the homogeneous reaction with TsOH formed up to $56 \%$ of bisanisyl $\mathrm{F}$ due to the consecutive hydrolysis of anisole, oxidation of the formed methanol to formaldehyde and condensation reaction with anisole, only $4 \%$ of bisanisyl $\mathrm{F}$ was formed with H-Beta. Lastly, p,p'-bianisyl selectively precipitated from the reaction mixture upon cooling down, not only simplifying the work-up, but also yielding high purity crystals (Supplementary Figures 30-31). The regioselective coupling also applies to disubstituted arenes like $o$-xylene, from which the desired 3,4,3',4'-tetramethylbiphenyl was obtained in $90 \%$ overall selectivity (Fig. 5b). The latter is a direct precursor of 3,4,3',4'-biphenyldicarboxylic acid, from which high value polyimide can be produced.
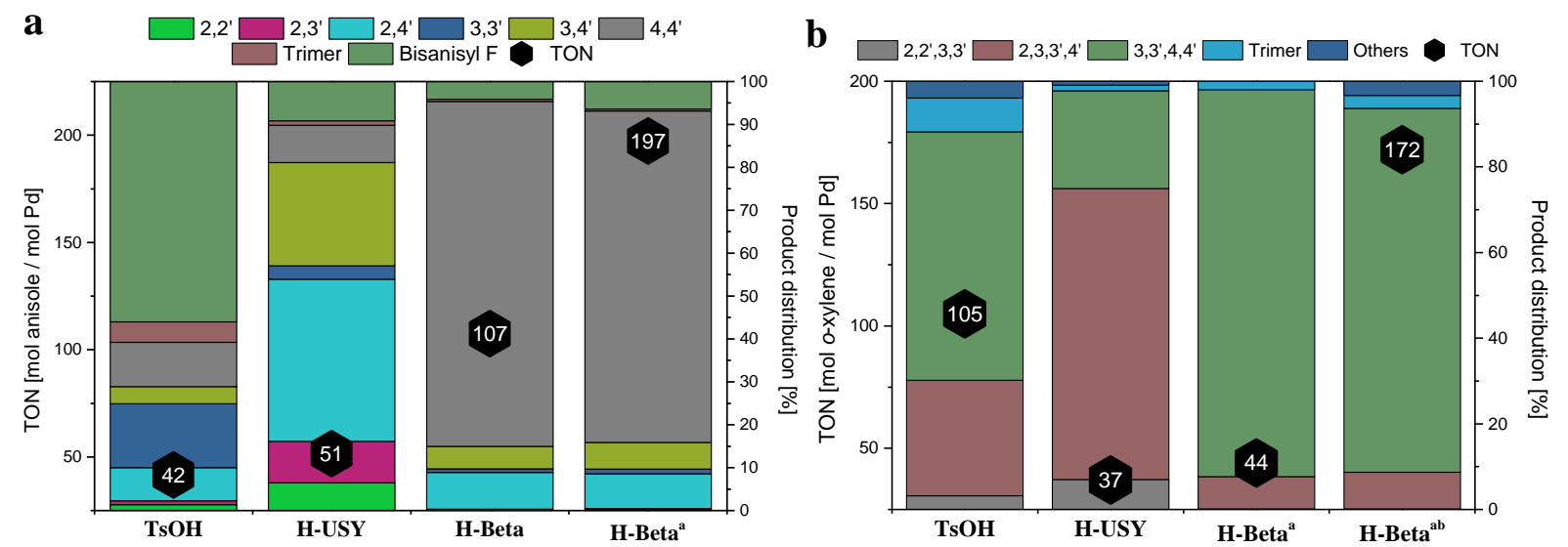

Fig. 5: Substrate scope. a,b, Oxidative coupling of anisole (a) and $o$-xylene (b). Reaction conditions: $15 \mu \mathrm{mol} \mathrm{Pd}(\mathrm{OAc})_{2}, 2 \mathrm{ml}$ arene, 16 hours 16 bar $\mathrm{O}_{2}$. Following amounts were employed: TsOH (0.3 mmol) and $1 \mathrm{ml} \mathrm{AcOH}, \mathrm{H}-\mathrm{USY}(\mathrm{Si} / \mathrm{Al}=40,50 \mathrm{mg}), \mathrm{H}-\mathrm{Beta}(\mathrm{Si} / \mathrm{Al}=75,100$ $\mathrm{mg}) .{ }^{\mathrm{a}} 3 \mathrm{mmol}$ of acetic was added, ${ }^{\mathrm{b}}$ reaction conducted at $110^{\circ} \mathrm{C}$.

\section{Density functional theory calculations}

To support the experimental observations and to obtain in depth mechanistic information, a full catalytic cycle was proposed and calculated by means of a combination of first principle static and molecular dynamics (MD) based dispersion-corrected DFT calculations. The first principles MD calculations were employed to explore the flexible behavior of the active catalytic site when docked to the zeolite in various stages of catalysis at realistic temperature and toluene loading, whereas static DFT calculations afforded adsorption free energies and allowed for the construction of regiodivergent reaction profiles to explore the origin of shape-selectivity in the reaction. The proposed catalytic cycle for the homocoupling reaction of toluene in H-Beta is reported in Figure 6a, whereas the associated free energy profile is shown in Figure 6b.

The catalytic reaction begins with adsorption of $\mathrm{Pd}(\mathrm{OAc})_{2}$ into the zeolite framework, where, relative to the empty $\mathrm{H}$-Beta and the isolated $\mathrm{Pd}(\mathrm{OAc})_{2}$, the adsorption free energy is favorable and amounts to $-75 \mathrm{~kJ} / \mathrm{mol}$ (species II) at $363 \mathrm{~K}$ (Fig. 6b). Subsequently, the actual docking can take place as described experimentally to release $\mathrm{AcOH}$ and afford $\mathrm{Pd}(\mathrm{OAc})$ species III (-80 
$\mathrm{kJ} / \mathrm{mol}$ ). This is mildly exergonic with respect to the preceding intermediate II, with a decrease in free energy of $5 \mathrm{~kJ} / \mathrm{mol}$. This proposed mechanism of docking to form III is fully supported by ${ }^{13} \mathrm{C}$ NMR measurements (vide supra, Fig. 3). The docked Pd species III then acts as initial species in the catalytic cycle and, based on our calculations, we propose that the reaction proceeds through four elementary reaction steps (Fig. 6). After the first toluene molecule has been adsorbed in the zeolite with a favorable free energy gain of $37 \mathrm{~kJ} / \mathrm{mol}, \mathrm{C}-\mathrm{H}$ activation takes place through a concerted metalation-deprotonation (CMD, Step 1 in Fig. 6), a pathway that is well-studied in literature ${ }^{24}$. Firstly, the toluene must enter in the coordination sphere of Pd, substituting one of the zeolite oxygens to afford $\eta^{2}$-(tolyl)Pd species $\mathbf{V}(-122 \mathrm{~kJ} / \mathrm{mol})$. The presence of $\mathbf{V}$ as key reaction intermediate is in good agreement with the XAS measurements of the catalyst pre-loaded with toluene (Fig. 3). Then, CMD can take place, where the calculated activation energies indicate that the reaction involving the para carbon is the most accessible, as the barrier amounts to $91 \mathrm{~kJ} / \mathrm{mol}$, vs. $101 \mathrm{~kJ} / \mathrm{mol}$ and $103 \mathrm{~kJ} / \mathrm{mol}$ for activation at the meta and ortho positions respectively (Supplementary Figure 40). This suggests that the large overall 97\% para selectivity observed experimentally is mainly governed by the kinetics of this initial CMD step. It might be noticed that the para product has a higher energy than the others; this is caused by the methyl group directly pointing toward the zeolite walls and creating some short contacts (Supplementary Figure 41). Further support for para activation was gained through an MD simulation of the reactant state, in which a predominant interaction between $\mathrm{Pd}$ and the toluene para carbon was observed (Supplementary Figures 42-44).

After the first CMD step, we propose further C-C coupling to occur through migratory insertion (MI, Step 2 in Fig. 6, Supplementary Figures 45-49) ${ }^{25,26}$. The calculated reaction barriers for this process are relatively low $(68 \mathrm{~kJ} / \mathrm{mol}$ for $m$, $p$ '-selectivity, $69 \mathrm{~kJ} / \mathrm{mol}$ for $p$, $p$ '-selectivity and 89 $\mathrm{kJ} / \mathrm{mol}$ for $o, p^{\prime}$-selectivity). To further test the validity of the proposed MI mechanism, we computed an alternative second CMD mechanism. The resulting barriers for such processes were much higher (with $\Delta \mathrm{G}^{\ddagger}=187 \mathrm{~kJ} / \mathrm{mol}$ for $p$, $p^{\prime}$-selectivity, Supplementary Figure 51 and Supplementary Tables 14-15), thus giving further support to the MI mechanism.

Moreover, experimental kinetic studies revealed a first-order rate dependence in $\mathrm{Pd}$ (Supplementary Figure 36), thus further supporting the proposed MI mechanism as the favored mechanism of C-C coupling over a bimetallic transmetalation process. While the MI barrier difference between $m, p^{\prime}$ and $p, p^{\prime}$ is small (with $\Delta \Delta \mathrm{G}^{\ddagger}=1 \mathrm{~kJ} / \mathrm{mol}$ for the regiodivergent analogues of TS(VII-VIII)), the $o, p$ ' activation energy is much higher, which arises from the increased steric clashing between the methyl group and the zeolite pore (Supplementary Figure 49). The calculations thus suggest that the predominant overall para selectivity is primarily dictated by the first CMD step, while more subtle effects are at play in the rest of the catalytic cycle to afford the overall 77\% yield for $p, p$ '-bitolyl (Supplementary Figure 47).

Subsequently, from VIII, the transfer of a hydrogen atom from the C-C coupled bitolyl moiety to Pd needs to take place. However, the lack of an available base does not allow for a direct reductive deprotonation, while the anti-configuration of $\mathrm{Pd}$ and the hydrogen prevents a $\beta$-hydride elimination ${ }^{26,27}$. We thus propose that in Step 3 a hydrogen transfer process from the resulting C$\mathrm{C}$ coupled cyclohexadienyl adduct VIII to the Pd center can take place, facilitated by $\mathrm{AcOH}$ itself. However, accurate characterization of corresponding transition states proved challenging, and so explicit TS energies are not reported in Fig. 6b (Supplementary Figure 50). The eventually obtained Pd hydride IX $(-145 \mathrm{~kJ} / \mathrm{mol})$ was found to be a stable energy minimum in the free energy reaction cycle. Finally, from IX, active site regeneration (Step 4) is proposed to take place via $\mathrm{O}_{2-}$ 
insertion. Characterization of this process was carried out with a $5 \mathrm{~T}$ cluster model in order to efficiently compute the spin-forbidden nature of the mechanism, as previously identified by Stahl 28. These calculations revealed that hydrogen atom abstraction (HAA) is favored to form the resulting $\mathrm{Pd}-\mathrm{OOH}$ species and ultimately release $\mathrm{H}_{2} \mathrm{O}_{2}$ (Supplementary Figures 52-53)
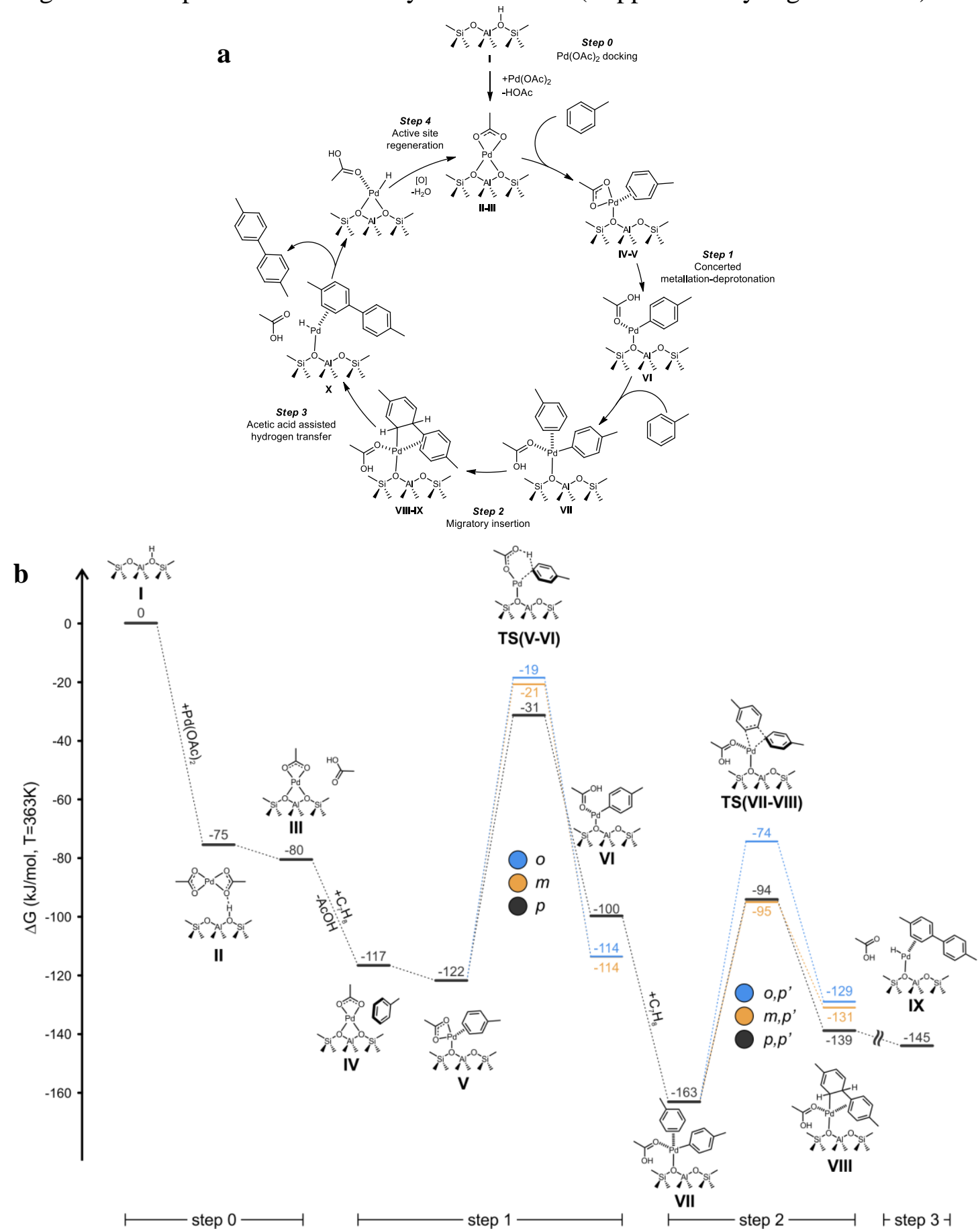

Fig. 6: Proposed catalytic cycle for the oxidative coupling of toluene using H-Beta. a, Reaction scheme. b, Free energy profile of the proposed mechanism for the oxidative coupling of toluene. The profile $(\mathrm{kJ} / \mathrm{mol})$ was computed at the B3LYP-D3//PBE-D3 level of theory at $363 \mathrm{~K}$. The schematic representations of the intermediates and transition states are related to the mechanism 
leading to the $p, p$ '-bitolyl product. Enthalpic and entropic contributions to the free energy are reported in Supplementary Tables 10-15.

\section{Conclusions}

We report the development of a strategy to control the regioselectivity in the $\mathrm{C}-\mathrm{H}$ functionalization of aromatics without functional handle. The elusive para-selectivity is obtained through a nontraditional shape-selectivity in which exchanged cationic palladium in zeolites is utilized, rather than the acidic sites of zeolites. Not only does the technology grant access to a novel range of monomers for advanced polymers; the methodology also provides a paradigm for introducing shape-selectivity in transition metal catalyzed $\mathrm{C}-\mathrm{H}$ activations of arenes.

\section{Methods}

\section{Reaction Procedure}

Generally, toluene $(2.00 \mathrm{ml}, 18.88 \mathrm{mmol}$, Acros), acetic acid (172 $\mu 1,0.3 \mathrm{mmol}$, Acros) and $n$-decane $\left(50.0 \mu \mathrm{l}\right.$, internal standard) were added to $\mathrm{Pd}(\mathrm{OAc})_{2}(3.37 \mathrm{mg}, 0.015 \mathrm{mmol}$, Acros $)$ and $\mathrm{H}$-Beta (100.0 mg, Südchemie, $\mathrm{Si} / \mathrm{Al}=75)$ in a $3 \mathrm{ml}$ glass liner. Homogeneous reactions were performed with $0.3 \mathrm{mmol}$ of the additive and $1 \mathrm{ml}$ of acetic acid, while reactions with zeolites employed $50 \mathrm{mg}$ of the solid without acetic acid. Zeolites with a Si/Al above 50 employed $100 \mathrm{mg}$ of the solid. The liner was sealed in a homemade, stainless steel autoclave (Supplementary Figure 1 ), and purged five times with pure $\mathrm{O}_{2}$ and subsequently pressurized with pure $\mathrm{O}_{2}$ to 16 bar. The reactor was placed in a preheated 4-well aluminum block. The internal temperature dependence was calibrated beforehand, and the set temperature of the heating block was adjusted as to obtain internally $90^{\circ} \mathrm{C}$.

After 16 hours, the reactor was cooled, and the zeolite was separated from the reaction mixture via centrifugation. The reaction mixture was analyzed with GC-FID. When anisole was used as aromatic reagent, the 4,4'-bianisyl product precipitated from the reaction medium upon cooling down. Therefore this mixture was extracted with $20 \mathrm{ml}$ of $\mathrm{CHCl}_{3}$ before the analysis with GC-FID so as to fully solubilize all products. In accordance to literature reports, the TON is defined as TON $=2 \times$ mol biaryl $/ \mathrm{mol} \mathrm{Pd}$.

The reactors have intentional weak spots at the capillaries on the top of the reactor which function as burst discs. Note: a thorough safety assessment has to be made before applying such hazardous conditions and these reactions should only be performed in proper equipment that ensures safe handling at all times.

\section{Reaction analysis}

Reaction mixtures were analyzed quantitatively on a Shimadzu GC-2014 equipped with a CP-SIL $5 \mathrm{CB}$ column (Agilent, 100\% PDMS, 60 meters, $0.25 \mu \mathrm{m}$ film thickness, $0.32 \mathrm{~mm}$ ID). Samples of $1 \mu \mathrm{l}$ were injected automatically with an AOC-20s autosampler and AOC-20i auto-injector aided by the GCsolution softwarebundle (version 2.44.00). Products were identified on an Agilent 6890 gas chromatograph equipped with a HP-1 MS column and coupled to a 5973 MSD mass spectrometer or by comparison with commercially obtained or synthesized reference samples. ${ }^{1} \mathrm{H}$ NMR spectra of liquid samples were recorded on a Bruker Avance III HD 400 console at 400 $\mathrm{MHz}$, equipped with a $5 \mathrm{~mm}$ PABBO BB/ $/{ }^{19} \mathrm{~F}-{ }^{1} \mathrm{H} / \mathrm{D}$ probe and the data were analyzed using the MestReNova 12.0.2 software package. 


\section{Pre-loading}

Zeolites can be pre-loaded with $\mathrm{Pd}(\mathrm{OAc})_{2}$ prior to the reaction by contacting the solid with an appropriate amount of $\mathrm{Pd}(\mathrm{OAc})_{2}$ in a suitable solvent (e.g. $\mathrm{CHCl}_{3}$, toluene). After stirring for 24 hours, the zeolite was separated by centrifugation, and washed twice with the loading solvent (10 $\mathrm{ml} / \mathrm{g}$ zeolite). The solid was then dried in vacuo $\left(30^{\circ} \mathrm{C}, 30 \mathrm{mbar}\right.$, overnight) and used as such.

\section{Data availability}

The findings of this study are available in the main text or the supplementary materials. Atomic coordinates of optimized computational models and initial and final configurations of molecular dynamics trajectories are supplied in a Supplementary Data file. All data are available from the authors upon reasonable request.

\section{References}

1. Hassan, J., Sévignon, M., Gozzi, C., Schulz, E. \& Lemaire, M. Aryl-Aryl Bond Formation One Century after the Discovery of the Ullmann Reaction. Chem. Rev., 102, 1359-1469 (2002).

2. Mondschein, R. J. et al., Synthesis and Characterization of Amorphous Bibenzoate (Co)polyesters: Permeability and Rheological Performance. Macromolecules, 50, 7603-7610 (2017).

3. De Smit, E. et al., Hydroalkylation catalyst and process for use thereof. U.S. patent 2014/0378697 (2014).

4. Dakka, J. M. et al. Biphenyl esters, their production and their use in the manufacture of plasticizers. U.S. patent 9,556,103 (2017).

5. Chen, X., Engle, K. M., Wang, D.-H. \& Yu, J.-Q. Palladium(II)-catalyzed C-H activation/C-C cross-coupling reactions: versatility and practicality. Angew. Chem. Int. Ed., 48, 5094-5115 (2009).

6. Xu, B.-Q., Sood, D., Iretskii, A.V. \& White, M. G. Direct Synthesis of Dimethylbiphenyls by Toluene Coupling in the Presence of Palladium Triflate and Triflic Acid. J. Catal., 187, 358-366 (1999).

7. Izawa, Y. \& Stahl, S. S. Aerobic Oxidative Coupling of $o$-Xylene: Discovery of 2Fluoropyridine as a Ligand to Support Selective Pd-Catalyzed C-H Functionalization. Adv. Synth. Catal., 352, 3223-3229 (2010).

8. Wang, D., Izawa, Y. \& Stahl, S. S. Pd-Catalyzed Aerobic Oxidative Coupling of Arenes: Evidence for Transmetalation between Two Pd(II)-Aryl Intermediates. J. Am. Chem. Soc., 136, 9914-9917 (2014).

9. Wang, D. \& Stahl, S. S. Pd-Catalyzed Aerobic Oxidative Biaryl Coupling: Non-Redox Cocatalysis by $\mathrm{Cu}(\mathrm{OTf})_{2}$ and Discovery of $\mathrm{Fe}(\mathrm{OTf})_{3}$ as a Highly Effective Cocatalyst. J. Am. Chem. Soc., 139, 5704-5707 (2017).

10. Álvarez-Casao, Y. et al., Palladium-Catalyzed Cross-Dehydrogenative Coupling of $o$-Xylene: Evidence of a New Rate-Limiting Step in the Search for Industrially Relevant Conditions. ChemCatChem, 10, 2620-2626 (2018).

11. Yang, Y., Lan, J. \& You, J. Oxidative C-H/C-H Coupling Reactions between Two (Hetero)arenes. Chem. Rev., 117, 8787-8863 (2017).

12. Kuhl, N., Hopkinson, M. N., Wencel-Delord, J. \& Glorius, F. Beyond Directing Groups: Transition-Metal-Catalyzed CH Activation of Simple Arenes. Angew. Chem. Int. Ed., 51, 10236-10254 (2012). 
13. Sambiagio, C. et al., comprehensive overview of directing groups applied in metal-catalysed C-H functionalisation chemistry. Chem. Soc. Rev., 47, 6603-6743 (2018).

14. Leow, D., Li, G., Mei, T.-S. \& Yu, J.-Q. Activation of remote meta-C-H bonds assisted by an end-on template. Nature, 486, 518-522 (2012).

15. Boursalian, G. B., Ham, W. S., Mazzotti, A. R. \& Ritter, T. Charge Transfer Directed Radical Substitution Enables para-Selective C-H Functionalization. Nat. Chem., 8, 810-815 (2016).

16. Berger, F. et al., Site-selective and versatile aromatic C-H functionalization by thianthrenation. Nature, 567, 223-228 (2019).

17. Dey, A., Maity, S. \& Maiti, D. Reaching the south: metal-catalyzed transformation of the aromatic para-position. Chem. Commun., 52, 12398-12414 (2016).

18. Van Speybroeck, V. et al., Advances in theory and their application within the field of zeolite chemistry. Chem. Soc. Rev., 44, 7044-7111 (2015).

19. Kosinov, N., Liu, C., Hensen, E. J. M. \& Pidko, E. A. Engineering of Transition Metal Catalysts Confined in Zeolites. Chem. Mater., 30, 3177-3198 (2018).

20. Lawton, S. L., Leonowicz, M. E., Partridge, R. D., Chu, P. \& Rubin, M. K. Twelve-ring pockets on the external surface of MCM-22 crystals. Micropor. Mesopor. Mat., 23, 109-117 (1998).

21. Van Velthoven N. et al., Single-site metal-organic framework catalysts for the oxidative coupling of arenes via C-H/C-H activation. Chem. Sci., 10, 3616-3622 (2019).

22. Kaplan, G. Preparation of biphenols by oxidative coupling of alkylphenols using a recyclable copper catalyst. U.S. patent 2003/0050515 (2003)

23. Eckardt, M., Greb, A., Simat, T. J. Polyphenylsulfone (PPSU) for baby bottles: a comprehensive assessment on polymer-related non-intentionally added substances (NIAS). Food Addit. Contam. Part A, 35, 1421-1437, (2018)

24. Davies, D. L., Macgregor, S. A. \& McMullin, C. L. Computational Studies of CarboxylateAssisted C-H Activation and Functionalization at Group 8-10 Transition Metal Centers. Chem. Rev., 117, 8649-8709 (2017).

25. Chen, B., Hou, X., Li, Y. \& Wu, Y. Mechanistic Understanding of the Unexpected Meta Selectivity in Copper-Catalyzed Anilide C-H Bond Arylation. J. Am. Chem. Soc., 133, 7668-7671 (2011).

26. Deng, C., Zhang, J. \& Lin, Z. Theoretical Studies on Pd(II)-Catalyzed meta-Selective C-H Bond Arylation of Arenes. ACS Catal., 8, 2498-2507 (2018).

27. Lane, B. S., Brown, M. A. \& Sames, D. Direct Palladium-Catalyzed C-2 and C-3 Arylation of Indoles: A Mechanistic Rationale for Regioselectivity. J. Am. Chem. Soc. 127, 8050-8057 (2005). 28. Popp, B. V. \& Stahl., S. S. Insertion of Molecular Oxygen into a Palladium-Hydride Bond: Computational Evidence for Two Nearly Isoenergetic Pathways. J. Am. Chem. Soc., 129, 14, 44104422 (2007).

29. Konnick, M. \& Stahl, S. S. Reaction of Molecular Oxygen with a Pd ${ }^{\mathrm{II}}$-Hydride To Produce a $\mathrm{Pd}^{\mathrm{II}}$-Hydroperoxide: Experimental Evidence for an HX-Reductive-Elimination Pathway. J. Am. Chem. Soc. 130, 5753-5762 (2008).

\section{Acknowledgments}

We thank N. Van Velthoven for discussion. The XAS experiments were performed on beamline BM26A at the European Synchrotron Radiation Facility (ESRF), Grenoble, France. This work was funded by grants from FWO (1S17620N for J.V.; project G0D0518N, G0F2320N, G078118N; EoS BioFACT), the Flemish government (CASAS Methusalem program for D.D.V.). V.V.S, J.H. and M.B. acknowledge the Research Board of Ghent University (BOF) and funding from the European Union's Horizon 2020 research and innovation program (consolidator ERC grant 
agreement No 647755 - DYNPOR (2015-2020)). The computational resources and services used were provided by Ghent University (Stevin Supercomputer Infrastructure) and the VSC (Flemish Supercomputer Center), funded by the Research Foundation - Flanders (FWO). A.S. and A.B. acknowledge the funding from Russian Science Foundation (joint RSF-FWO grant \# 20-4301015). A.K. and G.M. acknowledge the financial support from the Slovenian Research Agency (research core funding No. P1-0021 and project No. N1-0079).

\section{Contributions}

J.V. was responsible for the conception, design and interpretation of the experiments under the supervision of D.D.V.. Additional experiments were performed by S.V.M. DFT calculations were performed by J.H., S.N. and M.B. under the supervision of V.V.S. XAS experiments were conceived and performed by A.B. and A.S.. NMR experiments were conceived and performed by A.K. and G.M.. All authors discussed the results and commented on the manuscript.

\section{Ethics declarations}

\section{Competing interests}

J.V., P.T. and D.D.V. filed a patent application GB1804905.6 prior to an international patent application PCT/EP2019/057746. 


\section{Supplementary Information}

\section{Shape-Selective C-H Activation of Aromatics to Biarylic Compounds Using Molecular Palladium in Zeolites}

Jannick Vercammen ${ }^{1}$, Massimo Bocus ${ }^{2}$, Sam Neale ${ }^{2}$, Aram Bugaev ${ }^{3}$, Sam Van Minnebruggen ${ }^{1}$, Julianna Hajek ${ }^{2}$, Patrick Tomkins ${ }^{1}$, Alexander Soldatov ${ }^{3}$, Andraž Krajnc ${ }^{4}$, Gregor Mali ${ }^{4}$, Véronique Van Speybroeck ${ }^{2 *}$, Dirk E. De Vos ${ }^{1 *}$

${ }^{1}$ Centre for Membrane Separations, Adsorption, Catalysis, and Spectroscopy for Sustainable Solutions (cMACS), KU Leuven, Leuven, Belgium

${ }^{2}$ Center for Molecular Modeling (CMM), Ghent University, Zwijnaarde, Belgium

${ }^{3}$ The Smart Materials Research Institute, Southern Federal University, Rostov-on-Don, Russia.

${ }^{4}$ Department of Inorganic Chemistry and Technology, National Institute of Chemistry, Ljubljana, Slovenia.

*Correspondence to: Veronique.vanspeybroeck@ugent.be (V.V.S.); dirk.devos@kuleuven.be (D.D.V.). 


\section{Table of Contents}

SUPPLEMENTARY METHODS

General information

$\begin{array}{lr}\text { Catalyst characterization } & 4\end{array}$

$\begin{array}{ll}\text { Computational study } & 5\end{array}$

$\begin{array}{lr}\text { Reactor setup } & 7\end{array}$

$\begin{array}{lr}\text { SUPPLEMENTARY DISCUSSION } & 8\end{array}$

$\begin{array}{lr}\text { Homogeneous Reference Reactions } & 8\end{array}$

$\begin{array}{ll}\text { Optimizing the Pd-Beta system } & 12\end{array}$

Reaction optimization for H-Beta (Si/Al=32) 12

Reaction optimization for H-Beta (Si/Al=75) 19

X-Ray Absorption Spectroscopy (XAS) 23

X-Ray absorption near-edge structure (XANES) 23

Extended X-ray Absorption Fine Structure (EXAFS) 25

$\begin{array}{lr}\text { Advanced NMR Characterization } & 28\end{array}$

$\begin{array}{ll}\text { Other Experiments } & 32\end{array}$

Stability, heterogeneity and re-usability of the catalyst 33

$\begin{array}{ll}\text { Substrate Scope } & 37\end{array}$

$\begin{array}{ll}\text { Kinetic Study } & 42\end{array}$

Computational Study $\quad 50$

H-Beta unit cell $\quad 50$

Step 0: $\mathrm{Pd}(\mathrm{OAc})_{2}$ docking in $\mathrm{H}$-Beta $\quad 50$

Step 1: Concerted metalation deprotonation (CMD) 52

Step 2: Migratory insertion $\quad 57$

Step 3: Evidences for hydrogen transfer to Pd 63

Alternative $2^{\text {nd }} \mathrm{CMD} / \mathrm{RC}$ mechanism - free energies from static calculations 64

Step 4: Evaluation of $\mathrm{O}_{2}$-insertion pathways: characterization of hydrogen atom abstraction (HAA) and hydrogen

metathesis-insertion (HMI) $\quad 66$

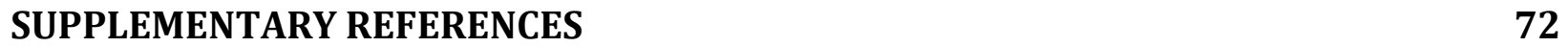




\section{Supplementary Methods}

\section{General information}

Chemicals were purchased from commercial suppliers (Acros Organics, Sigma-Aldrich, J\&K Scientific, TCI Europe, or VWR International) and used without further purification. Sulphated $\mathrm{ZrO}_{2}$ and sulphated MOF-808 (2.5 sulphates per $\mathrm{Zr}$ SBU) were prepared according to reported methods ${ }^{1,2}$. Nafion SAC-13, Amberlyst-15 (H-form), Basolite A100, activated $\mathrm{Al}_{2} \mathrm{O}_{3}$ (acidic, Brockmann I) and Dowex 50WX2 (H-form) were purchased from Sigma-Aldrich. Following zeolites from this study were either obtained commercially or kindly provided: H-MCM-22 (China Catalyst Holding Co., Ltd., Si/Al=14), H-MOR (ZM-980, Zéocat, Si/Al=100), H-USY (CBV-760, Zeolyst, $\mathrm{Si} / \mathrm{Al}=40$ ), H-Beta (PQ Corporations for $\mathrm{Si} / \mathrm{Al}=12.5$, Zeochem for $\mathrm{Si} / \mathrm{Al}=32$, Südchemie, now Clariant, for $\mathrm{Si} / \mathrm{Al}=75$, Zeolyst for $\mathrm{Si} / \mathrm{Al}=150$ ), Na-Beta (Südchemie, now Clariant, $\mathrm{Si} / \mathrm{Al}=12.5$ ). Other zeolites were synthesized via reported procedures.

The synthesis of B-Beta was adapted from a reported procedure ${ }^{3}$. Boric acid $(0.1967 \mathrm{~g})$ was dissolved in an aqueous solution of tetraethylammonium hydroxide (Alfa Aesar, 35\% w/w, 11.0 $\mathrm{ml})$, diluted with water $(8.62 \mathrm{ml})$. The solution was stirred for $30 \mathrm{~min}$. Subsequently Cab-O-Sil M5 (Cabot, $2.9 \mathrm{~g}$ ) was added within $15 \mathrm{~min}$. The solution was stirred for 2 hours. Subsequently zeolite beta seeds $(18.0 \mathrm{mg})$, as prepared in reference ${ }^{3}$, were added. The solution was stirred for 4 hours, and then transferred to a Teflon liner, which was sealed inside a stainless steel autoclave. The autoclave was placed in an oven at $150^{\circ} \mathrm{C}$ for 4 days. Next the solid was separated from the suspension by filtration and thoroughly washed with water. The dried solid was calcined at $550^{\circ} \mathrm{C}$ for $3 \mathrm{~h}$ at a heating rate of $1{ }^{\circ} \mathrm{C} / \mathrm{min}$.

The synthesis of Ga-Beta was adapted from a reported procedure ${ }^{4}$. Tetraethyl orthosilicate $(9.2 \mathrm{~g})$ was hydrolysed in an aqueous solution of tetraethylammonium hydroxide (Alfa Aesar, 35\% w/w, $10.05 \mathrm{~g})$. Subsequently gallium nitrate $(0.7976 \mathrm{~g})$ in water $(3.75 \mathrm{ml})$ and sodium hydroxide $(0.2352$ $\mathrm{g})$ in water $(2.5 \mathrm{ml})$ were added within $20 \mathrm{~min}$. The mixture was stirred for 1 hour, and then transferred to a Teflon liner, which was sealed inside a stainless steel autoclave. The autoclave was placed in an oven at $140^{\circ} \mathrm{C}$ for 9 days. Next the solid was separated from the suspension by filtration and thoroughly washed with water. The dried solid was calcined at $550^{\circ} \mathrm{C}$ for $2 \mathrm{~h}$ at a heating rate of $1{ }^{\circ} \mathrm{C} / \mathrm{min}$. The solid was then ion exchanged three times with an aqueous solution of $\mathrm{NH}_{4} \mathrm{NO}_{3}\left(0.1 \mathrm{M}, 100 \mathrm{ml} / \mathrm{g}\right.$ zeolite); subsequently the material was calcined at $550^{\circ} \mathrm{C}$ for $2 \mathrm{~h}$ at a heating rate of $1^{\circ} \mathrm{C} / \mathrm{min}$. The material was used as such.

The synthesis of ZSM-12 was adapted from Okubo et al. ${ }^{5}$. Sodium hydroxide $(0.0369 \mathrm{~g})$ and aluminium hydroxide (Alfa Aesar, min. 76.5\%, $0.0712 \mathrm{~g}$ ) were dissolved in water (2.565 ml); subsequently an aqueous solution of tetraethylammonium hydroxide (Alfa Aesar, 35\% w/w, 3.930 $\mathrm{ml})$ was added. Finally, Ludox HS-40 $(4.220 \mathrm{ml})$ was added. This mixture was stirred for $30 \mathrm{~min}$, and then transferred to a Teflon liner, which was sealed inside a stainless steel autoclave. The autoclave was placed in an oven at $160^{\circ} \mathrm{C}$ for 5 days. Next the solid was separated from the suspension by filtration and thoroughly washed with water. The dried solid was calcined at $550^{\circ} \mathrm{C}$ for $2 \mathrm{~h}$ at a heating rate of $1^{\circ} \mathrm{C} / \mathrm{min}$. The solid was then ion exchanged three times with an aqueous solution of $\mathrm{NH}_{4} \mathrm{NO}_{3}(0.1 \mathrm{M}, 100 \mathrm{ml} / \mathrm{g}$ zeolite $)$; subsequently the material was calcined at $550^{\circ} \mathrm{C}$ for $2 \mathrm{~h}$ at a heating rate of $1{ }^{\circ} \mathrm{C} / \mathrm{min}$. The material was used as such. 


\section{Catalyst characterization}

Powder X-ray diffraction (PXRD) data were recorded on a Malvern PANalytical Empyrean diffractometer equipped with at PIXcel 3D 1x1 detector. Samples were loaded onto a 96-well sample holder and patterns were recorded at room temperature in transmission geometry within a $1.3^{\circ}-50^{\circ} 2 \Theta$-range with a step size of $0.013^{\circ}$. The theoretical patterns were simulated by Mercury 3.10 based on the corresponding CIF files.

$\mathrm{N}_{2}$ physisorption isotherms were collected at $77 \mathrm{~K}$ on a Micromeritics 3Flex Surface Analyzer. The specific surface area $\left(\mathrm{S}_{\mathrm{BET}}\right)$ was determined using the BET method $\left(0.05-0.3 \mathrm{p} / \mathrm{p}_{0}\right.$ range $)$ and the specific external surface area $\left(\mathrm{S}_{\text {ext }}\right)$ and micropore volume $\left(\mathrm{V}_{\text {micro }}\right)$ were obtained using t-plot analysis. Before analyses the samples were evacuated at $423 \mathrm{~K}$ for $16 \mathrm{~h}$.

X-ray absorption experiments were conducted at BM26A beamline of ESRF (Grenoble, France). The samples were pressed into pellets of the optimal thickness and the measurements were performed in transmission geometry by ionization chambers. The energy was selected by $\mathrm{Si}(111)$ double-crystal monochromator operated in a step-wised mode. The rejection of higher harmonics was achieved by Pt-coated mirrors. The spectra were collected in the energy range $24200-$ $25100 \mathrm{eV}$, with a step of 3 and $1.5 \mathrm{eV}$ in the pre-edge and XANES regions, respectively, while in the EXAFS region a uniform step of $0.05 \AA^{-1}$ in the $k$-space was chosen. The spectra processing (normalization, energy calibration and beckground subtraction) and first-shell Fourier-analysis was performed in Demeter package ${ }^{6}$. Theoretical XANES spectra were calculated within the finite difference approach of FDMNES ${ }^{7}$. The convolution parameters were adjusted by comparing the experimental and theoretical spectra of $\mathrm{Pd}_{3}(\mathrm{OAc})_{6}$; geometry parameters of the model $\mathbf{V}$ for XANES calculation were tuned by means of PyFitIt software ${ }^{8}$. Uncertainties in the EXAFS analysis were calculated according to literature ${ }^{63}$.

Solid-state NMR experiments were carried out on a $600 \mathrm{MHz}$ Varian VNMRS spectrometer, equipped with a $3.2 \mathrm{~mm}$ HX CPMAS probe. Larmor frequencies for ${ }^{13} \mathrm{C}$ and ${ }^{27} \mathrm{Al}$ nuclei were 150.72 MHz and 156.19 MHz, respectively. In all the experiments, the sample rotation frequency was $16 \mathrm{kHz} .{ }^{27} \mathrm{Al}$ magic-angle spinning (MAS) NMR measurements employed a short $1.0 \mu \mathrm{s}$ excitation pulse and a recycling delay of $0.15 \mathrm{~s} ; 20000$ scans were collected for Pd-Beta and 8000 for H-Beta. In the ${ }^{13} \mathrm{C}$ MAS NMR experiment, Hahn-echo pulse sequence was used with $\pi / 2$ and $\pi$ pulses of $2.4 \mu \mathrm{s}$ and $4.8 \mu \mathrm{s}$, respectively, and the inter-pulse delay of one rotation period. The recycling delays were $100 \mathrm{~s}$ and $120 \mathrm{~s}$, and the numbers of repetitions were 1800 and 32 for PdBeta and crystalline $\mathrm{Pd}(\mathrm{OAc})_{2}$, respectively. ${ }^{1} \mathrm{H}-{ }^{13} \mathrm{C}$ cross-polarization (CP) MAS NMR measurements employed a ${ }^{1} \mathrm{H}$ excitation pulse of $2.7 \mu \mathrm{s}$ and ramped amplitude $\mathrm{CP}$ block of $3 \mathrm{~ms}$. For Pd-Beta, the delay was $0.2 \mathrm{~s}$ and 50000 scans were accumulated, whereas for the crystalline $\mathrm{Pd}(\mathrm{OAc})_{2}$ the delay was $3 \mathrm{~s}$ and the number of scans was 1024 . In the $2 \mathrm{D}{ }^{13} \mathrm{C}-{ }^{13} \mathrm{C}$ spin-diffusion NMR experiment, the starting ${ }^{13} \mathrm{C}$ magnetization was enhanced by ${ }^{1} \mathrm{H}-{ }^{13} \mathrm{C}$ cross polarization. During the spin-diffusion mixing time of $100 \mathrm{~ms}$ radio-frequency driven recoupling (RFDR) was employed. The 2D measurements on $\mathrm{Pd}(\mathrm{OAc})_{2}$ and $\mathrm{Pd}$-Beta consisted of 20 increments in the indirect dimension; spectral widths were $1 \mathrm{kHz}$ and $4 \mathrm{kHz}$, recycling delays were $0.8 \mathrm{~s}$ and $0.4 \mathrm{~s}$, and numbers of scans were 64 and 8000 for $\mathrm{Pd}(\mathrm{OAc})_{2}$ and $\mathrm{Pd}-$ Beta, respectively. The ${ }^{13} \mathrm{C} \mathrm{CP}-$ $\mathrm{DQ}$ (double quantum)-filtered experiment started with a ${ }^{1} \mathrm{H}-{ }^{13} \mathrm{C} \mathrm{CP}$ block, and was followed by 64 POST-C7 blocks $(8 \mathrm{~ms}){ }^{9}$ for the excitation of the ${ }^{13} \mathrm{C}$ DQ coherences and another 64 POST-C7 blocks for the reconversion of the DQ coherences to zero-quantum coherences. For Pd-Beta sample 1500000 scans were accumulated with the repetition delay of $0.2 \mathrm{~s}$, and for the crystalline $\mathrm{Pd}(\mathrm{OAc})_{2} 2048$ scans were collected with the delay of $2 \mathrm{~s}$. Calculation of the expected intensities 
of the DQ-filtered signals for a $\mathrm{Pd}(\mathrm{OAc})_{2}$ trimer and a $\mathrm{Pd}(\mathrm{OAc})_{2}$ monomer were carried out with the SIMPSON software package ${ }^{10}$. For the monomer, a ${ }^{13} \mathrm{C}-{ }^{13} \mathrm{C}$ spin-pair with an internuclear distance of $4.9 \AA$, as obtained from the model of intermediate II (Figure 6b), was studied. For the DQ-filtered signal of the trimer, signals of various spin systems were added (15 spin pairs, 20 spin triplets, 15 spin quadruplets, 6 spin quintets and one spin sextet) with appropriate weights, corresponding to a $68 \%$ probability of a carbon site being occupied by an NMR-active ${ }^{13} \mathrm{C}$ nucleus. The geometries of the spin systems were derived from the positions of the six carboxyl $\mathrm{C}$ atoms within the $\mathrm{Pd}_{3}(\mathrm{OAc})_{6}$ trimer of the crystalline palladium acetate.

\section{Computational study}

The ab initio MD simulations were performed using the CP2K software package ${ }^{11}$ in the NPT ensemble at $363 \mathrm{~K}$ and 1 bar. During the simulations, the temperature was controlled by a chain of five Nosé-Hoover thermostats ${ }^{12}$ and the pressure by an MTK barostat ${ }^{13,14}$. The PBE functional ${ }^{15}$ with the parametrization of revPBE ${ }^{16}$ was employed with a combined Gaussian and Plane Wave (GPW) basis sets approach ${ }^{17,18}$. The DZVP-GTH basis set with pseudopotentials ${ }^{19}$ was used for all atoms except Pd, for which a MOLOPT basis set ${ }^{20}$ was used instead. Dispersive forces were accounted for with Grimme D3 dispersion correction scheme. The time step for integration of the equations of motion was set to $0.5 \mathrm{fs}$.

The static DFT simulations were performed in a H-Beta unit cell consisting of $64 \mathrm{~T}$ atoms using the Vienna Ab Initio Simulation Package (VASP 5.4) ${ }^{21,22,23}$ with the PBE functional ${ }^{24}$ and using Grimme D3 dispersion corrections ${ }^{25}$. In the calculations, the projector augmented wave (PAW) method ${ }^{26,27}$ was used with a plane-wave energy cutoff of $700 \mathrm{eV}$ and a self-consistent field (SCF) convergence criterion of $10^{-5} \mathrm{eV}$. The sampling of the Brillouin zone was restricted to the $\Gamma$-point. Transition states were initially optimized with the improved dimer method ${ }^{28}$ and subsequently refined with a quasi-Newton algorithm ${ }^{29}$. The initial geometries of reactant and product for each transition state were generated starting from a slight displacement along the normal mode corresponding to the transition state crossing and then fully optimized with a conjugate gradient method. The phonon calculations were performed using VASP. The normal mode analysis (NMA) was performed applying a partial Hessian vibrational analysis (PHVA) ${ }^{30,31,32}$ within the harmonic oscillator approximation using TAMkin ${ }^{33}$. This means that instead of the whole system only the adsorbed species and an $8 \mathrm{~T}$ cluster of the framework were taken into account in the NMA. Because of the flat potential energy surface of adsorbed species into zeolites, imaginary modes with very low frequencies are extremely difficult to get rid of even after multiple reoptimizations perturbing the system along the undesired mode. For this reason, we decided to consider the geometry optimization converged if, after two subsequent reoptimizations, the energy variation was lower than $1 \mathrm{~kJ} / \mathrm{mol}$. The residual imaginary frequencies were replaced with arbitrary frequencies of 60 $\mathrm{cm}^{-1}$, following the procedure of De Moor ${ }^{34}$. Moreover, as the very low frequencies modes were affected by remarkable numerical error and significantly contributing to the calculated entropy, we also replaced every mode below $60 \mathrm{~cm}^{-1}$ with a $60 \mathrm{~cm}^{-1}$ mode, as already proposed in the literature ${ }^{35,36,37}$. Once geometry optimizations and frequency calculations were completed, further single-point calculations were performed for each species with the B3LYP-D3 functional ${ }^{38,39}$ and the same basis-set used in the optimization procedure, to obtain overall adsorption free energies at a composite B3LYP-D3//PBE-D3 level.

DFT calculations for the 5T cluster model were performed with Gaussian 09 (Revision D.01). Geometry optimizations were performed using the B3LYP functional. A pruned 99,590 integral grid was used for higher numerical precision. In the geometry optimizations, Pd was descried with 
the Stuttgart-Dresden Effective Core Potentials and corresponding basis sets (SDDAll) ${ }^{40,41}$, while all other atoms were described with the Ahlrichs double- $\zeta$ def2-SVP basis set ${ }^{42}$. This basis set combination is also referred to simply as "BS1". Local minima and saddle points were confirmed by vibrational frequency analysis at this level of theory, with the confirmation of no imaginary modes, or a single imaginary mode corresponding to the transformation the saddle point is capturing. The vibrational modes were also used to obtain Gibbs free energy corrections calculated at $363.15 \mathrm{~K}$, where frequencies under $60 \mathrm{~cm}^{-1}$ were raised to $60 \mathrm{~cm}^{-1}$, in order to replicate the treatment of low modes in the periodic calculations. This was done with Paton et al.'s GoodVibes code $^{43}$. Minimum-energy crossing points (MECPs) intersecting between the singlet $(\mathrm{S}=0)$ and the triplet $(\mathrm{S}=1)$ surfaces were identified using Harvey's MECP code (interfaced to Gaussian 09 with the wrapper code "easymecp") ${ }^{44}$ which minimizes the gradient difference vector between the two adiabatic surfaces. Following identification of the MECP, state-averaged vibrational analyses was carried out with Glowacki's glowfreq code ${ }^{45}$. This confirmed the presence of $3 \mathrm{~N}-7$ positive, real normal modes which were used to compute the (quasi-harmonic) vibrational partition function and obtain the Gibbs free energies of the crossing points using Paton et. al.'s code goodvibes, using the same procedure for local minima and saddle points. Calculation of the spin-hopping probability, as is outlined by Harvey to be required to capture the best estimate of the rate of spincrossover, was not considered in this work. Single point corrections of all species obtained through the above procedures, were performed with B3LYP and the larger triple- $\zeta$ Def2-TZVPPD basis set for all atoms (including the relevant ECP for Pd) $46,47,48$, with empirical D3BJ dispersion correction also included ${ }^{49,50}$. As this basis set isn't included as a keyword within Gaussian 09, the basis-set exchange library was used to obtain the relevant coefficients for use in the calculations ${ }^{51}$. 


\section{Reactor setup}

a

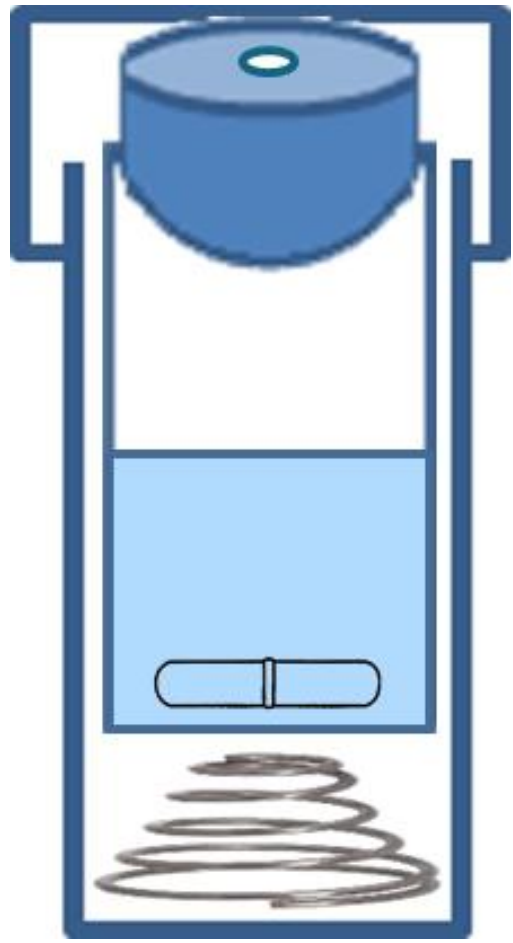

b

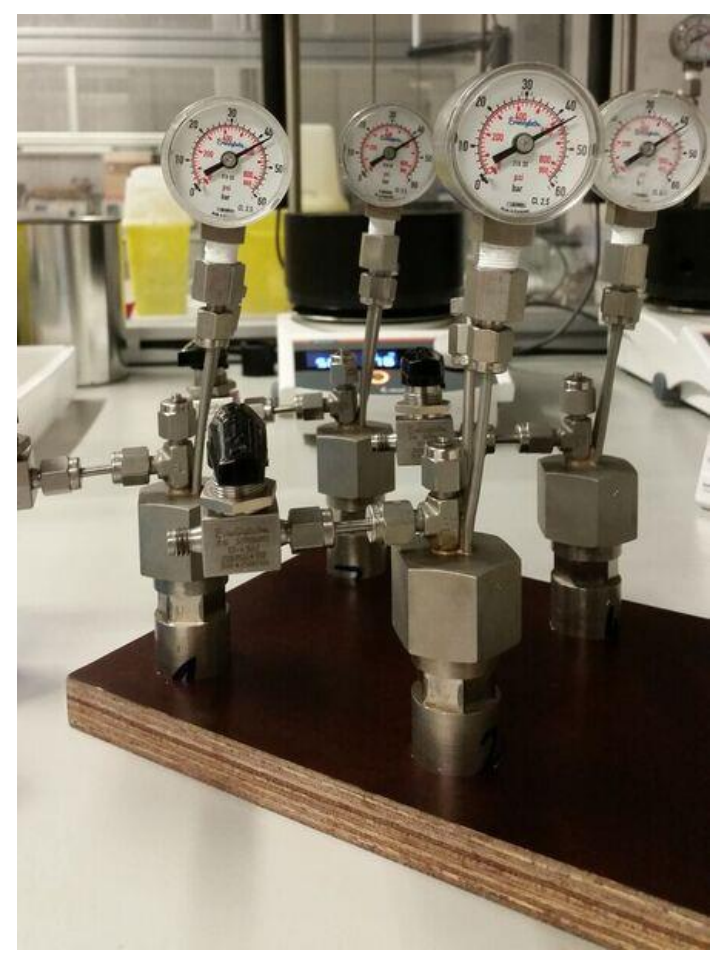

Supplementary Figure 1. Batch reactors for oxidative coupling of arenes. The scheme (a) and picture (b) show the small scale autoclave set-up which was used in this work. Reactions were conducted inside a glass liner $(3 \mathrm{ml})$, which is topped with a PTFE stopper with a small hole in the middle to allow gas exchange. To avoid boiling over of the solvent, there is a conical, stainless steel spring (Inexal) under the glass liner. Autoclaves were further equipped with a pressure gauge and two-way ball valve to allow pressurizing the vessel with $\mathrm{O}_{2}$. 


\section{Supplementary Discussion}

\section{Homogeneous Reference Reactions}

Given the strong impact of the latest study of Stahl and coworkers on the state-of-the-art, we repeated the reactions in the very precise conditions of JACS 139 (2017) 5704, Figure 5C, but at a 3.75 times larger scale $(3.4 \mathrm{ml}$ reaction volume instead of $0.9 \mathrm{ml})$, with a $\mathrm{Fe}(\mathrm{OTf})_{3}$ to $\mathrm{Pd}(\mathrm{OAc})_{2}$ ratio of 1 (Supplementary Table 1, entries 1 and 3). Modifications to these reaction conditions were investigated that allow for a better positioning towards the Pd zeolite results (Supplementary Table 1).

Replication of the reaction with $o$-xylene as reactant led to a slightly lower TON of 100 (entry 1 ; vs. reported 150). The use of high pressures of oxygen decreases the TON slightly (Entry 2 and 4), perhaps due to oxidative degradation of the 2-fluoropyridine ligand. Surprisingly, the use of higher reaction temperatures decreases the TON (Entry 5 and 6). Replacing $o$-xylene with toluene as reagent leads to a slightly higher TON of 133 (Entry 3). Furthermore, a clear decrease in orthosubstituted products is observed in the presence of 2-fluoropyridine, compared to reactions without 2-fluoropyridine (Entry 3, 7, 9 and 11). Addition of trace amounts of water (Entry 8) leads to a decrease in the TON of this reaction. Decreasing the amount of acetic acid, from cosolvent concentrations to the concentrations used in our work, leads to a strong decrease in the TON (Entry 9). Lastly, the $\mathrm{Fe}(\mathrm{OTf})_{3}$ additive seems to be essential for obtaining an active catalytic species in Stahl's conditions (Entry 8 and 9). 
Supplementary Table 1. Homogeneously catalyzed reactions in conditions identical to those of Stahl ${ }^{[\mathrm{A}]}$

\begin{tabular}{|c|c|c|c|c|c|c|c|c|c|c|c|c|c|c|c|c|}
\hline \multirow{2}{*}{ Entry } & \multirow{2}{*}{ Arene } & \multirow{2}{*}{ Amount } & \multirow{2}{*}{$\begin{array}{l}\text { AcOH } \\
{[\mathrm{mmol}]}\end{array}$} & \multirow{2}{*}{$\begin{array}{l}\text { 2-F } \\
\text { Pyridine }\end{array}$} & \multirow{2}{*}{$\mathrm{Fe}(\mathrm{OTf})_{3}$} & \multirow{2}{*}{$\begin{array}{l}\text { Yield } \\
{[\%]}\end{array}$} & \multirow{2}{*}{ TON } & \multicolumn{4}{|c|}{ Product distribution [\%] } & \multirow[b]{2}{*}{$3,4^{\prime}$} & \multirow[b]{2}{*}{$4,4^{\prime}$} & \multirow[b]{2}{*}{ Trimer } & \multirow[b]{2}{*}{ Benzylic } & \multirow[b]{2}{*}{ Other } \\
\hline & & & & & & & & $2,2^{\prime}$ & $2,3^{\prime}$ & $2,4^{\prime}$ & $3,3^{\prime}$ & & & & & \\
\hline 1 & $o$-Xylene & $15 \mathrm{mmol}$ & 26.2 & + & + & 10 & 100 & $0 \%$ & $7 \%$ & & $84 \%$ & & & $1 \%$ & & $7 \%$ \\
\hline 2 & $o$-Xylene ${ }^{[\mathrm{B}]}$ & $15 \mathrm{mmol}$ & 26.2 & + & + & 6 & 64 & $0 \%$ & $7 \%$ & & $77 \%$ & & & $1 \%$ & & $15 \%$ \\
\hline 3 & Toluene & $15 \mathrm{mmol}$ & 26.2 & + & + & 13 & 133 & $0 \%$ & $4 \%$ & $4 \%$ & $19 \%$ & $40 \%$ & $20 \%$ & $6 \%$ & & $7 \%$ \\
\hline 4 & Toluene ${ }^{[\mathrm{B}]}$ & $15 \mathrm{mmol}$ & 26.2 & + & + & 12 & 120 & $0 \%$ & $4 \%$ & $4 \%$ & $21 \%$ & $41 \%$ & $18 \%$ & $4 \%$ & & $7 \%$ \\
\hline 5 & Toluene ${ }^{[\mathrm{C}]}$ & $15 \mathrm{mmol}$ & 26.2 & + & + & 13 & 126 & $0 \%$ & $4 \%$ & $3 \%$ & $26 \%$ & $41 \%$ & $15 \%$ & $6 \%$ & $0 \%$ & $5 \%$ \\
\hline 6 & Toluene ${ }^{[D]}$ & $15 \mathrm{mmol}$ & 26.2 & + & + & 10 & 103 & $0 \%$ & $5 \%$ & $3 \%$ & $29 \%$ & $38 \%$ & $12 \%$ & $6 \%$ & $0 \%$ & $6 \%$ \\
\hline 7 & Toluene & $15 \mathrm{mmol}$ & 26.2 & - & + & 1 & 13 & $5 \%$ & $14 \%$ & $18 \%$ & $12 \%$ & $23 \%$ & $12 \%$ & $4 \%$ & $0 \%$ & $11 \%$ \\
\hline 8 & Toluene $^{[\mathrm{E}]}$ & $15 \mathrm{mmol}$ & 26.2 & + & + & 7 & 71 & $0 \%$ & $3 \%$ & $3 \%$ & $27 \%$ & $42 \%$ & $16 \%$ & $3 \%$ & & $6 \%$ \\
\hline 9 & Toluene & $18.88 \mathrm{mmol}$ & 3.0 & - & + & 1 & 11 & $11 \%$ & $16 \%$ & $22 \%$ & $7 \%$ & $17 \%$ & $9 \%$ & $5 \%$ & $1 \%$ & $13 \%$ \\
\hline 10 & Toluene & $18.88 \mathrm{mmol}$ & 3.0 & + & - & $<1$ & 1 & $1 \%$ & $7 \%$ & $5 \%$ & $23 \%$ & $23 \%$ & $7 \%$ & & $2 \%$ & $33 \%$ \\
\hline 11 & Toluene & $18.88 \mathrm{mmol}$ & 3.0 & + & + & 2 & 28 & $1 \%$ & $6 \%$ & $6 \%$ & $18 \%$ & $38 \%$ & $20 \%$ & $2 \%$ & $0 \%$ & $8 \%$ \\
\hline
\end{tabular}


Since regioselectivities are preferably compared at the same temperatures, we aimed at establishing an alternative homogeneous reference system, active in similar conditions of temperature and $\mathrm{O}_{2}$ pressure as the heterogeneous system. Therefore, additional homogeneous experiments were conducted under high pressures of oxygen. At these higher pressures the requirement for the 2-fluoropyridine ligand was examined, and higher temperatures were evaluated to maximize the TON (Supplementary Figure 2). A strong increase in the TON was observed upon increasing the reaction temperature in the absence of the 2-fluoropyridine ligand; the increase was less steep in its presence. In the absence of the ligand, a higher TON was observed at $110^{\circ} \mathrm{C}$ and $130^{\circ} \mathrm{C}$, compared to the reactions which contained the ligand. The product distribution in the presence of the ligand shifted to the distribution obtained without the ligand, showing its decreased effect at higher temperatures. When using toluene, selectivities for the 4,4'isomer vary between 9-14 \% (without 2-fluoropyridine) and 14-18\% (with the ligand).

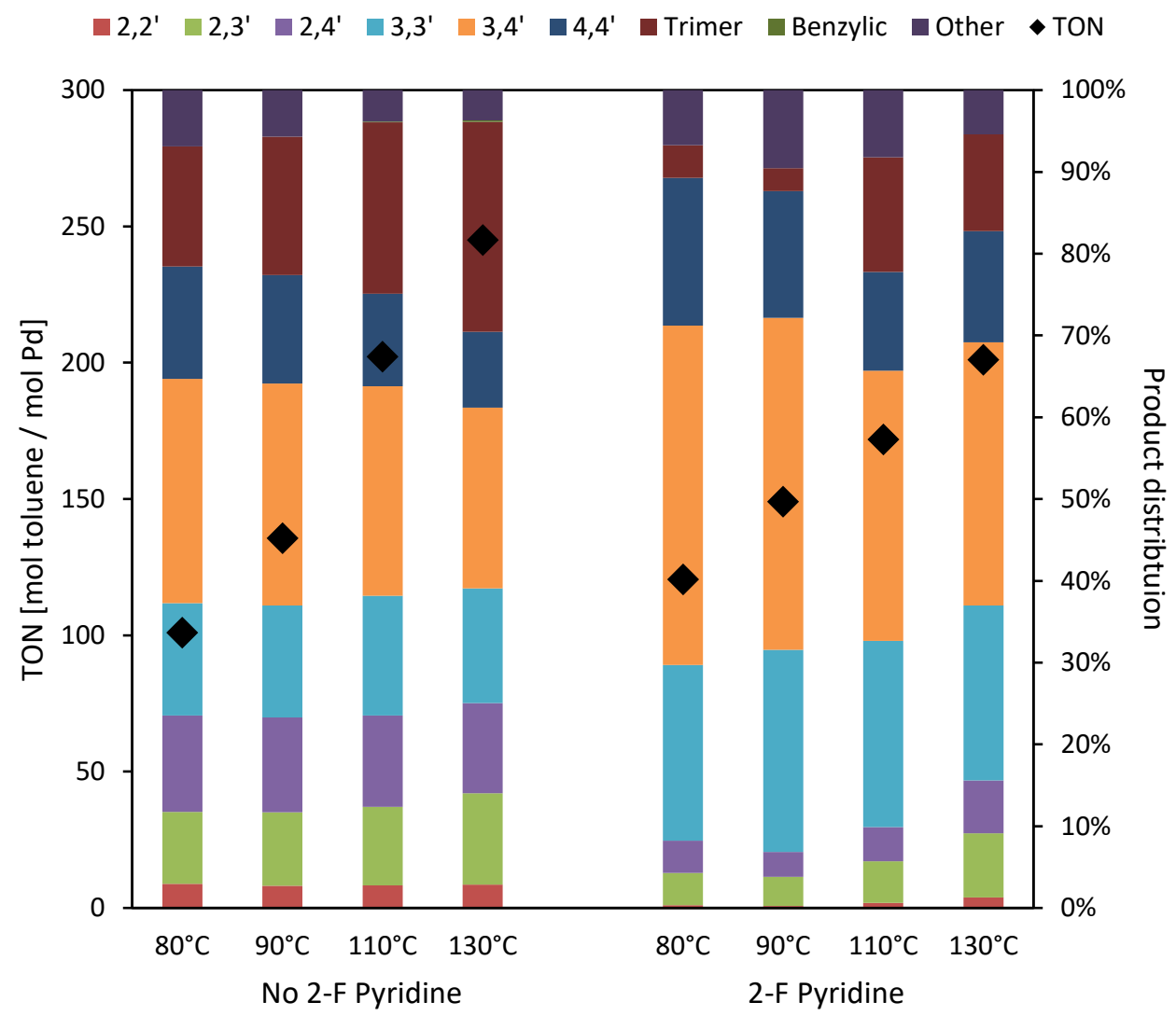

Supplementary Figure 2. Temperature profile for homogeneous reaction system under elevated pressure of oxygen. Reaction conditions: $15 \mu \mathrm{mol} \mathrm{Pd}(\mathrm{OAc})_{2}, 15 \mu \mathrm{mol} \mathrm{Fe}(\mathrm{OTf})_{3}, 0$ or $30 \mu \mathrm{mol} 2-$ fluoropyridine, $15 \mathrm{mmol}$ toluene, $1.5 \mathrm{ml} \mathrm{AcOH}, 16$ bar O$_{2}, 16$ hours. 


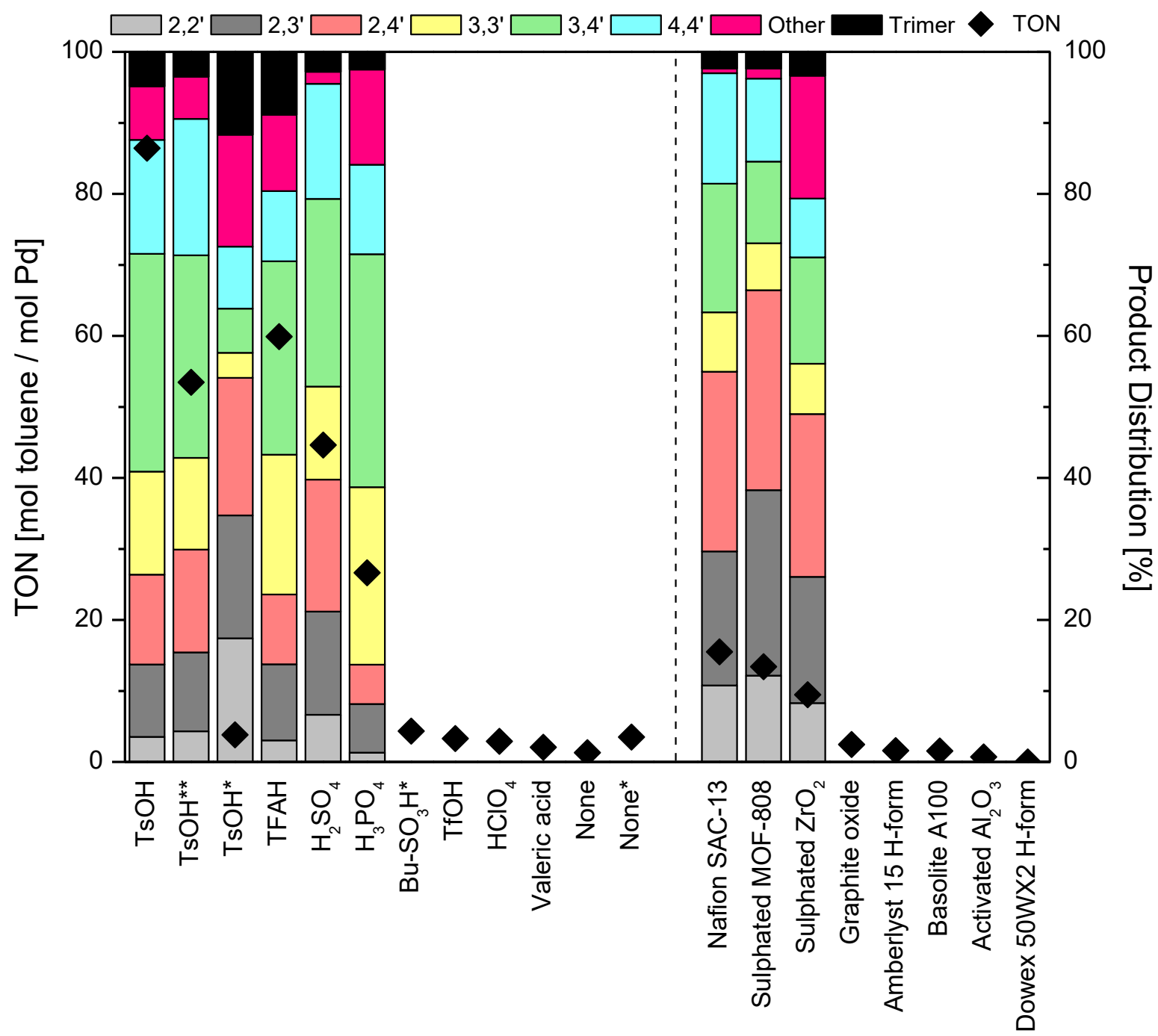

Supplementary Figure 3. Variation of acidic additive. Reactions were carried out using $15 \mu \mathrm{mol}$ $\mathrm{Pd}(\mathrm{OAc})_{2}, 2 \mathrm{ml}$ of toluene, $16 \mathrm{bar}$ of $\mathrm{O}_{2}$ at $90^{\circ} \mathrm{C}$ for $16 \mathrm{~h}$. Reactions with soluble acids were performed with $0.3 \mathrm{mmol}$ of the additive (20 eq to $\mathrm{Pd}$ ) and $1 \mathrm{ml}$ of acetic acid, while reactions with solid acids used $50 \mathrm{mg}$ of the solid without acetic acid. *No acetic acid was added. **429 $\mu 1$ of acetic acid (500 eq to Pd) was added instead of $1 \mathrm{ml}$. 


\section{Optimizing the Pd-Beta system}

\section{Reaction optimization for H-Beta (Si/Al=32)}

Initial optimization of the reaction conditions was performed on the oxidative coupling of toluene with $\mathrm{H}$-Beta $(\mathrm{Si} / \mathrm{Al}=32)$. The crucial importance of a higher $\mathrm{Si} / \mathrm{Al}$ was only later observed. Variation of the Pd precursor showed the importance of a carboxylate counter anion for a good activity (Supplementary Figure 4). No reaction was observed with a homogeneous or heterogeneous catalyst with Pd in the zerovalent state.

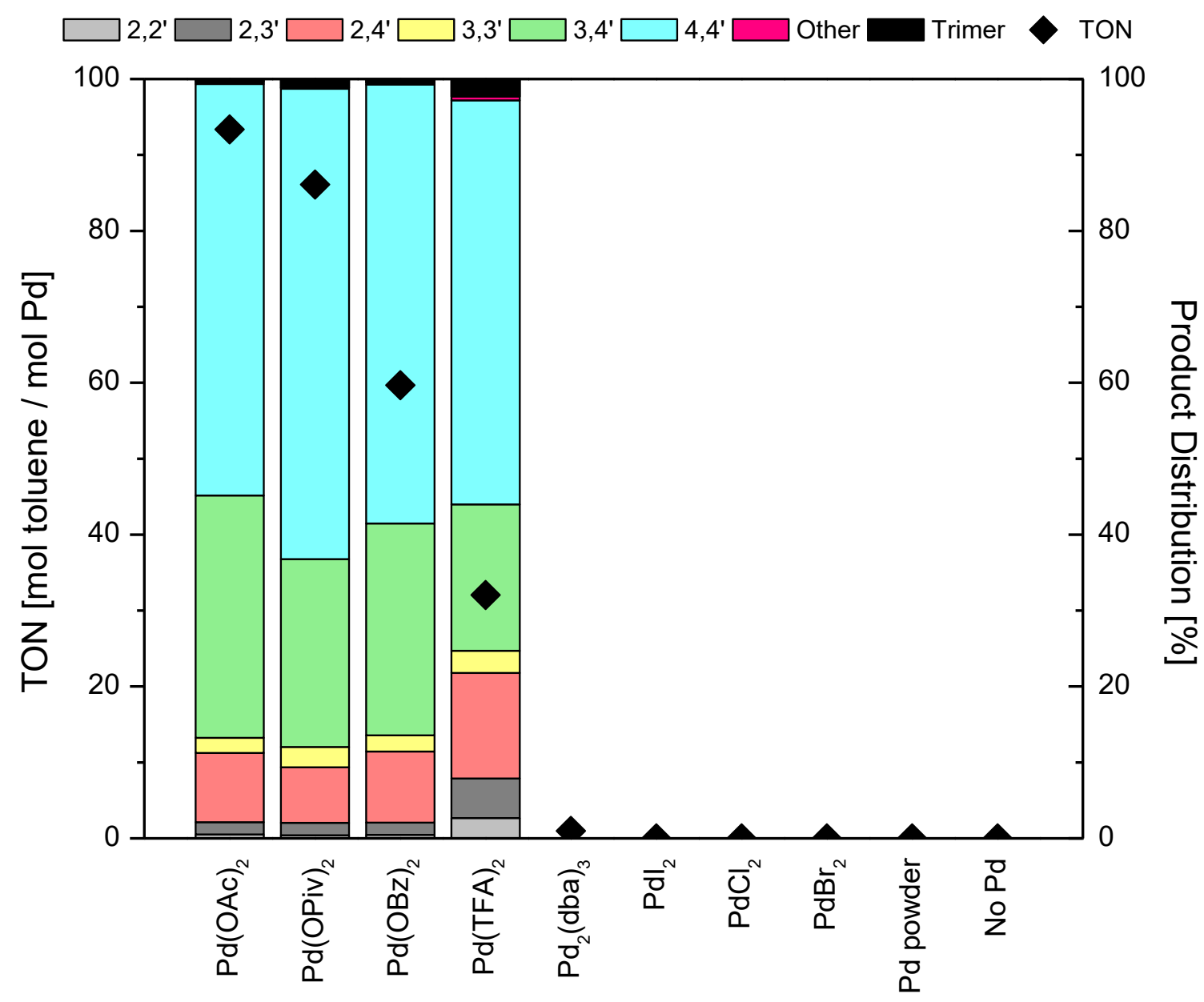

Supplementary Figure 4. Variation of the palladium precursor. Reactions were carried out using $15 \mu \mathrm{mol}$ Pd precursor, $50 \mathrm{mg} \mathrm{H}$-Beta ( $\mathrm{Si} / \mathrm{Al}=32), 2 \mathrm{ml}$ of toluene, $16 \mathrm{bar}$ of $\mathrm{O}_{2}$ at $90^{\circ} \mathrm{C}$ for $16 \mathrm{~h}$. 
Different solvents were assessed in the oxidative coupling of toluene with H-Beta (Supplementary Figure 5). The best performance was obtained with non-coordinating, apolar solvents (e.g. $n$ octane, $n$-hexane). Surprisingly, a satisfactory activity and selectivity were also obtained with acetic acid. However, the solventless conditions far outperformed all assessed solvents. We propose that the dilution and weakened interactions with toluene are responsible for the obtained lower rates in the solvated reactions.

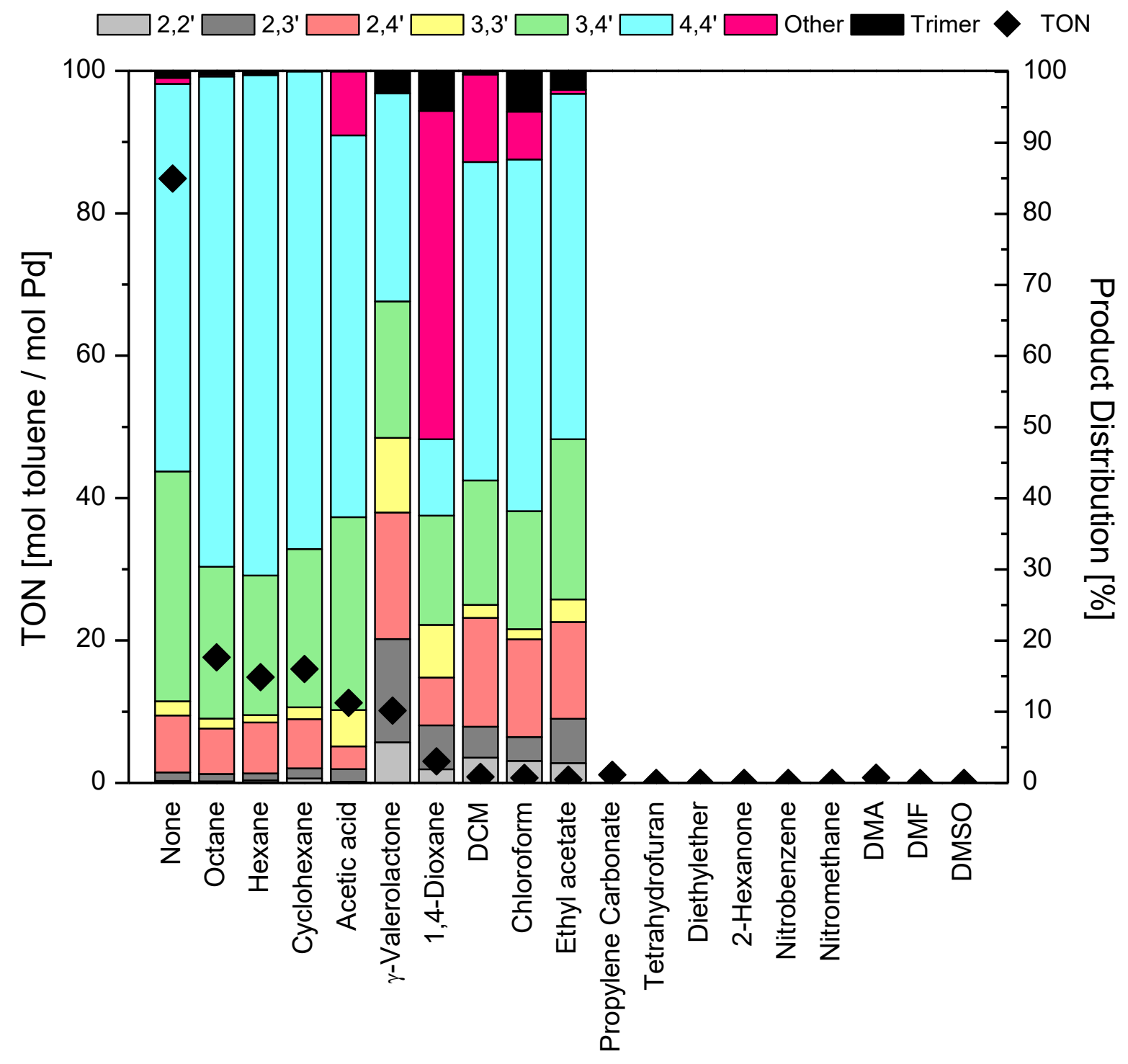

Supplementary Figure 5. Solvent screening. Reactions were carried out using $15 \mu \mathrm{mol} \operatorname{Pd}(\mathrm{OAc})_{2}$, $50 \mathrm{mg} \mathrm{H}$-Beta $(\mathrm{Si} / \mathrm{Al}=32), 0.5 \mathrm{ml}$ of toluene, $1.5 \mathrm{ml}$ solvent, 16 bar of $\mathrm{O}_{2}$ at $90^{\circ} \mathrm{C}$ for $16 \mathrm{~h}$. No additional solvent or additional toluene was added in the solventless example. 
A kinetic profile was constructed in the oxidative coupling of toluene with $\mathrm{H}-\mathrm{Beta}(\mathrm{Si} / \mathrm{Al}=32)$ (Fig S6). A decline in activity after 5 hours was observed, together with a fast initial decline in regioselectivity. For a similar experiment with a more suitable zeolite, see Fig. 4.

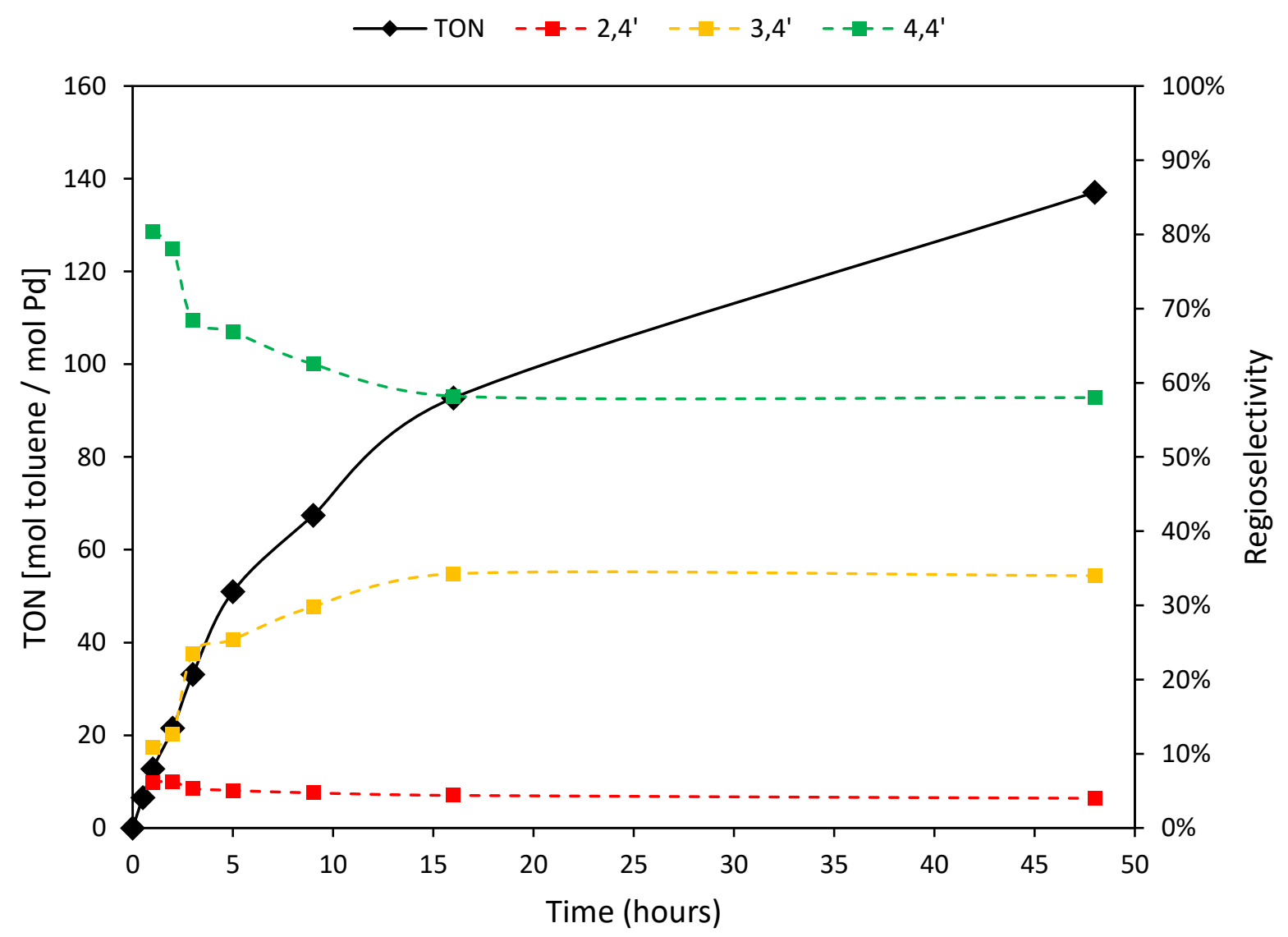

Supplementary Figure 6. Kinetic profile for $\mathrm{H}-\mathrm{Beta}(\mathrm{Si} / \mathrm{Al}=32)$. Reactions were carried out using $15 \mu \mathrm{mol} \mathrm{Pd}(\mathrm{OAc})_{2}, 50 \mathrm{mg}$ of $\mathrm{H}-\mathrm{Beta}(\mathrm{Si} / \mathrm{Al}=32), 2 \mathrm{ml}$ of toluene, 16 bar of $\mathrm{O}_{2}$ at $90^{\circ} \mathrm{C}$ for different times. 
The reaction temperature was increased up to a temperature of $170^{\circ} \mathrm{C}$ (Supplementary Figure 7). Although the TON increases up to 268 at $150^{\circ} \mathrm{C}$, a simultaneous decrease in the regioselectivity is observed as well. This selectivity loss is not observed when the most appropriate zeolite $(\mathrm{Si} / \mathrm{Al}=$ 75) is used (Supplementary Figure 7).

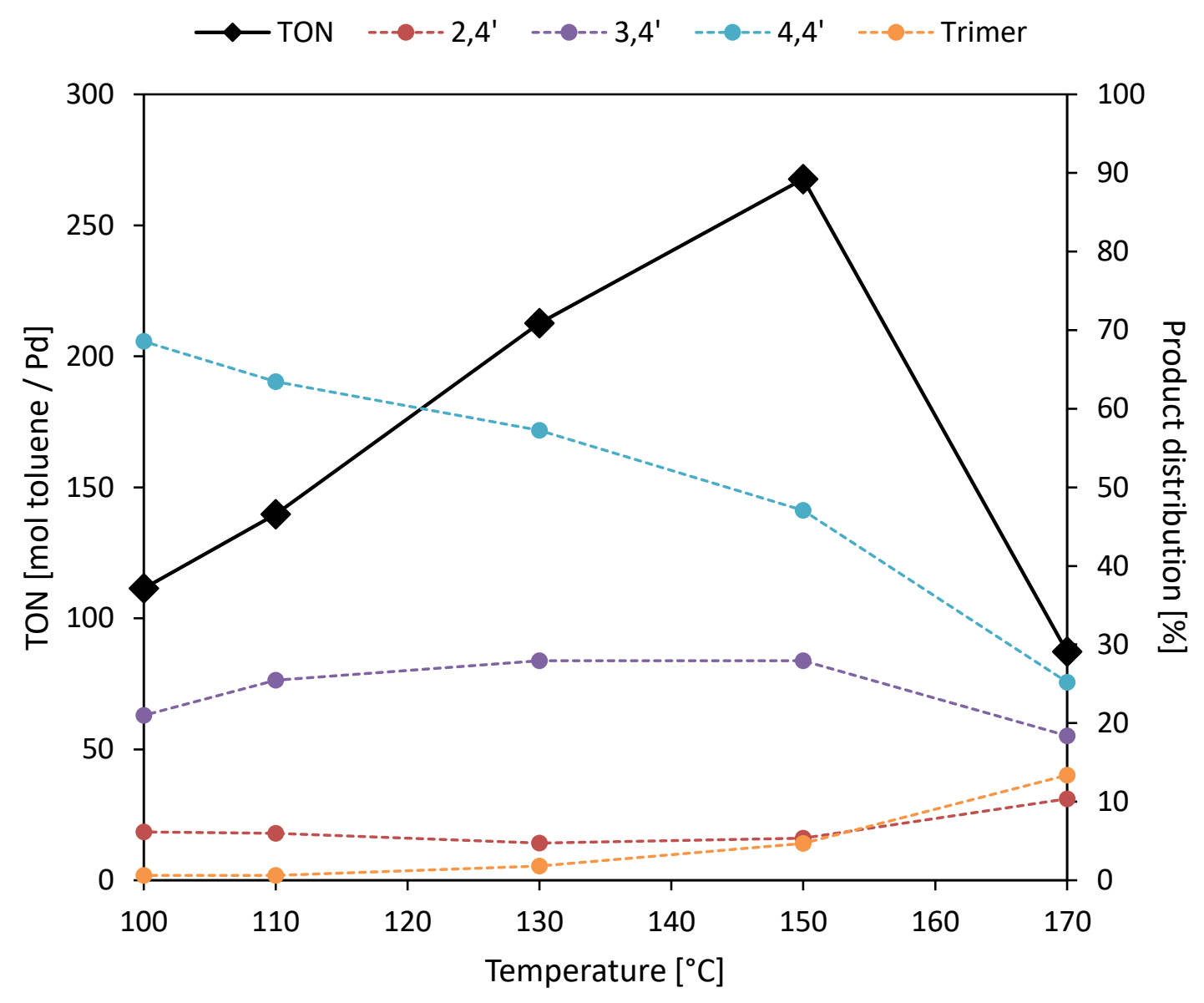

Supplementary Figure 7. Variation of the reaction temperature for $\mathrm{H}$-Beta $(\mathrm{Si} / \mathrm{Al}=32)$ in the absence of additional acetic acid. Reactions were carried out using $15 \mu \mathrm{mol} \mathrm{Pd}(\mathrm{OAc})_{2}, 50 \mathrm{mg} \mathrm{H}-$ Beta $(\mathrm{Si} / \mathrm{Al}=32), 2 \mathrm{ml}$ of toluene, 16 bar of $\mathrm{O}_{2}$ at different temperatures for $16 \mathrm{~h}$. 
The applied pressure of $\mathrm{O}_{2}$ was varied in the oxidative coupling of toluene with $\mathrm{H}-\mathrm{Beta}(\mathrm{Si} / \mathrm{Al}=32)$ (Supplementary Figure 8). A TON of 1 is observed in the absence of $\mathrm{O}_{2}$, which increases up to a TON of 100 by increasing the $\mathrm{O}_{2}$ pressure up to 20 bar.

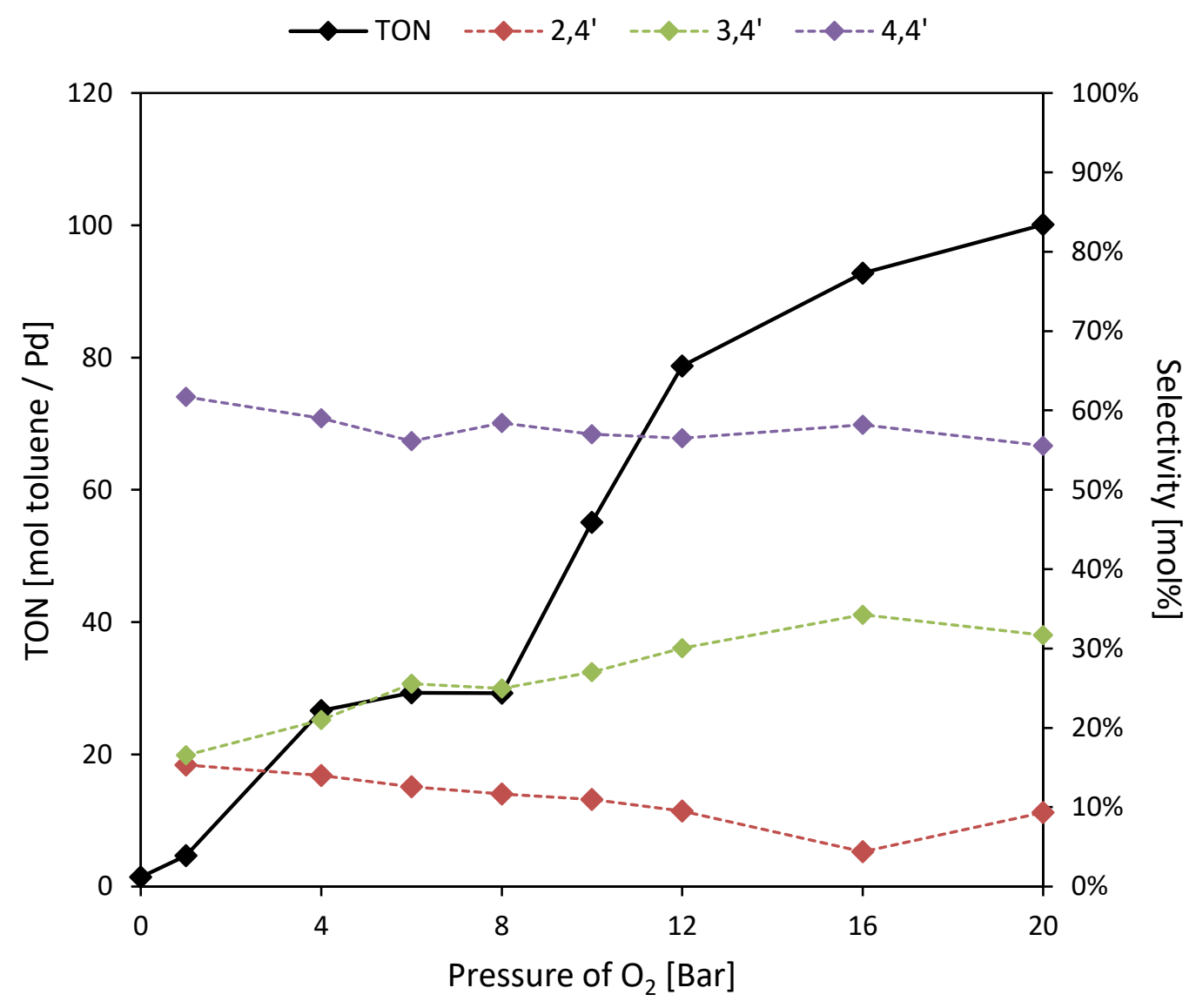

Supplementary Figure 8. Variation of the oxygen pressure. Reactions were carried out using 15 $\mu \mathrm{mol} \mathrm{Pd}(\mathrm{OAc})_{2}, 50 \mathrm{mg} \mathrm{H}-\mathrm{Beta}(\mathrm{Si} / \mathrm{Al}=32), 2 \mathrm{ml}$ of toluene, different pressures of $\mathrm{O}_{2}$ at $90^{\circ} \mathrm{C}$ for $16 \mathrm{~h}$. 
The amount of $\mathrm{H}$-Beta $(\mathrm{Si} / \mathrm{Al}=32)$ was varied in the oxidative coupling of toluene with $\mathrm{H}$-beta $(\mathrm{Si} / \mathrm{Al}=32)$ (Supplementary Figure 9). An increase of the TON up to 106, together with an increase of the selectivity for 3,4'- and 4,4'-dimethylbiphenyl was observed up to $75 \mathrm{mg}$ of the zeolite. At higher zeolite amounts the TON dropped to an approximately constant amount of 80, while the selectivity for 4,4'-dimethylbiphenyl increased slightly and the selectivity for 3,4'-dimethylbiphenyl decreased slightly. For a similar experiment with a more suitable zeolite, see Fig. 1.

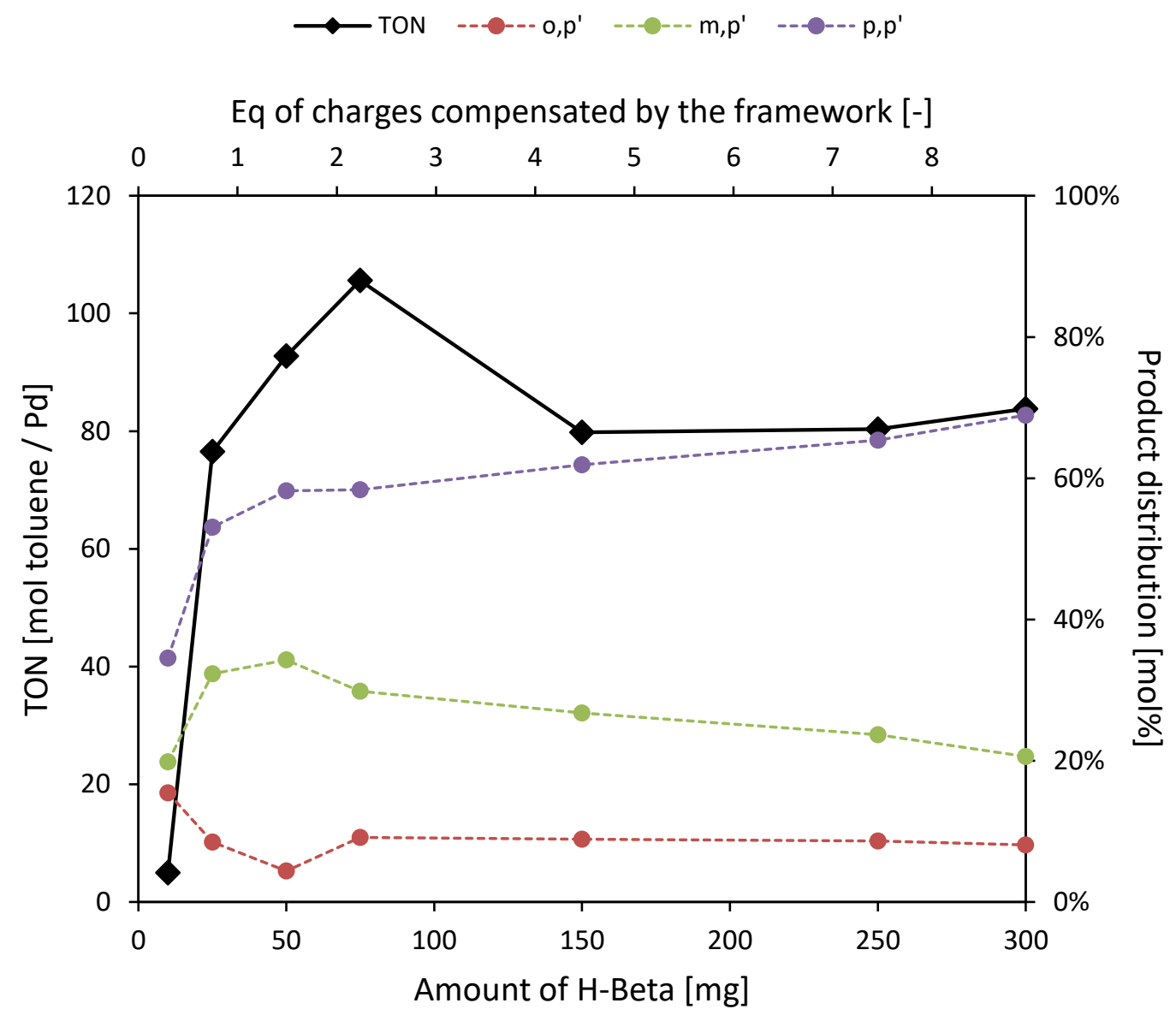

Supplementary Figure 9. Variation of the amount of $\mathrm{H}$-Beta $(\mathrm{Si} / \mathrm{Al}=32)$. Reactions were carried out using $15 \mu \mathrm{mol} \mathrm{Pd}(\mathrm{OAc})_{2}$, different amounts of $\mathrm{H}$-Beta $(\mathrm{Si} / \mathrm{Al}=32), 2 \mathrm{ml}$ of toluene, $16 \mathrm{bar}$ of $\mathrm{O}_{2}$ at $90^{\circ} \mathrm{C}$ for $16 \mathrm{~h}$. 
Zeolite $\mathrm{H}-\mathrm{Beta}(\mathrm{Si} / \mathrm{Al}=32)$ was dealuminated by treatment with concentrated nitric acid, and the obtained solid was subsequently tested in the oxidative coupling of toluene (Supplementary Figure 10). The crystallinity was monitored by comparison with the parent $\mathrm{H}-\mathrm{Beta}(\mathrm{Si} / \mathrm{Al}=32$ ), and apparently did not decrease after the acid treatment. An increase in the TON together with a similar product distribution was obtained in the reaction after a dealumination of 20 minutes. After longer dealumination times, the addition of the zeolite to the reaction did not significantly boost the TON, and a similar product distribution was obtained after a deep dealumination as if no zeolite was added.

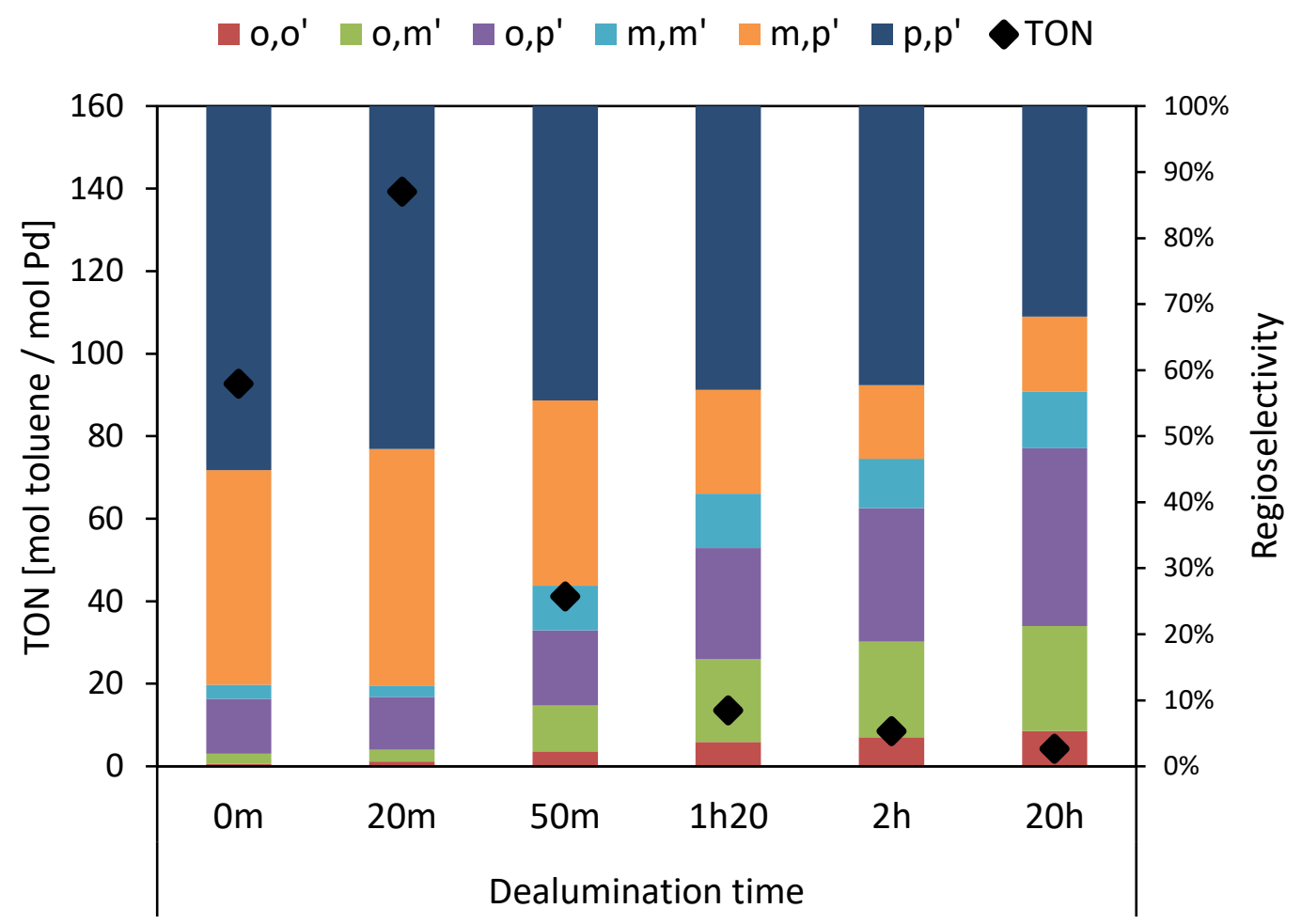

Supplementary Figure 10. Dealumination of H-Beta $(\mathrm{Si} / \mathrm{Al}=32)$. Zeolite $\mathrm{H}-\mathrm{Beta}(\mathrm{Si} / \mathrm{Al}=32)$ was dealuminated at different times and subsequently tested as additive in the oxidative coupling of toluene. Dealumination procedure: Zeolites were treated with $50 \mathrm{ml} \mathrm{HNO}_{3}(65 \%)$ per gram of zeolite at $110^{\circ} \mathrm{C}$ for different times. Subsequently, the obtained suspensions were filtered and washed with copious amounts of water. The obtained solid was dried overnight at $60^{\circ} \mathrm{C}$, and calcined prior to use in the reaction $\left(1^{\circ} \mathrm{C} / \mathrm{min}, 550^{\circ} \mathrm{C}\right.$ for 4 hours $)$. Reaction conditions: $15 \mu \mathrm{mol}$ $\mathrm{Pd}(\mathrm{OAc})_{2}, 50 \mathrm{mg}$ zeolite, $2 \mathrm{ml}$ toluene, $90^{\circ} \mathrm{C}, 16$ bar $\mathrm{O}_{2}, 16$ hours. 
Reaction optimization for H-Beta (Si/Al=75)

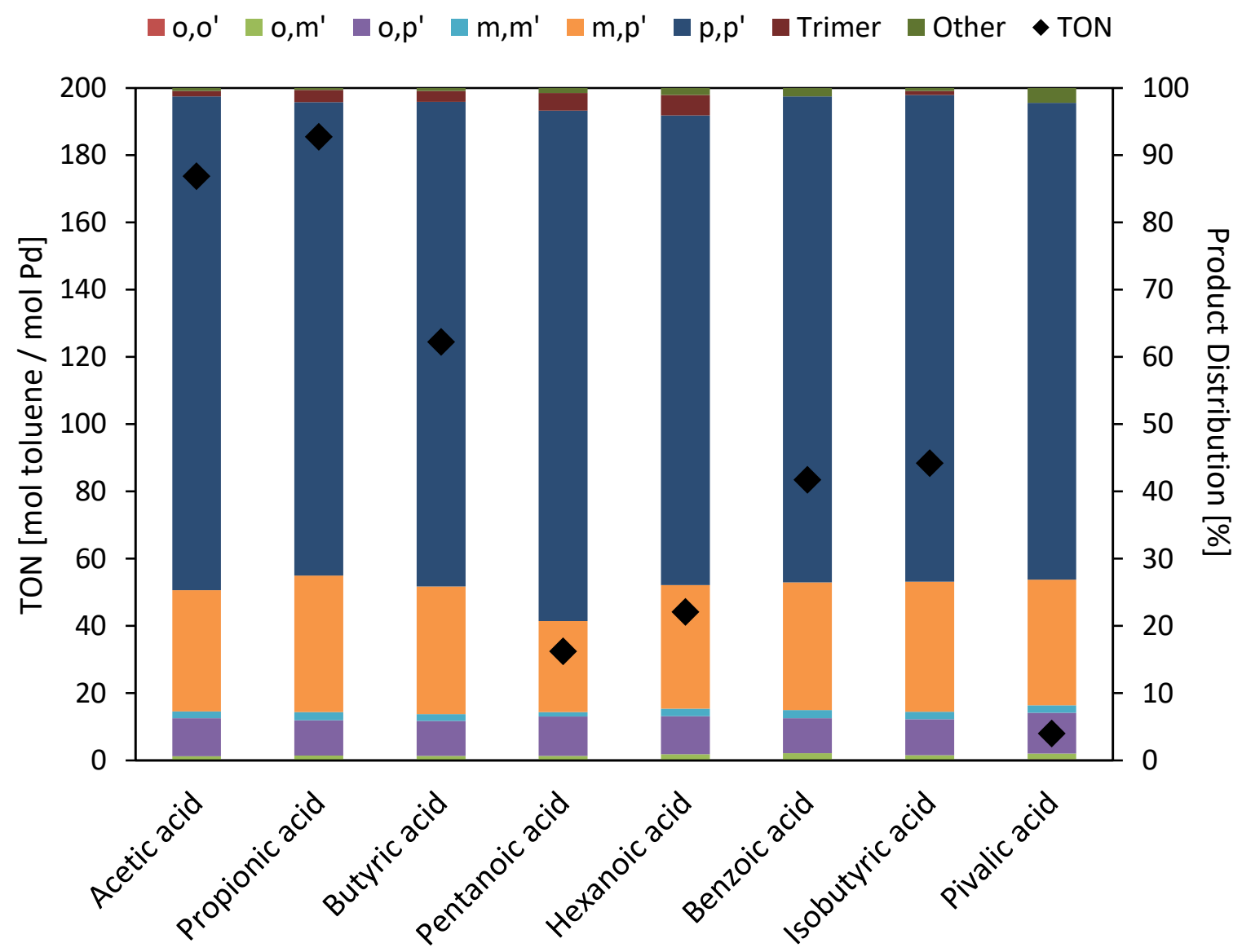

Supplementary Figure 11. Screening of additives with $\mathrm{H}-\mathrm{Beta}(\mathrm{Si} / \mathrm{Al}=75)$. Reactions were carried out using $15 \mu \mathrm{mol} \mathrm{Pd}(\mathrm{OAc})_{2}, 100 \mathrm{mg} \mathrm{H}-\mathrm{Beta}$ ( $\mathrm{Si} / \mathrm{Al}=75$ ), $3.75 \mathrm{mmol}$ additive (250 eq to $\mathrm{Pd}), 2 \mathrm{ml}$ of toluene, 16 bar of $\mathrm{O}_{2}$ at $90^{\circ} \mathrm{C}$ for $16 \mathrm{~h}$. 


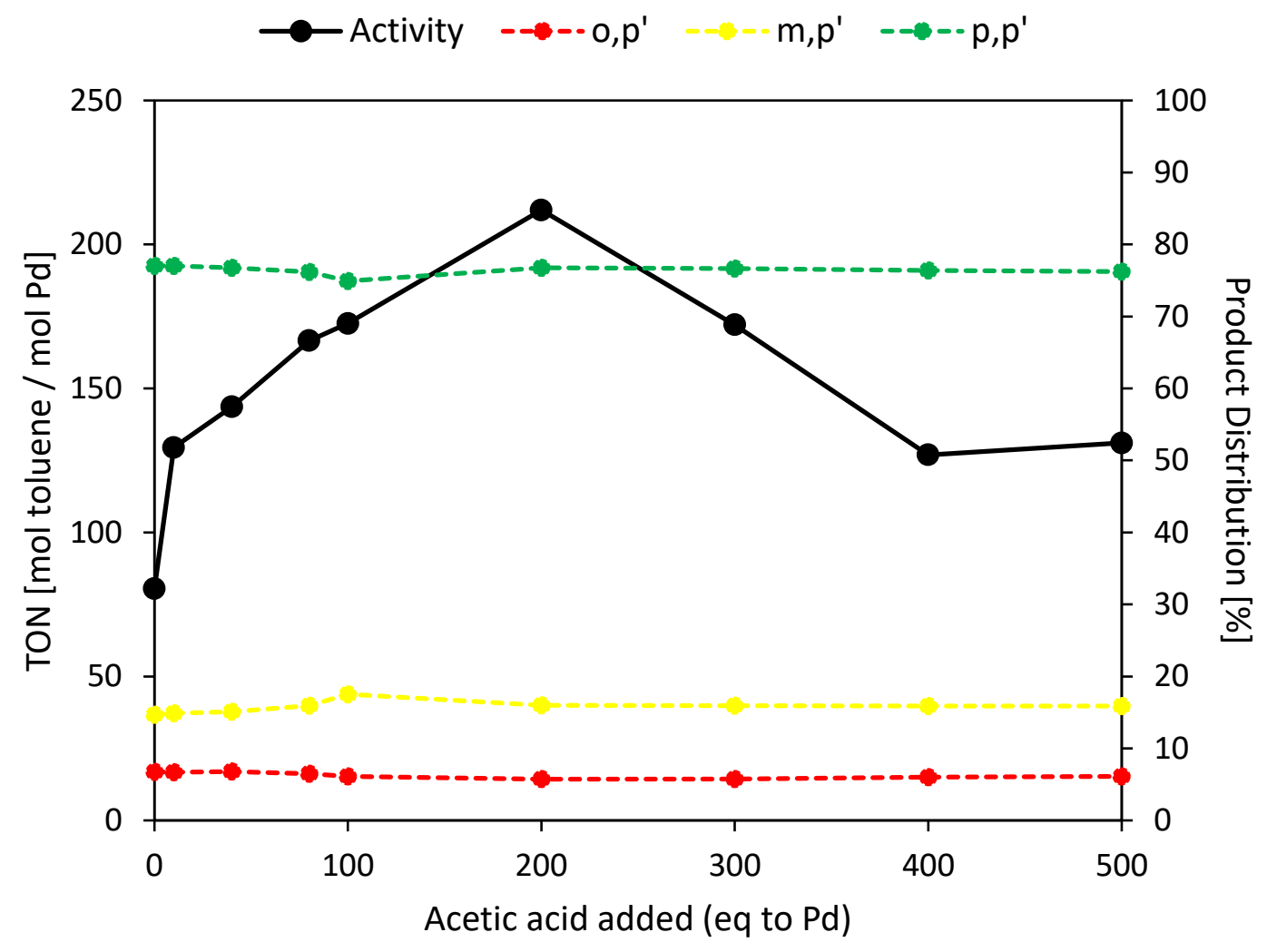

Supplementary Figure 12. Different amounts of acetic acid as additive. Reactions were carried out using $15 \mu \mathrm{mol} \mathrm{Pd}(\mathrm{OAc})_{2}, 100 \mathrm{mg} \mathrm{H}$-Beta ( $\left.\mathrm{Si} / \mathrm{Al}=75\right), 2 \mathrm{ml}$ of toluene, different amounts of acetic acid, 16 bar of $\mathrm{O}_{2}$ at $90^{\circ} \mathrm{C}$ for $16 \mathrm{~h}$. 
Supplementary Table 2. Screening of additives in the zeolite system under atmospheric pressure of oxygen. ${ }^{[\mathrm{A}]}$

\begin{tabular}{|c|c|c|c|c|c|c|c|c|c|c|c|c|c|c|c|}
\hline \multirow{2}{*}{ Entry } & \multirow{2}{*}{$\begin{array}{l}\text { Toluene } \\
\text { [mmol] }\end{array}$} & \multirow{2}{*}{$\begin{array}{l}\text { AcOH } \\
{[\mathrm{mmol}]}\end{array}$} & \multirow{2}{*}{$\begin{array}{l}\text { Zeolite } \\
{[\mathrm{mg}]}\end{array}$} & \multirow{2}{*}{ Additive } & \multirow{2}{*}{ Yield [\%] } & \multirow{2}{*}{ TON } & \multicolumn{9}{|c|}{ Product Distribution [\%] } \\
\hline & & & & & & & $2,2^{\prime}$ & $2,3^{\prime}$ & $2,4^{\prime}$ & $3,3^{\prime}$ & $3,4^{\prime}$ & $4,4^{\prime}$ & Trimer & Benzylic & Other \\
\hline 1 & 15 & 26.2 & 100 & & 0.8 & 8 & 0 & 1 & 5 & 1 & 19 & 58 & 0 & 3 & 14 \\
\hline 2 & 15 & 26.2 & 100 & 2-F Pyridine ${ }^{[\mathrm{B}]}$ & 0.3 & 3 & 0 & 2 & 2 & 5 & 26 & 40 & 3 & & 23 \\
\hline 3 & 18.88 & 3.0 & 200 & & 0.9 & 12 & 0 & 0 & 6 & 1 & 14 & 60 & 0 & 14 & 5 \\
\hline 4 & 18.88 & 3.0 & 100 & $t$-Butyl nitrite ${ }^{[C]}$ & $<0.1$ & $<1$ & & & & & & & & & \\
\hline 5 & 18.88 & 3.0 & 200 & $\mathrm{Cu}(\mathrm{OAc})_{2}{ }^{[\mathrm{C}]}$ & 1.3 & 16 & 0 & 1 & 6 & 1 & 20 & 63 & 0 & 2 & 7 \\
\hline 6 & 18.88 & 3.0 & 200 & $\mathrm{Cu}(\mathrm{OAc})_{2}$ & 1.3 & 17 & 0 & 1 & 7 & 1 & 18 & 63 & & 4 & 6 \\
\hline 7 & 18.88 & 3.0 & 200 & $\mathrm{Cu}(\mathrm{OTFA})_{2}$ & 2.1 & 26 & 0 & 1 & 8 & 1 & 17 & 64 & 0 & 5 & 3 \\
\hline 8 & 18.88 & 3.0 & 200 & $\mathrm{Cu}\left(\mathrm{BF}_{4}\right)_{2}$ & 2.1 & 26 & 0 & 1 & 7 & 1 & 19 & 67 & 0 & 5 & \\
\hline 9 & 18.88 & 3.0 & 200 & $\mathrm{Cu}(\mathrm{OTf})_{2}$ & 2.7 & 34 & 0 & 1 & 6 & 1 & 16 & 70 & 0 & 1 & 5 \\
\hline 10 & 18.88 & 3.0 & 200 & AgOTFA & 0.8 & 11 & 0 & 1 & 7 & 1 & 15 & 60 & & 7 & 10 \\
\hline 11 & 18.88 & 3.0 & 200 & AgOTf & 1.0 & 12 & 1 & 2 & 8 & 1 & 15 & 47 & 0 & 16 & 10 \\
\hline 12 & 18.88 & 3.0 & 200 & $\mathrm{Fe}(\mathrm{OTf})_{3}$ & 4.1 & 52 & 1 & 1 & 8 & 1 & 18 & 60 & 1 & 5 & 4 \\
\hline 13 & 18.88 & 3.0 & 200 & $\mathrm{Hf}(\mathrm{OTf})_{4}$ & 0.4 & 5 & 0 & 2 & 5 & 3 & 19 & 46 & 0 & 0 & 25 \\
\hline 14 & 18.88 & 3.0 & 200 & $\mathrm{Sc}(\mathrm{OTf})_{3}$ & 1.3 & 17 & 1 & 1 & 6 & 1 & 14 & 47 & 0 & 21 & 9 \\
\hline 15 & 18.88 & 3.0 & 200 & $\mathrm{Yb}(\mathrm{OTf})_{3}$ & 1.9 & 24 & 0 & 1 & 7 & 1 & 16 & 62 & 0 & 14 & \\
\hline 16 & 18.88 & 3.0 & 200 & $\mathrm{La}(\mathrm{OTf})_{3}$ & 2.3 & 29 & 0 & 1 & 7 & 1 & 15 & 58 & 0 & 12 & 6 \\
\hline 17 & 18.88 & 3.0 & 200 & $\mathrm{ZrF}_{4}$ & 1.7 & 21 & 0 & 1 & 7 & 1 & 17 & 59 & 0 & 11 & 4 \\
\hline 18 & 18.88 & 3.0 & 200 & $\mathrm{CsF}$ & 1.7 & 21 & 0 & 1 & 8 & 1 & 18 & 62 & 0 & 7 & 4 \\
\hline 19 & 18.88 & 3.0 & 200 & $\mathrm{Co}(\mathrm{OAc})_{2}$ & 1.2 & 15 & 0 & 1 & 6 & 1 & 18 & 65 & 0 & 1 & 8 \\
\hline 20 & 18.88 & 3.0 & 200 & $\mathrm{Mo}(\mathrm{OAc})_{2}$ & 1.7 & 22 & 0 & 1 & 8 & 1 & 17 & 62 & 0 & 8 & 3 \\
\hline 21 & 18.88 & 3.0 & 200 & $\mathrm{NH}_{4} \mathrm{VO}_{3}$ & 2.0 & 25 & 0 & 1 & 7 & 1 & 17 & 64 & 0 & 4 & 6 \\
\hline 22 & 18.88 & 3.0 & 200 & $\mathrm{~K}_{2} \mathrm{Cr}_{2} \mathrm{O}_{7}$ & 1.7 & 22 & 0 & 1 & 7 & 1 & 17 & 66 & 0 & 6 & 3 \\
\hline 23 & 18.88 & 3.0 & 200 & $\mathrm{H}_{3} \mathrm{PW}_{12} \mathrm{O}_{40}$ & 0.9 & 11 & 1 & 2 & 8 & 1 & 15 & 59 & & 8 & 7 \\
\hline
\end{tabular}


Palladium was pre-loaded onto zeolite $\mathrm{H}$-Beta $(\mathrm{Si} / \mathrm{Al}=75)$ by contacting $\mathrm{Pd}(\mathrm{OAc})_{2}$ in different solvents with the zeolite (Supplementary Figure 13). A heterogeneous Pd,H-Beta was obtained which performed similarly in the oxidative coupling of toluene than the case in which Pd is loaded in-situ upon the zeolite. The best performance was obtained when toluene was used as loading solvent. Due to the possible reaction at room temperature which could skew the results, this loading solvent was avoided for further experiments, and $\mathrm{CHCl}_{3}$ was preferred instead.

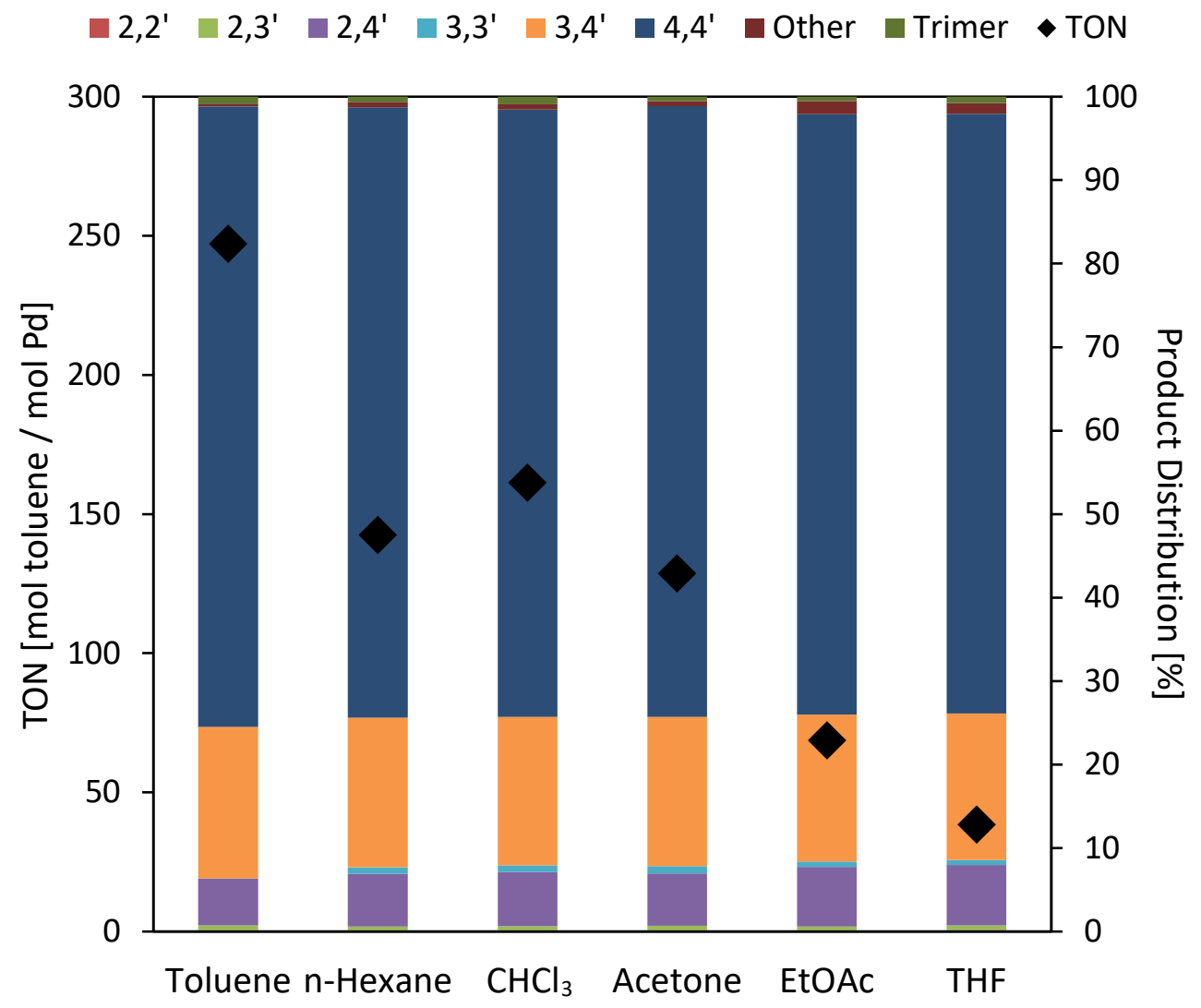

Supplementary Figure 13. Pre-loading of palladium on H-Beta ( $\mathrm{Si} / \mathrm{Al}=75)$. H-Beta $(\mathrm{Si} / \mathrm{Al}=75)$ was contacted with $\mathrm{Pd}(\mathrm{OAc})_{2}(15 \mu \mathrm{mol} \mathrm{Pd} / 100 \mathrm{mg}$ zeolite, $\mathrm{Pd} / \mathrm{Al}=0.68)$ in different solvents $(10$ $\mathrm{ml} / \mathrm{g}$ zeolite) at room temperature. After 24 hours, the zeolite was separated by centrifugation, and washed twice with the loading solvent $(10 \mathrm{ml} / \mathrm{g}$ zeolite). The solid was then dried in vacuo $\left(30^{\circ} \mathrm{C}, 30 \mathrm{mbar}\right.$, overnight) and used as such. Reaction conditions: $100 \mathrm{mg} \mathrm{Pd}, \mathrm{H}-\mathrm{Beta}(\mathrm{Si} / \mathrm{Al}=75)$, $172 \mu \mathrm{l}$ acetic acid (200 eq to $\mathrm{Pd}$ ), $2 \mathrm{ml}$ toluene, $90^{\circ} \mathrm{C}, 16$ bar $\mathrm{O}_{2}, 16$ hours. 


\section{X-Ray Absorption Spectroscopy (XAS)}

Palladium acetate was loaded onto zeolite Beta $(\mathrm{Si} / \mathrm{Al}=32)$ according to the procedure of Supplementary Figure 13 using different solvents (DCM, toluene, isopentane). We expect that trimeric $\mathrm{Pd}_{3}(\mathrm{OAc})_{6}$ species will not be broken up in the apolar isopentane, which will result in a physical mixture of $\mathrm{Pd}_{3}(\mathrm{OAc})_{6}$ and the zeolite. In DCM and toluene, the trimers are hypothesized to be converted to monomers, which subsequently enter the zeolite. Toluene was especially chosen to mimic the environment of the catalytic reaction as closely as possible, but the absence of high pressure oxygen and additional acetic acid could result in the formation of $\mathrm{Pd}$ nanoparticles due to the coupling reaction occurring without reoxidation of $\operatorname{Pd}(0)$ to $\operatorname{Pd}(\mathrm{II})$.

\section{X-Ray absorption near-edge structure (XANES)}

The XANES region is a fingerprint of the local coordination and oxidation state, and it comes as an independent tool, complementary to EXAFS. Although a reference of pure Pd(II) attached to the zeolite framework is not available, theoretical XANES calculations based on DFT-optimized structures demonstrate high similarity in the near-edge region between $\mathrm{Pd}(\mathrm{OAc})_{2}$ and $\mathrm{Pd}(\mathrm{II})$ attached to two oxygen atoms of the zeolite framework (Supplementary Figure 14). The observed similarity is naturally explained by the square planar coordination with four oxygen neighbors in both cases. Therefore, the experimental spectrum of $\mathrm{Pd}(\mathrm{II})$ acetate $\left(\mathrm{Pd}_{3}(\mathrm{OAc})_{6}\right)$ was used as a reference for Pd single sites with square planar coordination inside the zeolite.

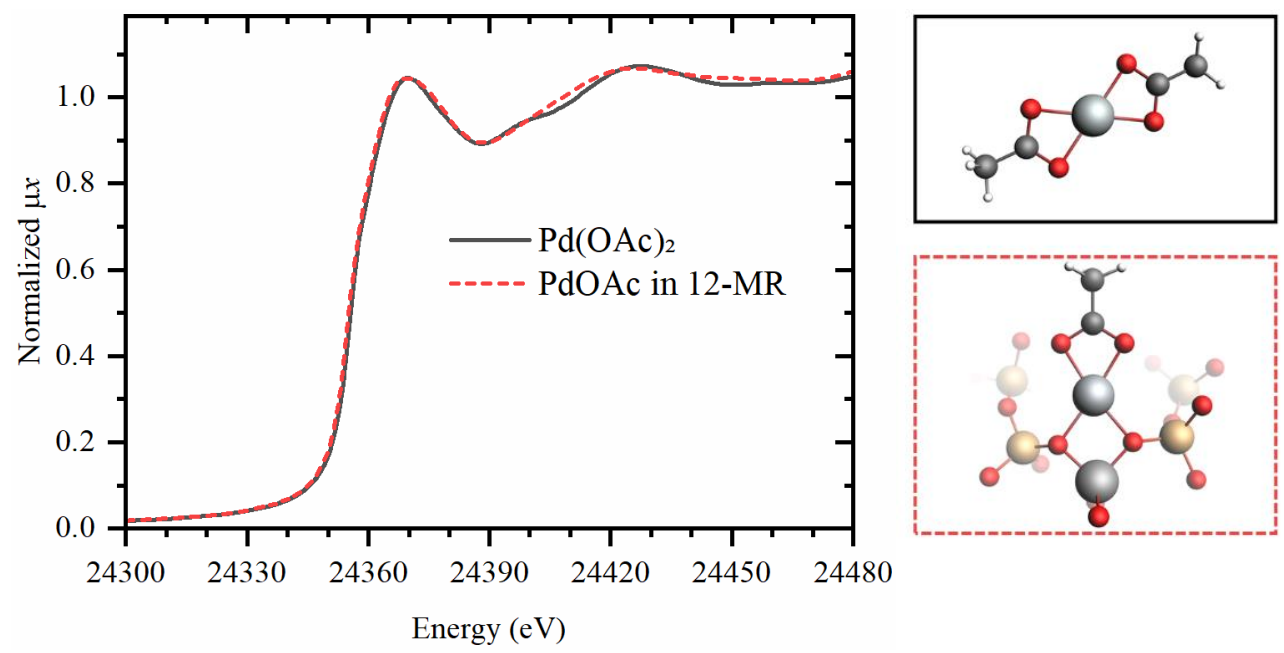

Supplementary Figure 14. Theoretical XANES spectra for monomeric $\mathrm{Pd}(\mathrm{OAc})_{2}$ (solid black) and $\mathrm{Pd}(\mathrm{II})$ attached to two oxygens of the zeolite framework (dashed red). The right part shows the structures used for calculation.

Linear combination analysis (LCA) of XANES by reference spectra is often used to estimate the concentration of different species in samples. The XANES region of the Pd-loaded Beta zeolite samples was fitted with linear combinations of $\mathrm{Pd}(\mathrm{OAc})_{2}$ and $\mathrm{Pd}$ foil as reference components (Supplementary Table 3). The results highlight a strong similarity of the XANES region of the Pd-Beta sample, pre-loaded in isopentane, with the spectrum of crystalline starting compound $\mathrm{Pd}_{3}(\mathrm{OAc})_{6}$, which might be due to the presence of non-dissolved $\mathrm{Pd}_{3}(\mathrm{OAc})_{6}$. The XANES region of the $\mathrm{Pd}$-Beta, loaded in toluene or DCM deviates from the spectrum of $\mathrm{Pd}_{3}(\mathrm{OAc})_{6}$. A reasonable fit is obtained by including the Pd foil reference for the Pd-Beta loaded from DCM, but not for the Pd-Beta, pre-loaded in toluene (Supplementary Figure 15). This shows that in the latter 
sample, Pd is present in a different local coordination environment than the measured reference components. Addition of $\mathrm{PdO}$ reference did not lead to a significant improvement of the fit.

Supplementary Table 3. LCA of the XANES region of Pd-Beta ( $\mathrm{Si} / \mathrm{Al}=32)$ with $\mathrm{Pd}_{3}(\mathrm{OAc})_{6}$ and Pd foil as reference components.

\begin{tabular}{|lll|}
\hline $\begin{array}{l}\text { Loading } \\
\text { solvent }\end{array}$ & $\mathrm{Pd}_{3}(\mathrm{OAc})_{6}$ & $\begin{array}{l}\mathrm{Pd} \\
\text { foil }\end{array}$ \\
\hline Toluene & 0.65 & 0.35 \\
Isopentane & 0.92 & 0.08 \\
DCM & 0.84 & 0.16 \\
\hline
\end{tabular}

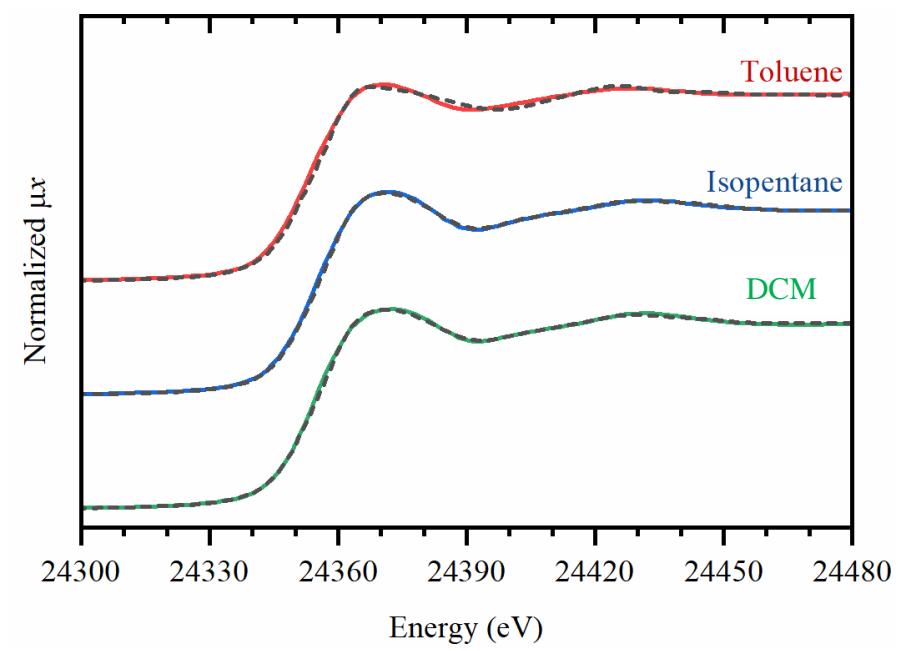

Supplementary Figure 15. Experimental XANES spectra of the Pd-Beta zeolites (colored curves) fitted by $\mathrm{Pd}$ foil and $\mathrm{Pd}_{3}(\mathrm{OAc})_{6}$ references (dashed black).

The experimental XANES regions of Pd-Beta, pre-loaded in toluene, and of the reference $\mathrm{Pd}_{3}(\mathrm{OAc})_{6}$ were subsequently compared (Supplementary Figure 16). A decrease in white line intensity and a small shift in the edge position to lower energies are observed, which could be linked to an increased electron density on Pd, or to presence of a softer ligand than acetate. This prompted us to use one of the catalytic intermediates proposed in Figure 6 of the paper, viz. the stable intermediate $\mathbf{V}$, as model for a theoretical XANES calculation. When comparing the theoretical spectra obtained by using the theoretically proposed $\mathbf{V}$ and the crystallographic structure of trimeric $\mathrm{Pd}_{3}(\mathrm{OAc})_{6}$ (CCDC 262708), similar deviations were observed as between the experimental XANES spectrum of Pd-Beta, pre-loaded in toluene, and of the reference $\mathrm{Pd}_{3}(\mathrm{OAc})_{6}$. To obtain the best agreement between the theoretical and experimental spectra, the distances from the Pd atom to the acetate ligand, toluene and the framework oxygen were varied by means of pyFitIt software. 


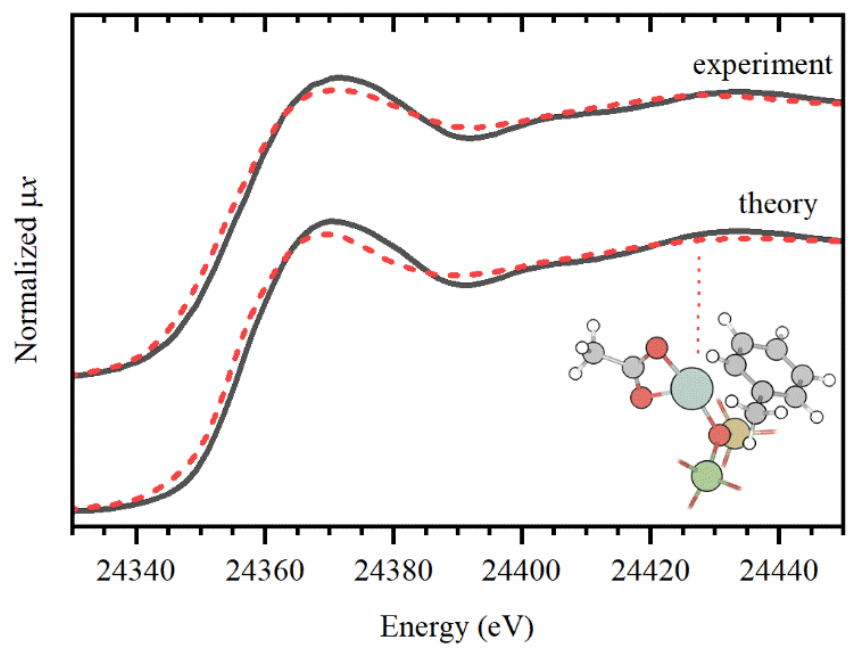

Supplementary Figure 16. (Top) Experimental XANES spectra of the $\operatorname{Pd}_{3}(\mathrm{OAc})_{6}$ reference (solid black) and Pd-Beta with toluene as loading solvent (dashed red); (bottom) theoretical spectra for trimeric $\mathrm{Pd}_{3}(\mathrm{OAc})_{6}$ (solid black), taken from CCDC database (262708) and the atomic model of intermediate $\mathbf{V}$ shown in the graph, with a toluene molecule close to $\mathrm{Pd}$.

\section{Extended X-ray Absorption Fine Structure (EXAFS)}

Subsequently, we probed the speciation of Pd by analysis of the Pd $K$-edge EXAFS region of the $\mathrm{Pd}$-loaded zeolites, crystalline $\mathrm{Pd}$ acetate and $\mathrm{Pd}$ foil. The first quantitative insight is provided by first-shell fitting of the EXAFS data (Supplementary Table 4). A single Pd-O contribution was used with coordination number $(N)$, interatomic distance $(R)$, and Debye-Waller factor $\left(\sigma^{2}\right)$ as variable parameters.

First of all, we should note the high similarity of all structural parameters between the crystalline $\mathrm{Pd}$ acetate reference and $\mathrm{Pd}-\mathrm{Beta}$, preloaded in isopentane, which indicates that $\mathrm{Pd}_{3}(\mathrm{OAc})_{6}$ was not dissociated in the highly apolar isopentane solvent. All other samples are characterized by: i) an increased Debye-Waller factor, which indicates the increased disorder in the first shell, and ii) the worse quality of fit evidenced by the R-factor, which indicates that either the single-shell Pd$\mathrm{O}$ model is not fully suitable, and/or that the samples contain a mixture of different phases. The former can be due to the fact that Pd is coordinated by two types of oxygen atoms, viz. from the zeolite framework, and from the acetate ligand.

Supplementary Table 4. First-shell EXAFS analysis of $\mathrm{Pd}(\mathrm{OAc})_{2}$ and $\mathrm{Pd}-\mathrm{Beta}(\mathrm{Si} / \mathrm{Al}=32)$, preloaded in different solvents, with only Pd-O contributions.

\begin{tabular}{|lllll|}
\hline & $R(\AA)$ & $N$ & $\sigma^{2}\left(\AA^{2}\right)$ & $R$-factor \\
\hline $\mathrm{Pd}_{3}(\mathrm{OAc})_{6}$ & $2.00 \pm 0.01$ & 4 (fixed) & $0.002 \pm 0.001$ & 0.007 \\
Pd-Beta (Toluene) & $2.02 \pm 0.01$ & $3.3 \pm 0.3$ & $0.005 \pm 0.001$ & 0.012 \\
Pd-Beta (Isopentane) & $2.00 \pm 0.01$ & $4.1 \pm 0.4$ & $0.003 \pm 0.001$ & 0.006 \\
Pd-Beta (DCM) & $2.02 \pm 0.02$ & $4.6 \pm 0.8$ & $0.005 \pm 0.002$ & 0.016 \\
\hline
\end{tabular}

The fitted value for the coordination number $N$ is $3.3 \pm 0.3$ for the Pd-Beta, pre-loaded in toluene, while for other samples it is close to 4 within the uncertainty. Since Pd nanoparticles could be present in the sample loaded from toluene (as noted above), this was further investigated by the addition of a Pd-Pd contribution (Supplementary Figure 17, Supplementary Table 5). The fit is 
significantly improved in the $2-3 \AA$ region. The interatomic distance of $2.77 \AA$ indicates the presence of Pd nanoparticles, rather than of dimeric or trimeric species. The Pd-O coordination number $N$ is now close to 3 . The low coordination number for the Pd-Pd contribution indicates that the nanoparticles are extremely small and/or are present in a very small amount with respect to monomeric Pd-species.

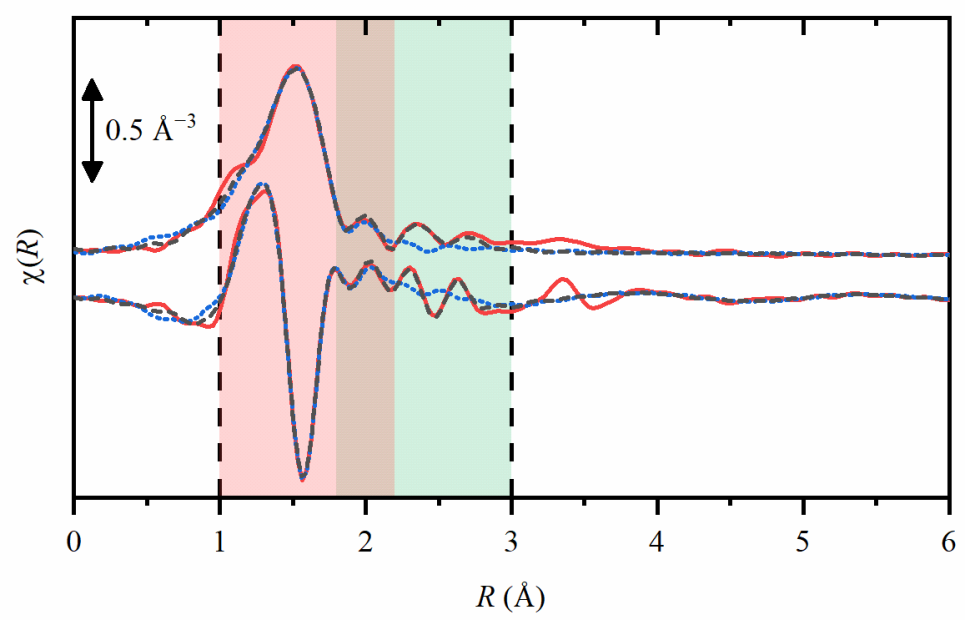

Supplementary Figure 17. Experimental (red) and fitted (dashed black) EXAFS spectra for PdBeta $(\mathrm{Si} / \mathrm{Al}=32)$, pre-loaded in toluene, with $\mathrm{Pd}-\mathrm{O}$ and $\mathrm{Pd}-\mathrm{Pd}$ contributions, highlighted by red and green background, respectively. The blue dotted line demonstrates the best fit with only the Pd-O contribution.

Supplementary Table 5. EXAFS analysis of Pd-Beta ( $\mathrm{Si} / \mathrm{Al}=32$ ), pre-loaded in toluene with Pd$\mathrm{O}$ and Pd-Pd contributions.

\begin{tabular}{|llll|}
\hline & $R(\AA)$ & $N(\times$ fraction $)$ & $\sigma^{2}\left(\AA^{2}\right)$ \\
\hline Pd-O & $2.02 \pm 0.01$ & $2.9 \pm 0.1$ & $0.004 \pm 0.001$ \\
Pd-Pd & $2.77 \pm 0.01$ & $0.30 \pm 0.17$ & $0.003 \pm 0.003$ \\
\hline
\end{tabular}

Alternatively, we used catalytic intermediate $\mathbf{V}$ as model for the higher shell EXAFS analysis, due to the good agreement with the experimental XANES spectrum. No Pd-Pd contributions of Pd nanoparticles were included in order to limit the number of variable parameters. The most intense single scattering and one multiple scattering (related to O-C scattering in the acetate) paths were included. All paths had independent interatomic distances as fitting variables. The coordination numbers were fixed according to the atomic model. Debye-Waller parameters for all atoms in the acetate and toluene were calculated based on the value refined for the nearest to Pd atom according to the equation: $\sigma_{i}=\sigma_{1} \sqrt{R_{i} / R_{1}} . \Delta E_{0}$ variable was set common for all paths. Another approximation which has to be noted is that some pairs of distances were assumed to be equal, such as $\mathrm{Pd}-\mathrm{C}$ distances to two nearest carbon atoms of the toluene, $\mathrm{Pd}-\mathrm{O}$ distances to two more distant framework oxygens, $\mathrm{Pd}-\mathrm{Al}$ and $\mathrm{Pd}-\mathrm{Si}$ distances. Even with so many constraints, the fit gives a good agreement with experiment with meaningful values listed in Supplementary Table 6. Since this fit and the previous fit (with only Pd-O and Pd-Pd contributions) contain significantly different numbers of variable parameters (and several approximations to decrease them), they are not directly comparable, and we cannot unambiguously say, which model is better. But the result 
clearly indicates that the theoretical structure $\mathbf{V}$ agrees quite well with the EXAFS observation. In reality, we may probably still have a mixture of this model and Pd nanoparticles, which would result in too many variable parameters to make a stable EXAFS fit.

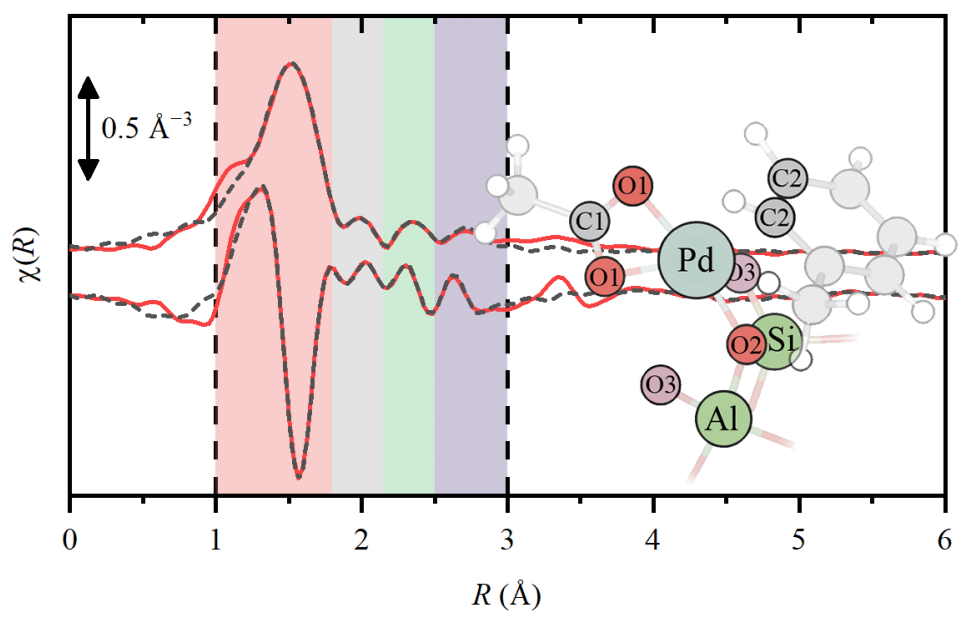

Supplementary Figure 18. Experimental (red) and fitted (dashed black) EXAFS spectra for PdBeta, pre-loaded in toluene. For the fit, the theoretically proposed intermediate $\mathbf{V}$ was used. The different background colors highlight the region with the major contribution from the atoms of the corresponding color.

Supplementary Table 6. EXAFS analysis of Pd-Beta, pre-loaded in toluene.

\begin{tabular}{|llll|}
\hline & $R(\AA)$ & $N$ (fixed) & $\sigma^{2}\left(\AA^{2}\right)$ \\
\hline Pd-O1 & & & \\
Pd-C $1_{\text {acetate }}$ & $2.00 \pm 0.01$ & 2 & $0.0027 \pm 0.0016$ \\
Pd-O1-C1 & $2.40 \pm 0.04$ & 1 & $0.0029^{*}$ \\
& $2.96 \pm 0.06$ & 4 & \\
Pd-O2 $2_{\text {framework }}$ & $2.11 \pm 0.03$ & 1 & $0.0028^{*}$ \\
Pd-O3 & & & $0.0033^{*}$ \\
Pd-Al $(\mathrm{Si})$ & $3.11 \pm 0.06$ & 2 & $0.020 \pm 0.011$ \\
& & & \\
Pd-C2 & & 2 & $0.0040 \pm 0.0027$ \\
\hline
\end{tabular}

Summarizing the above analysis, both XANES and EXAFS data, indicate the presence of monomeric $\mathrm{Pd}(\mathrm{II})$ as dominant species, and show that there is no (significant) contribution from di- or trimeric Pd. The data for the sample loaded in toluene agree well with the theoretical spectra for the intermediate $\mathbf{V}$ (cfr Figure 6 of the main paper). 


\section{Advanced NMR Characterization}

Palladium acetate $\left(\mathrm{Pd}(\mathrm{OAc})_{2}\right)$ was loaded onto zeolite Beta $(\mathrm{Si} / \mathrm{Al}=75)$ according to the procedure of Supplementary Figure 13 using DCM as the loading solvent. ${ }^{27} \mathrm{Al}$ MAS NMR spectra were recorded of both the fresh $\mathrm{H}-\mathrm{Beta}(\mathrm{Si} / \mathrm{Al}=75)$ and the loaded Pd-Beta. In the spectrum of the fresh H-Beta (Supplementary Figure 19) we can distinguish two overlapping sharp signals around 55 ppm that belong to four-coordinated, tetrahedral $\mathrm{Al}$ atoms occupying different framework $\mathrm{T}$ sites (one signal, $\mathrm{Al}(\mathrm{IV})_{\mathrm{b}}$, belongs to $\mathrm{Al}$ on $\mathrm{T} 1$ and $\mathrm{T} 2$ sites; the other signal, $\mathrm{Al}(\mathrm{IV})_{\mathrm{a}}$, to $\mathrm{Al}$ on $\mathrm{T} 3-\mathrm{T} 9$ sites). In addition, we can also see a much weaker narrow signal close to $0 \mathrm{ppm}$, which can be assigned to six-coordinated Al. In the literature the assignment of this signal is not equivocal; Zhao et al. assigned it to octahedral, extra-framework Al cations ${ }^{52}$.

The ${ }^{27} \mathrm{Al}$ MAS NMR spectrum of Pd-loaded Beta is similar to the spectrum of H-Beta, besides a broadening of the signal of tetrahedral Al. This broadening shows that the coordination environment of $\mathrm{Al}$ in Pd-Beta is slightly different than in H-Beta. The difference could result from a coordination with $\mathrm{Pd}$ or from a different arrangement or a decrease of the number of water molecules in the vicinity of Al.
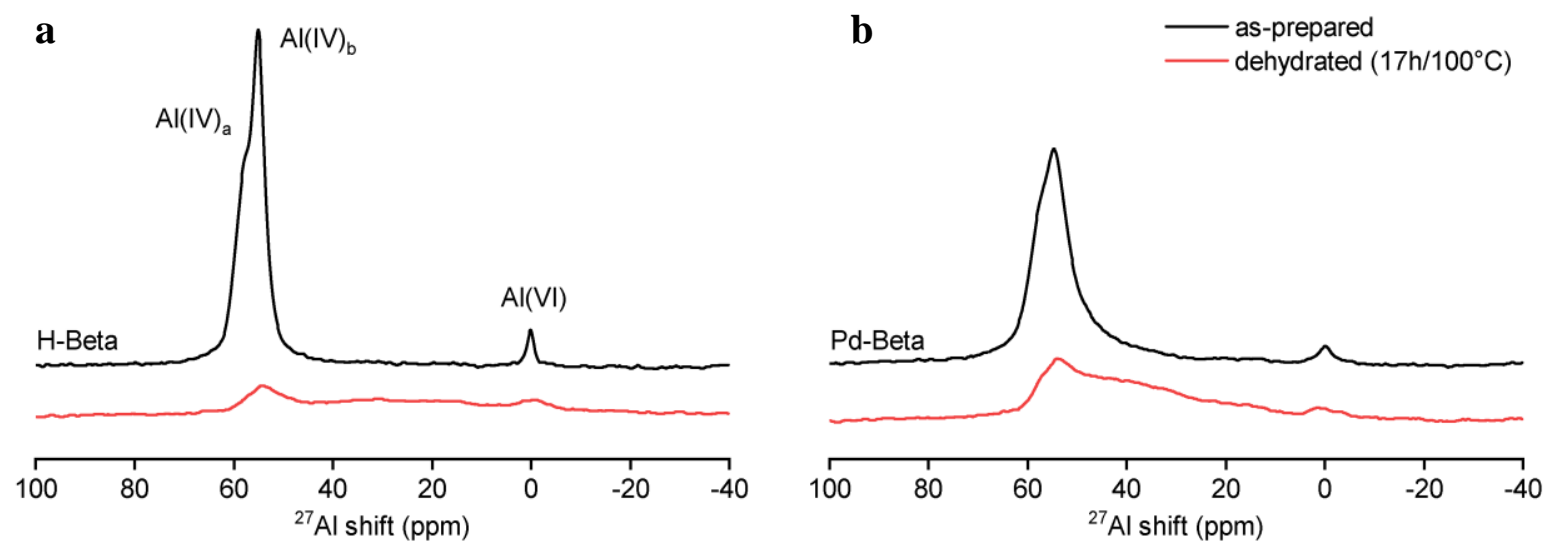

Supplementary Figure 19. ${ }^{27} \mathrm{Al}$ MAS NMR spectra of the as-prepared (black) and dehydrated (red) fresh H-Beta (a) and Pd-Beta (b).

Subsequently, we aimed to study the acetate ligand on Pd by ${ }^{13} \mathrm{C}$ MAS NMR spectroscopy. To this end, we prepared a $1 \mathrm{C}-{ }^{13} \mathrm{C}$-enriched $\mathrm{Pd}$ acetate in order to increase the sensitivity of these measurements. We recrystallized commercial, trimeric $\mathrm{Pd}_{3}(\mathrm{OAc})_{6}(20 \mathrm{mg})$ in hot $\mathrm{AcOH}-1-{ }^{13} \mathrm{C}$ (250 mg) using $n$-pentane as anti-solvent. The crystals were then filtered, and washed with $n$ pentane. The procedure yielded $19.5 \mathrm{mg}$ of ${ }^{13} \mathrm{C}$-enriched $\mathrm{Pd}_{3}(\mathrm{OAc})_{6}$ as an orange solid. A solution ${ }^{1} \mathrm{H}$ NMR spectrum of the obtained sample was compared to the solution ${ }^{1} \mathrm{H}$ NMR spectrum of the commercial $\mathrm{Pd}(\mathrm{OAc})_{2}$ precursor (Supplementary Figure 20, left). The multiplet structure of the former ${ }^{1} \mathrm{H}$ NMR spectrum, which is due to the J-coupling of ${ }^{1} \mathrm{H}$ nuclei with the ${ }^{13} \mathrm{C}$ nuclei, confirms the successful exchange of the ${ }^{13} \mathrm{C}$-enriched acetate ligands. Analysis of the singlets and doublets shows that the ${ }^{13} \mathrm{C}$-enriched $\mathrm{Pd}_{3}(\mathrm{OAc})_{6}$ contains $68 \%$ acetate- $1 \mathrm{C}-{ }^{13} \mathrm{C}$ ligands (Supplementary Figure 20, right). 


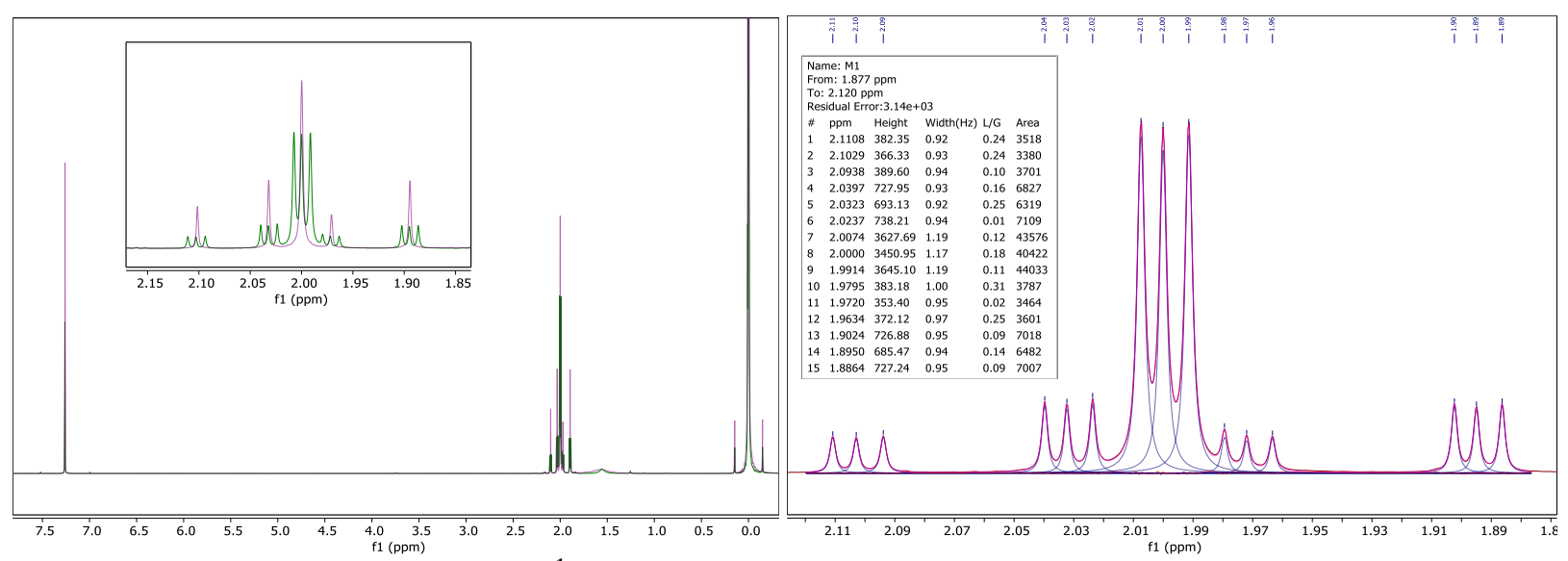

Supplementary Figure 20. Left: ${ }^{1} \mathrm{H}$ NMR spectrum $\left(400 \mathrm{MHz}, \mathrm{CDCl}_{3}\right)$ of commercial $\mathrm{Pd}(\mathrm{OAc})_{2}$ (purple) and ${ }^{13} \mathrm{C}$-enriched $\mathrm{Pd}(\mathrm{OAc})_{2}$ (green). Right: Deconvolution of the ${ }^{1} \mathrm{H}$ NMR spectrum of ${ }^{13} \mathrm{C}$-enriched $\mathrm{Pd}(\mathrm{OAc})_{2}$ in the region around $2 \mathrm{ppm}$.

The ${ }^{13} \mathrm{C}$-enriched $\mathrm{Pd}_{3}(\mathrm{OAc})_{6}$ was subsequently loaded onto $\mathrm{H}$-Beta ( $\mathrm{Si} / \mathrm{Al}=75$ ) according to the procedure of Supplementary Figure 13 using DCM as the loading solvent. The ${ }^{13} \mathrm{C}$ MAS NMR spectrum of the obtained Pd-Beta material was recorded and compared to the spectrum of the ${ }^{13} \mathrm{C}$-enriched $\mathrm{Pd}_{3}(\mathrm{OAc})_{6}$ precursor. In the ${ }^{13} \mathrm{C}$ MAS NMR spectrum of Pd-Beta (Supplementary Figure 21), three signals can be resolved, which resonate at 191, 187.5 and $178 \mathrm{ppm}$ and show a ratio of approximately 1:1:2.2 in the corresponding intensities. Based on its chemical shift, the signal at $178 \mathrm{ppm}$ can be assigned to free acetic acid, indicating that approximately half of the available acetate of $\mathrm{Pd}(\mathrm{OAc})_{2}$ is displaced in the loading procedure. This leaves one acetate ligand attached per Pd in the zeolite.

The two signals at 191 and $187.5 \mathrm{ppm}$ have chemical shifts rather similar to the signals of the bound carboxylates of $\mathrm{Pd}_{3}(\mathrm{OAc})_{6}$. The signals are however broad compared to those of $\mathrm{Pd}_{3}(\mathrm{OAc})_{6}$, which is probably due to a variety of similar but slightly different chemical environments within the zeolite. The presence of two groups of signals (two broad signals) could be related to two distinct aluminium environments, which are detected in the ${ }^{27} \mathrm{Al}$ MAS NMR spectra of zeolite beta and which correspond to Al occupying T1-T2 and T3-T9 sites.

$\mathbf{a}$

b
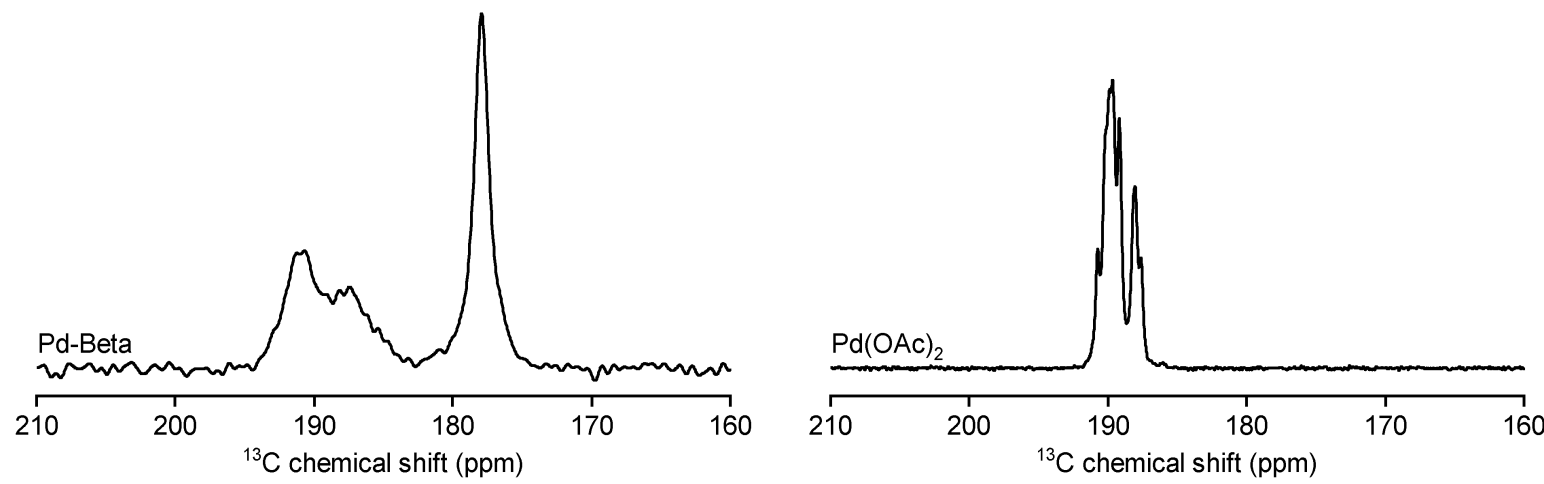

Supplementary Figure 21. ${ }^{13} \mathrm{C}$ MAS NMR spectra of Pd-Beta (a) and $1 \mathrm{C}-{ }^{13} \mathrm{C}$-enriched $\mathrm{Pd}_{3}(\mathrm{OAc})_{6}(\mathbf{b})$. Only the part of the spectrum with the ${ }^{13} \mathrm{C}$ signals of the carboxylates is shown. 
The ${ }^{13} \mathrm{C}$ signals of the methyl groups were drastically less intense because of the natural abundance of ${ }^{13} \mathrm{C}$ nuclei within these groups (circa $1 \%$ )

Subsequently, the mutual proximity of the acetate ligands in ${ }^{13} \mathrm{C}$-enriched $\mathrm{Pd}_{3}(\mathrm{OAc})_{6}$ and $\mathrm{Pd}$-Beta was probed using 2D ${ }^{13} \mathrm{C}-{ }^{13} \mathrm{C}$ spin-diffusion experiments (Supplementary Figure 22). The spindiffusion spectrum of $\mathrm{Pd}_{3}(\mathrm{OAc})_{6}$ exhibits many off-diagonal cross peaks, signifying efficient polarization transfer among the crystallographically distinct $\mathrm{COO}$ groups within this material. In contrast, the spectrum of Pd-Beta shows no off-diagonal cross peaks. This shows that in the PdBeta sample the COO groups resonating at $191 \mathrm{ppm}$ are not spatially close to the COO groups resonating at $187.5 \mathrm{ppm}$. The signal at $178 \mathrm{ppm}$ does not exhibit cross peaks with the other two signals either.
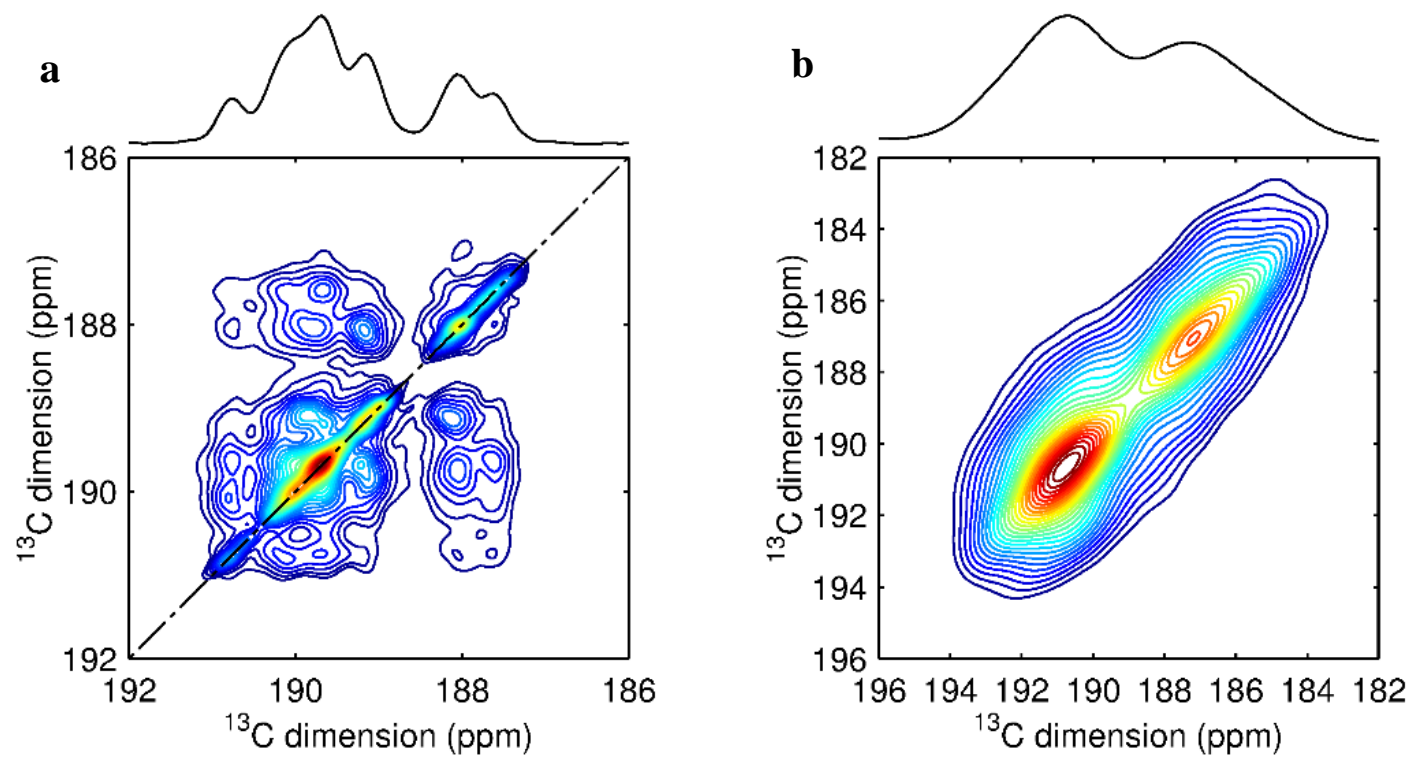

Supplementary Figure 22. 2D ${ }^{13} \mathrm{C}-{ }^{13} \mathrm{C}$ spin-diffusion MAS NMR spectra of the ${ }^{13} \mathrm{C}$-enriched $\mathrm{Pd}_{3}(\mathrm{OAc})_{6}(\mathbf{a})$ and $\mathrm{Pd}-\mathrm{Beta}(\mathbf{b})$.

Finally, to exclude spatial proximity of COO groups corresponding to the 191 and $187.5 \mathrm{ppm}$ signals within these groups, we carried out a $1 \mathrm{D}{ }^{13} \mathrm{C} \mathrm{DQ}$ (double-quantum)-filtered experiment (Supplementary Figure 23). Detecting a signal in such an experiment would signify that the corresponding $\mathrm{COO}$ group sees another $\mathrm{COO}$ group in its proximity. The experiment was further validated by simulation of intensities of the ${ }^{13} \mathrm{C} \mathrm{DQ}$-filtered signals for trimeric $\mathrm{Pd}_{3}(\mathrm{OAc})_{6}$ and for occluded, monomeric $\mathrm{Pd}(\mathrm{OAc})_{2}$. The simulation shows that using the $\mathrm{DQ}$ excitation and reconversion blocks with the duration of 8-10 ms, the two systems should give approximately equal DQ-filtered efficiencies, providing that the relaxation of DQ coherences during their excitation and reconversion was approximately equally slow in both species. Even after prolonged measurement times (four days for the Pd-Beta sample), no DQ-filtered signal was observed for the Pd-Beta sample which confirms the spatial isolation of each acetate group from other acetate groups. 

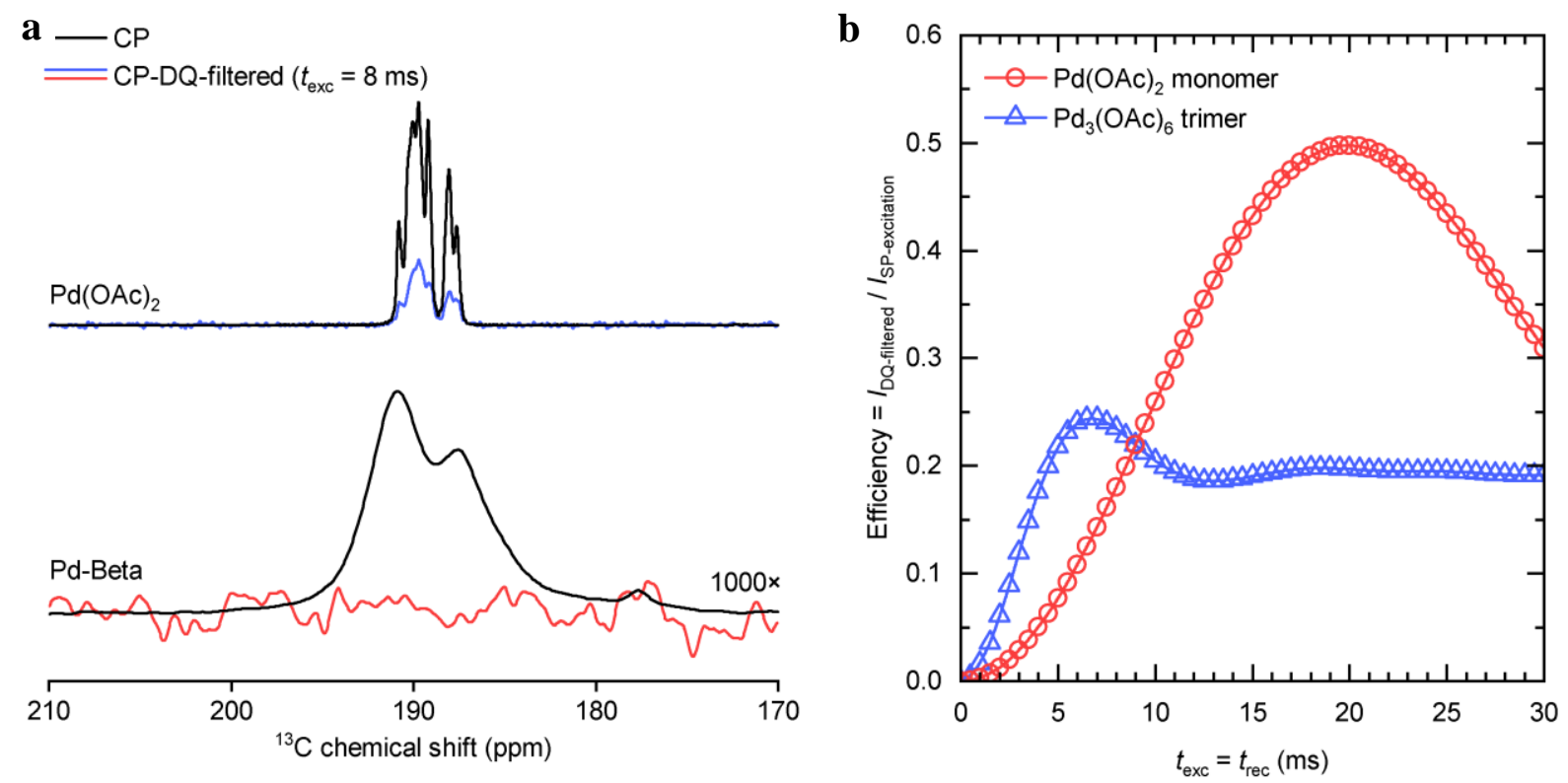

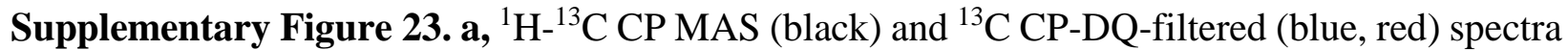
of the crystalline $\mathrm{Pd}_{3}(\mathrm{OAc})_{6}$ (top) and Pd-Beta (bottom). b, Simulation of intensities of the ${ }^{13} \mathrm{C}$ DQ-filtered signals of trimeric $\mathrm{Pd}_{3}(\mathrm{OAc})_{6}$ in the crystals and monomeric $\mathrm{Pd}(\mathrm{OAc})_{2}$ in zeolite beta, assuming $68 \%{ }^{13} \mathrm{C}$-enrichment.

Therefore, we conclude that the pre-loading procedure, wherein H-Beta is contacted with $\operatorname{Pd}(\mathrm{OAc})_{2}$, e.g. in DCM, will result in a species with a spatially isolated acetate fragment, which can only be assigned to a $\mathrm{Pd}(\mathrm{OAc})(\mathrm{OZ})$ species. For a monomeric $\mathrm{Pd}(\mathrm{OAc})_{2}$ species NMR experiments would detect proximity between the two acetate groups, while no NMR signal indicative of a bound acetate should have been recorded for a $\mathrm{Pd}(\mathrm{OZ})_{2}$ species. 


\section{Other Experiments}

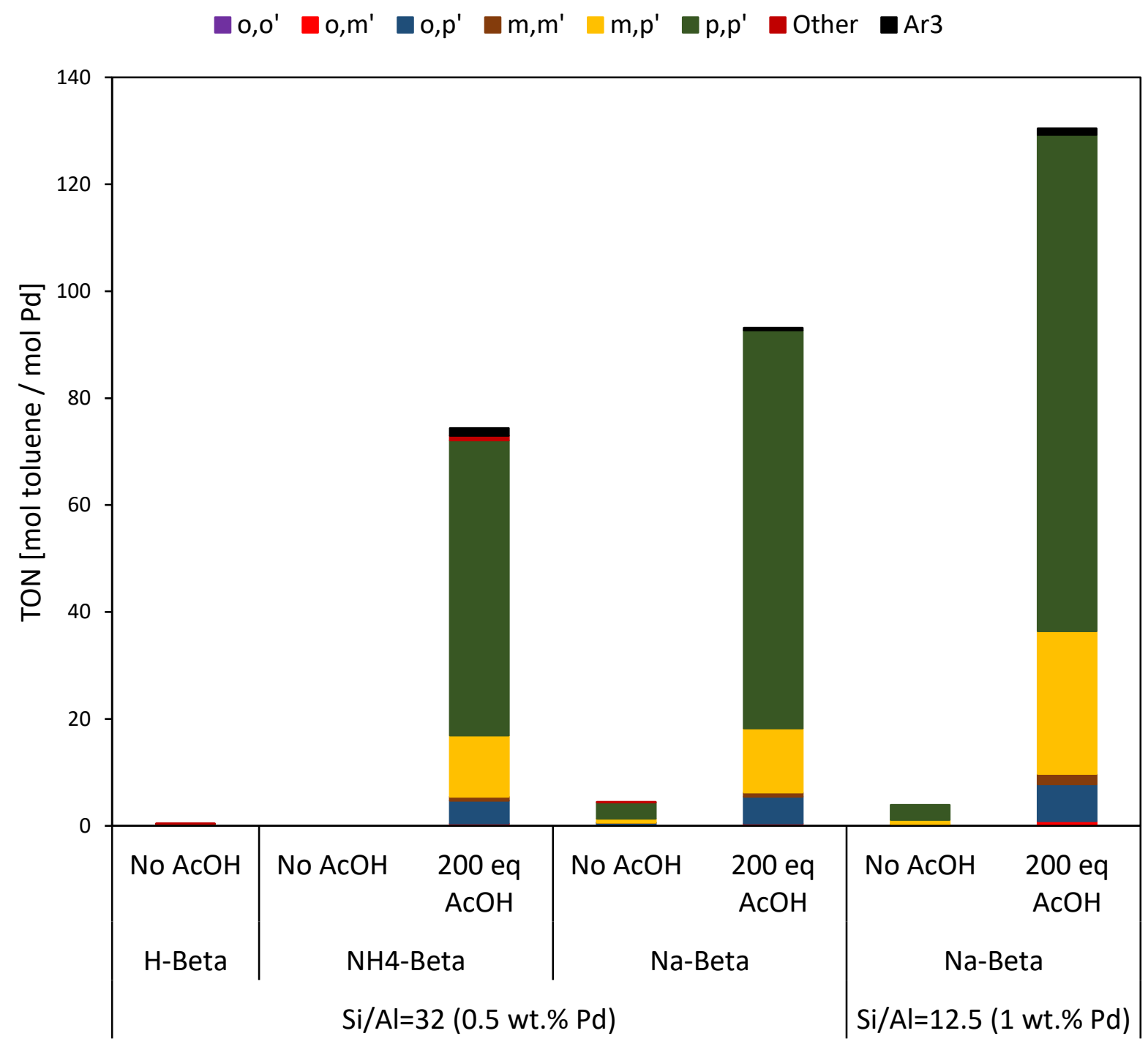

Supplementary Figure 24. Preparation of Pd-Beta with $\mathrm{Pd}\left(\mathrm{NH}_{3}\right)_{4}^{2+}$ precursors. Zeolite beta in different forms ( $\mathrm{H}, \mathrm{NH}_{4}$, and Na-form) and different $\mathrm{Si} / \mathrm{Al}$ (32 and 12.5) were ion-exchanged with an aqueous $\mathrm{Pd}\left(\mathrm{NH}_{3}\right)_{4}\left(\mathrm{NO}_{3}\right)_{2}$ solution $(1 \mathrm{~g}$ zeolite $/ 100 \mathrm{ml}$, room temperature). A full uptake of $\mathrm{Pd}$ was assumed, so as to obtain a Pd loading of $0.5 \mathrm{wt} \% \mathrm{Pd}$ and $1 \mathrm{wt} . \% \mathrm{Pd}$ for the zeolite with $\mathrm{Si} / \mathrm{Al}=32$ and 12.5 , respectively. After stirring for 24 hours, the zeolite was filtrated from solution, and washed with copious amounts of water. The obtained solids were dried overnight at $60^{\circ} \mathrm{C}$, and calcined subsequently $\left(0.5^{\circ} \mathrm{C} / \mathrm{min}\right.$ to $550^{\circ} \mathrm{C}$ for 4 hours $)$. The obtained Pd-Beta was tested as such under following reaction conditions: $15 \mu \mathrm{mol} \mathrm{Pd}$ or $319.2 \mathrm{mg}$ for $\mathrm{Pd}-\mathrm{Beta}(\mathrm{Si} / \mathrm{Al}=32)$ or $50 \mathrm{mg}$ for Pd-Beta ( $\mathrm{Si} / \mathrm{Al}=12.5$ ), $2 \mathrm{ml}$ toluene, $90^{\circ} \mathrm{C}, 16$ bar $\mathrm{O}_{2}, 16$ hours. Acetic acid (200 eq to $\mathrm{Pd}$ ) was added in the indicated reactions. 


\section{Stability, heterogeneity and re-usability of the catalyst}

Zeolite $\mathrm{H}$-Beta $(\mathrm{Si} / \mathrm{Al}=75)$ was pre-loaded in $\mathrm{CHCl}_{3}$ and reacted at different reaction temperatures $\left(90^{\circ} \mathrm{C}, 110^{\circ} \mathrm{C}, 130^{\circ} \mathrm{C} 150^{\circ} \mathrm{C}\right)$. The spent zeolite was recovered, and a PXRD diffractogram was recorded of each material (Supplementary Figure 25). No decrease in crystallinity is observed at the tested reaction temperatures. However at the reaction temperatures of $130^{\circ} \mathrm{C}$ and $150^{\circ} \mathrm{C}$, an additional reflection peak is observed around $40^{\circ}$, corresponding to the $\{111\}$ plane of $\mathrm{Pd}$ nanoparticles.

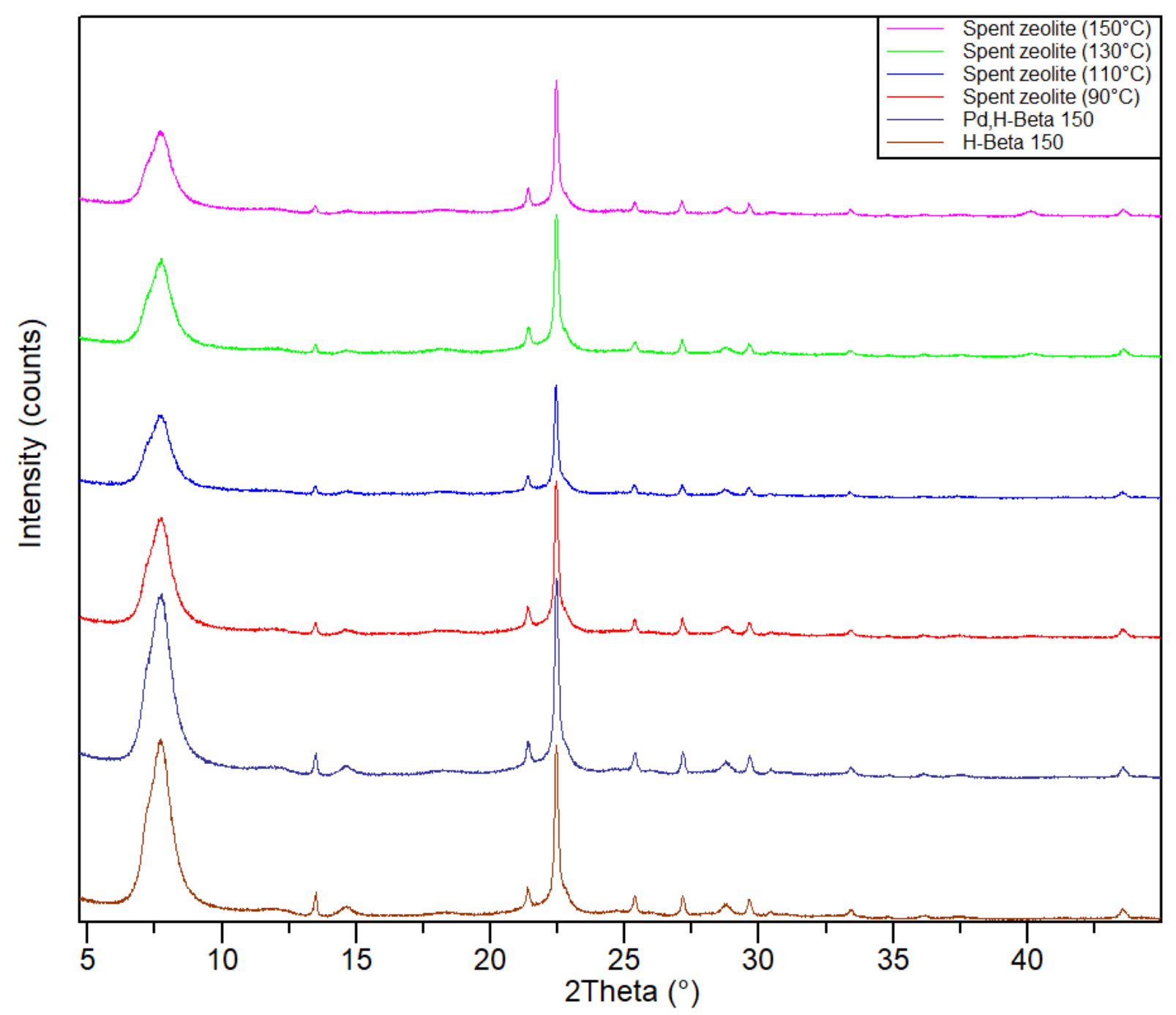

Supplementary Figure 25. PXRD patterns. Diffractograms were recorded of a fresh H-Beta ( $\mathrm{Si} / \mathrm{Al}=75)$ and of a pre-loaded Pd,H-Beta $\left(\mathrm{Si} / \mathrm{Al}=75,15 \mu \mathrm{mol} \mathrm{Pd} / 100 \mathrm{mg}\right.$, pre-loaded in $\mathrm{CHCl}_{3}$ $(10 \mathrm{ml} / \mathrm{g}))$. Pd,H-Beta was recovered after reaction at different reaction temperatures $(100 \mathrm{mg}$ $\mathrm{Pd}, \mathrm{H}-\mathrm{Beta}, 172 \mu \mathrm{l} \mathrm{AcOH}, 2 \mathrm{ml}$ toluene, 16 bar $\mathrm{O}_{2}, 16$ hours), washed with approximately $10 \mathrm{ml}$ acetone and dried in open air. This spent catalyst was then analyzed with PXRD. 
As a reference, the filtration test was performed on the homogeneous system with $\mathrm{TsOH}$ as additive (Supplementary Figure 26). The objective of this test is to verify the validity of the filtration test of Figure 4b. A loss of reactivity through decomposition of the Pd catalyst can in this way be probed. A decrease in the TON after the cold filtration procedure is indeed observed, indicative of a deactivation of the Pd catalyst during this procedure. Although no full deactivation is observed, this observation indeed implies that deactivation of the homogeneous, Pd catalyst occurs to some extent; thus the filtration test requires some adaptation in order to draw more compelling conclusions on the heterogeneity of the Pd-Beta catalyst.

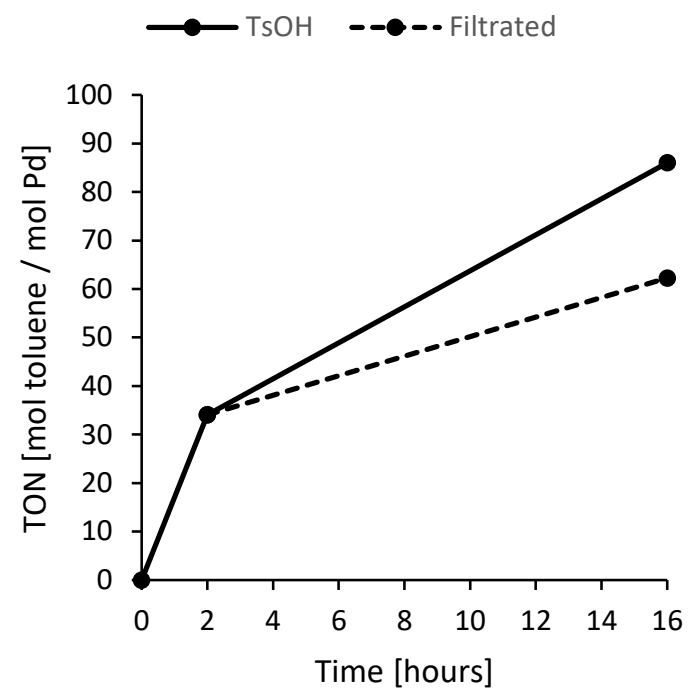

Supplementary Figure 26. Kinetic profile and filtration test for the oxidative coupling of toluene at 16 bar of $\mathrm{O}_{2}$. Reaction conditions: $15 \mu \mathrm{mol} \mathrm{Pd}(\mathrm{OAc})_{2}, 0.3 \mathrm{mmol} \mathrm{TsOH}, 1 \mathrm{ml} \mathrm{AcOH}, 2 \mathrm{ml}$ toluene, 16 bar $\mathrm{O}_{2}, 90^{\circ} \mathrm{C}$. For the filtration test, the reactor was cooled and the $\mathrm{O}_{2}$ atmosphere was released after 2 hours. Subsequently, the reaction mixture was filtered through a disposable syringe filter (CHROMAFIL PTFE, $0.20 \mu \mathrm{m}$ pore size) into a new liner. The liner was then sealed into an autoclave, flushed and pressurized with 16 bar of $\mathrm{O}_{2}$, and heated at $90^{\circ} \mathrm{C}$ for an additional 14 hours. 
We adapted the reaction conditions of the zeolite beta system to cope with atmospheric oxygen pressures through the addition of $\mathrm{Fe}(\mathrm{OTf})_{3}$ (vide supra, Supplementary Table 2, entry 12). Under these conditions, the filtration test was repeated, but as a hot filtration test without breaking the oxygen environment (Supplementary Figure 27). Furthermore, the same procedure was applied to the homogeneous conditions (Supplementary Table 1, entry 5) to further explore the validity of this test (Supplementary Figure 27). No deactivation of the homogeneous catalyst is observed under these conditions after performing the filtration $\left(\mathrm{Fe}(\mathrm{OTf})_{3} \text { Filtered vs. } \mathrm{Fe}(\mathrm{OTf})_{3}\right)_{\text {, while no }}$ additional product formation is observed after filtration of the reaction mixture containing zeolite Beta (H-Beta (Filtered) vs. H-Beta).

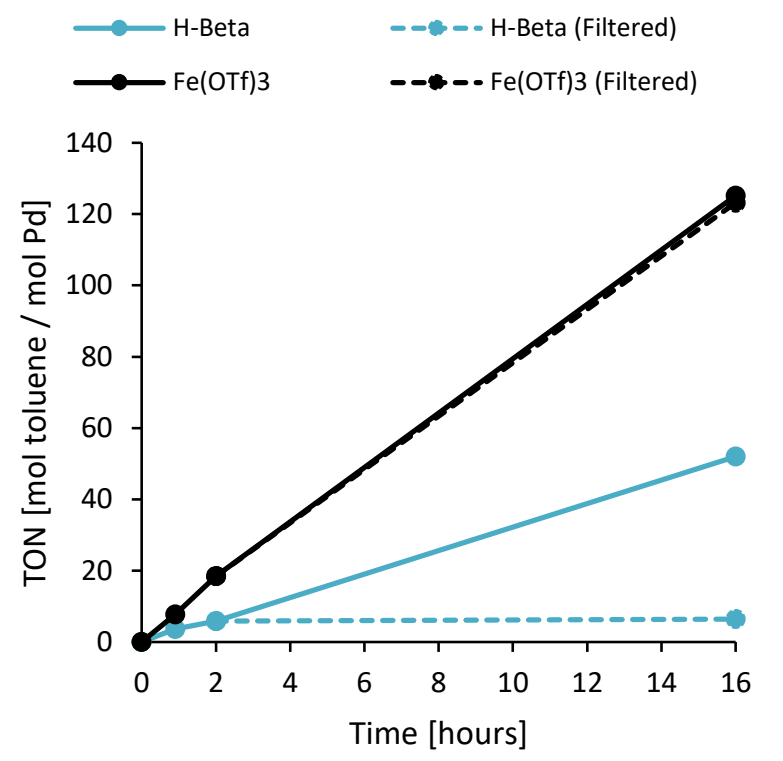

Supplementary Figure 27. Kinetic profile and filtration test for the oxidative coupling of toluene at atmospheric oxygen pressure. Reaction conditions: $15 \mu \mathrm{mol} \mathrm{Pd(OAc})_{2}, 15 \mu \mathrm{mol} \mathrm{Fe}(\mathrm{OTf})_{3}, 2 \mathrm{ml}$ toluene, $\mathrm{O}_{2}$ balloon, $90^{\circ} \mathrm{C}$. For ' $\mathrm{H}$-Beta', $200 \mathrm{mg}$ of zeolite beta $(\mathrm{Si} / \mathrm{Al}=75)$ and $172 \mu 1 \mathrm{AcOH}$ were employed, while the system of ' $\mathrm{Fe}(\mathrm{OTf}) 3$ ' used an additional $1.5 \mathrm{ml}$ of $\mathrm{AcOH}$. For the filtration test, the reaction mixture was extracted from the glass vial using a syringe with needle, and subsequently filtered through a disposable filter (CHROMAFIL PTFE, $0.20 \mu \mathrm{m}$ pore size) into a new, pre-heated glass vial connected to a balloon filled with $\mathrm{O}_{2}$. The glass vial for the H-Beta system contained $200 \mathrm{mg}$ fresh $\mathrm{H}-\mathrm{Beta}(\mathrm{Si} / \mathrm{Al}=75)$. The glass vial was allowed to react further for an additional 14 hours. 
Supplementary Table 7. Regeneration study of different zeolite catalysts in the oxidative coupling of toluene. ${ }^{[a]}$

\begin{tabular}{|c|c|c|c|c|c|}
\hline Zeolite & Regeneration & TON $1^{\text {st }}$ run & $\begin{array}{l}\text { TON } \\
\text { run }\end{array}$ & $2^{\text {nd }}$ & $\begin{array}{l}\text { TON } \\
\text { run }\end{array}$ \\
\hline H-Beta $(\mathrm{Si} / \mathrm{Al}=4.6)$ & Calcination $\left(550^{\circ} \mathrm{C}\right)^{[b]}$ & 20 & 19 & & \\
\hline H-Beta (Si/Al=12) & Calcination $\left(550^{\circ} \mathrm{C}\right)^{[\mathrm{b}]}$ & 52 & 130 & & 71 \\
\hline H-Beta $(\mathrm{Si} / \mathrm{Al}=75)$ & Calcination $\left(550^{\circ} \mathrm{C}\right)^{[b]}$ & 140 & 29 & & 28 \\
\hline H-Beta $(\mathrm{Si} / \mathrm{Al}=75)$ & Calcination $\left(720^{\circ} \mathrm{C}\right)^{[\mathrm{c}]}$ & 142 & 50 & & \\
\hline H-Beta $(\mathrm{Si} / \mathrm{Al}=75)$ & Extraction $^{[\mathrm{d}]}$ & 140 & $<1$ & & \\
\hline H-Beta $(\mathrm{Si} / \mathrm{Al}=75)$ & Vacuum treatment ${ }^{[\mathrm{e}]}$ & 140 & 2 & & \\
\hline
\end{tabular}

[a] Reaction conditions: $15 \mu \mathrm{mol} \mathrm{Pd}(\mathrm{OAc})_{2}$ and $100 \mathrm{mg} \mathrm{H}$-Beta (only in the $1^{\text {st }}$ run), $2 \mathrm{ml}$ toluene $/ 100 \mathrm{mg}$ zeolite, $\mathrm{AcOH}$ (30 eq to $\mathrm{Pd}$ ), $90^{\circ} \mathrm{C}, 16$ hours and $16 \mathrm{bar}_{2}$. [b] The zeolite was calcined in a muffle furnace as a shallow bed in static air $\left(550^{\circ} \mathrm{C}, 1^{\circ} \mathrm{C} / \mathrm{min}\right.$, retained for $\left.4 \mathrm{~h}\right)$. [c] The zeolite was calcined in a muffle furnace as a shallow bed in static air $\left(720^{\circ} \mathrm{C}, 0.5^{\circ} \mathrm{C} / \mathrm{min}\right.$, retained for 4 h). [d] The zeolite was extracted with $10 \mathrm{ml}$ of toluene, separated by centrifugation, and subsequently dried in vacuum $\left(30^{\circ} \mathrm{C}, 10 \mathrm{mbar}, 4 \mathrm{~h}\right)$ before the next run. [e] The zeolite was dried in vacuum $\left(30^{\circ} \mathrm{C}, 10 \mathrm{mbar}\right.$, overnight) before the next run. 


\section{Substrate Scope}

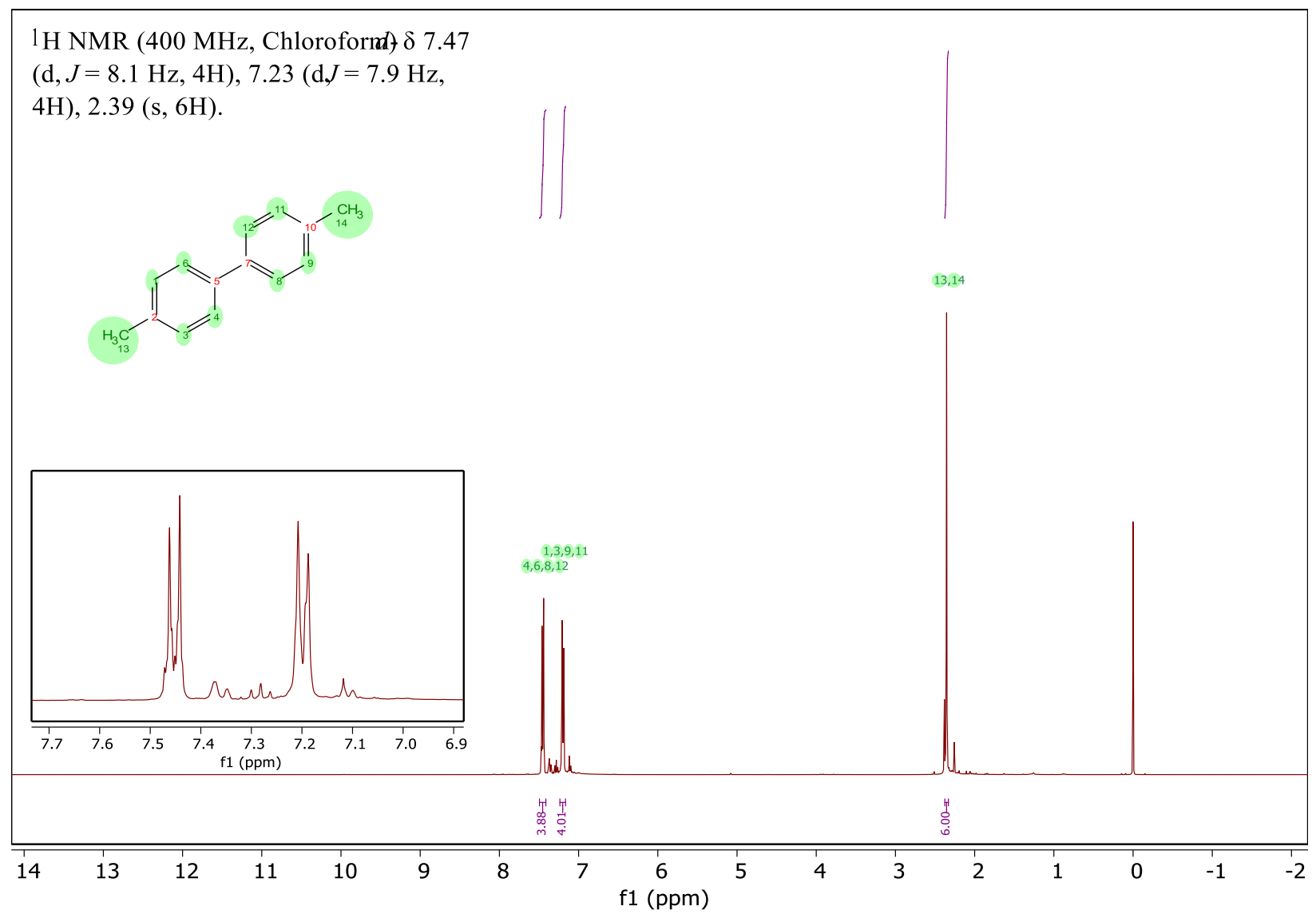

Supplementary Figure 28. ${ }^{1} \mathrm{H}$ NMR spectrum of crude product mixture of toluene. The product mixture was obtained under following reaction conditions: $15 \mu \mathrm{mol} \mathrm{Pd}(\mathrm{OAc})_{2}, 100 \mathrm{mg} \mathrm{H}-\mathrm{Beta}$ $(\mathrm{Si} / \mathrm{Al}=75), 200 \mathrm{eq} \mathrm{AcOH}, 2 \mathrm{ml}$ toluene, $90^{\circ} \mathrm{C}, 16$ bar $\mathrm{O}_{2}, 16$ hours. The mixture was extracted with $8 \mathrm{ml} \mathrm{CHCl}_{3}$, and subsequently filtered to remove the zeolite. Toluene, $\mathrm{CHCl}_{3}$ and acetic acid were removed in vacuo. The crude product mixture was dissolved in $\mathrm{CDCl}_{3}$ and analyzed by ${ }^{1} \mathrm{H}$ NMR. 


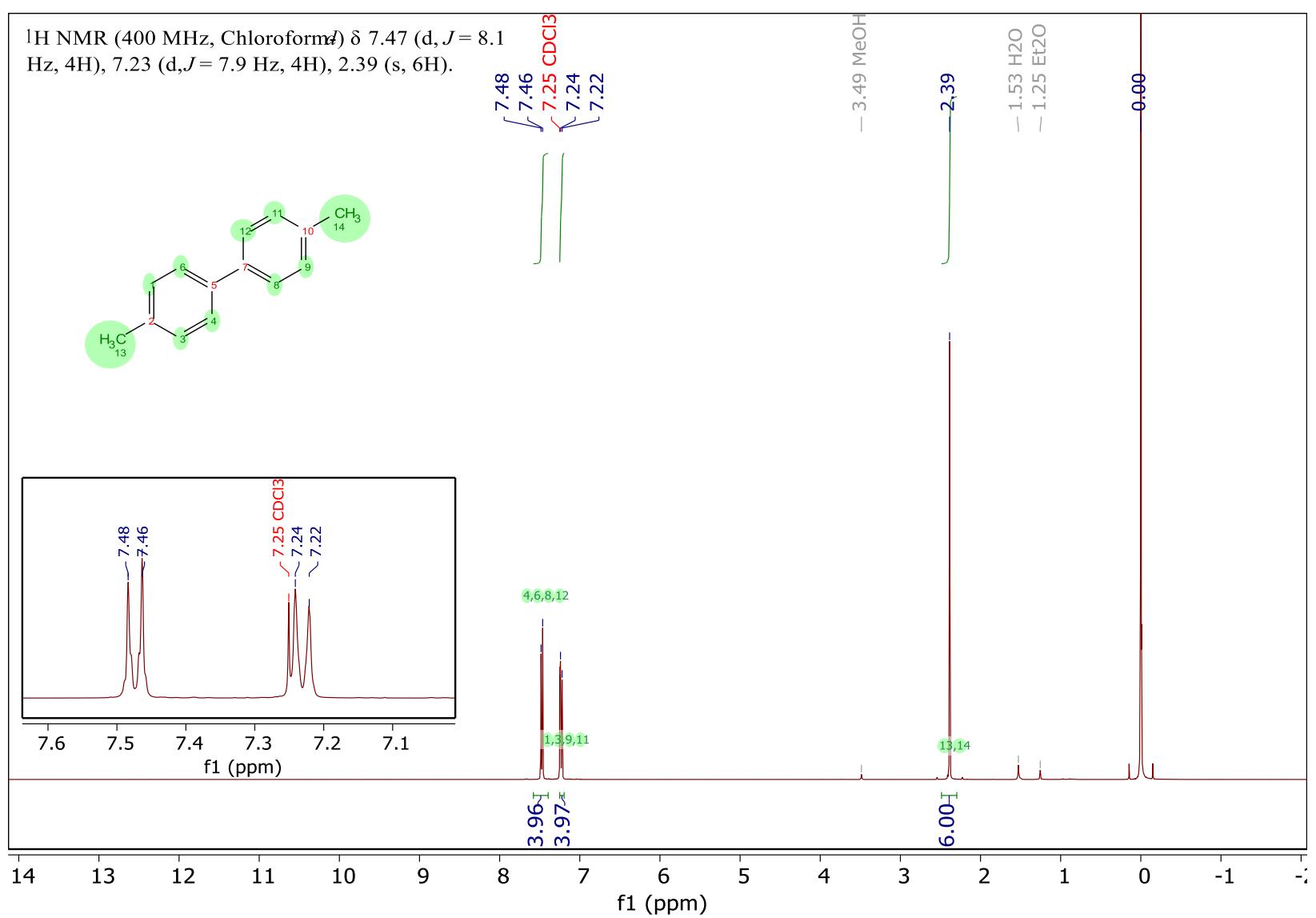

Supplementary Figure 29. ${ }^{1} \mathrm{H}$ NMR spectrum of isolated 4,4'-bitolyl. A crude product mixture was obtained according to the procedure of Supplementary Figure 28, and further purified by recrystallization from $\mathrm{MeOH}$. 
1H NMR (400 MHz, Chloroford)- $\delta 7.46(\mathrm{~d}, J=8.8 \mathrm{~Hz}, 4 \mathrm{H})$,
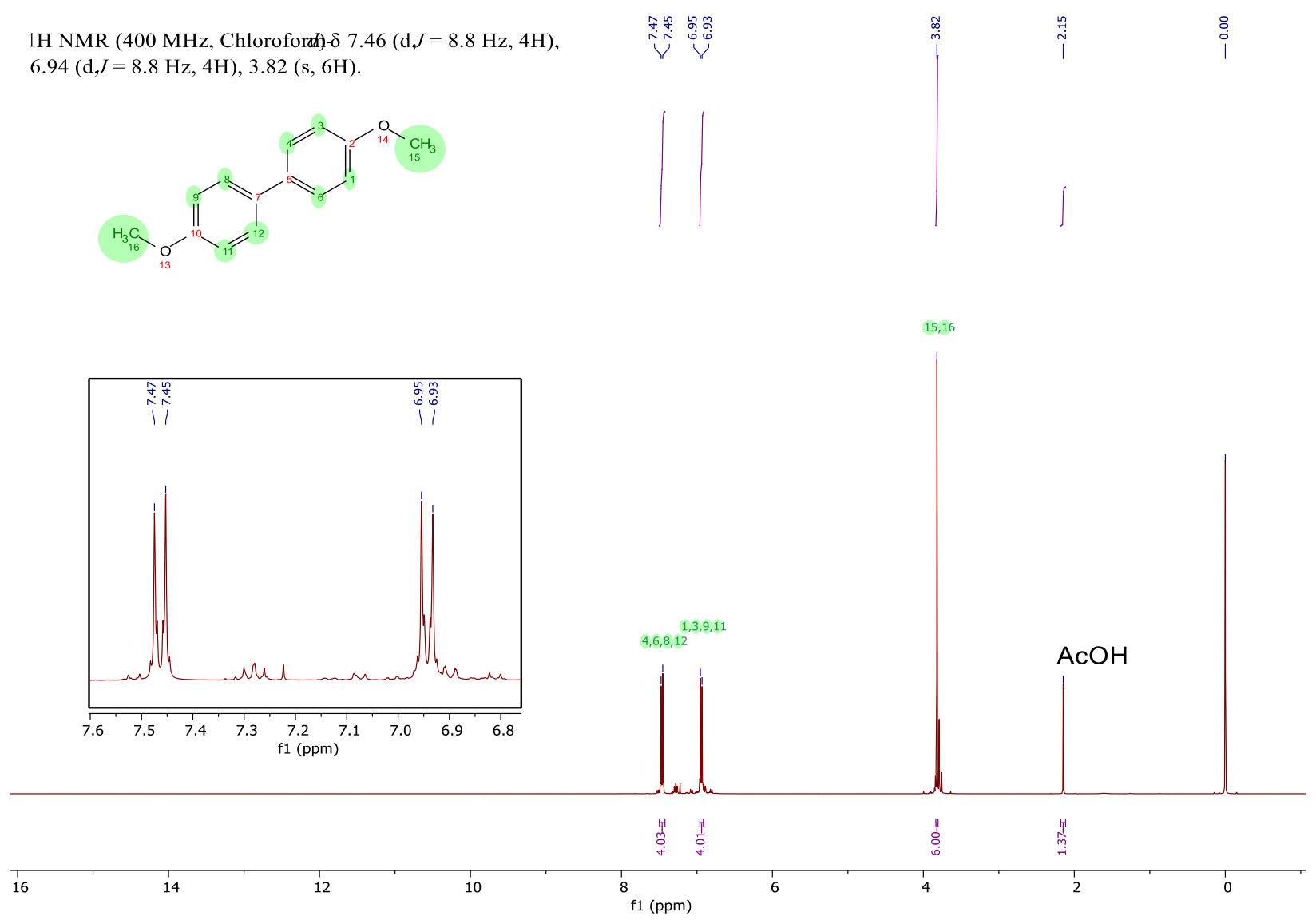

Supplementary Figure 30. ${ }^{1} \mathrm{H}$ NMR spectrum of crude product mixture of anisole. The product mixture was obtained under following reaction conditions: $15 \mu \mathrm{mol} \mathrm{Pd}(\mathrm{OAc})_{2}, 100 \mathrm{mg} \mathrm{H}$-Beta $(\mathrm{Si} / \mathrm{Al}=75), 30$ eq $\mathrm{AcOH}, 2 \mathrm{ml}$ anisole, $80^{\circ} \mathrm{C}, 16$ bar $\mathrm{O}_{2}, 16$ hours. The mixture was extracted with $8 \mathrm{ml} \mathrm{CHCl}_{3}$ to fully dissolve all reaction products, and subsequently filtered to remove the zeolite. Anisole and $\mathrm{CHCl}_{3}$ were removed in vacuo. The crude product mixture was dissolved in $\mathrm{CDCl}_{3}$ and analyzed by ${ }^{1} \mathrm{H}$ NMR. 
1H NMR (400 MHz, Chloroford $-\delta 7.48(\mathrm{~d}, J=8.8 \mathrm{~Hz}, 4 \mathrm{H})$, $6.96(\mathrm{~d}, J=8.8 \mathrm{~Hz}, 4 \mathrm{H}), 3.84(\mathrm{~s}, 6 \mathrm{H})$.

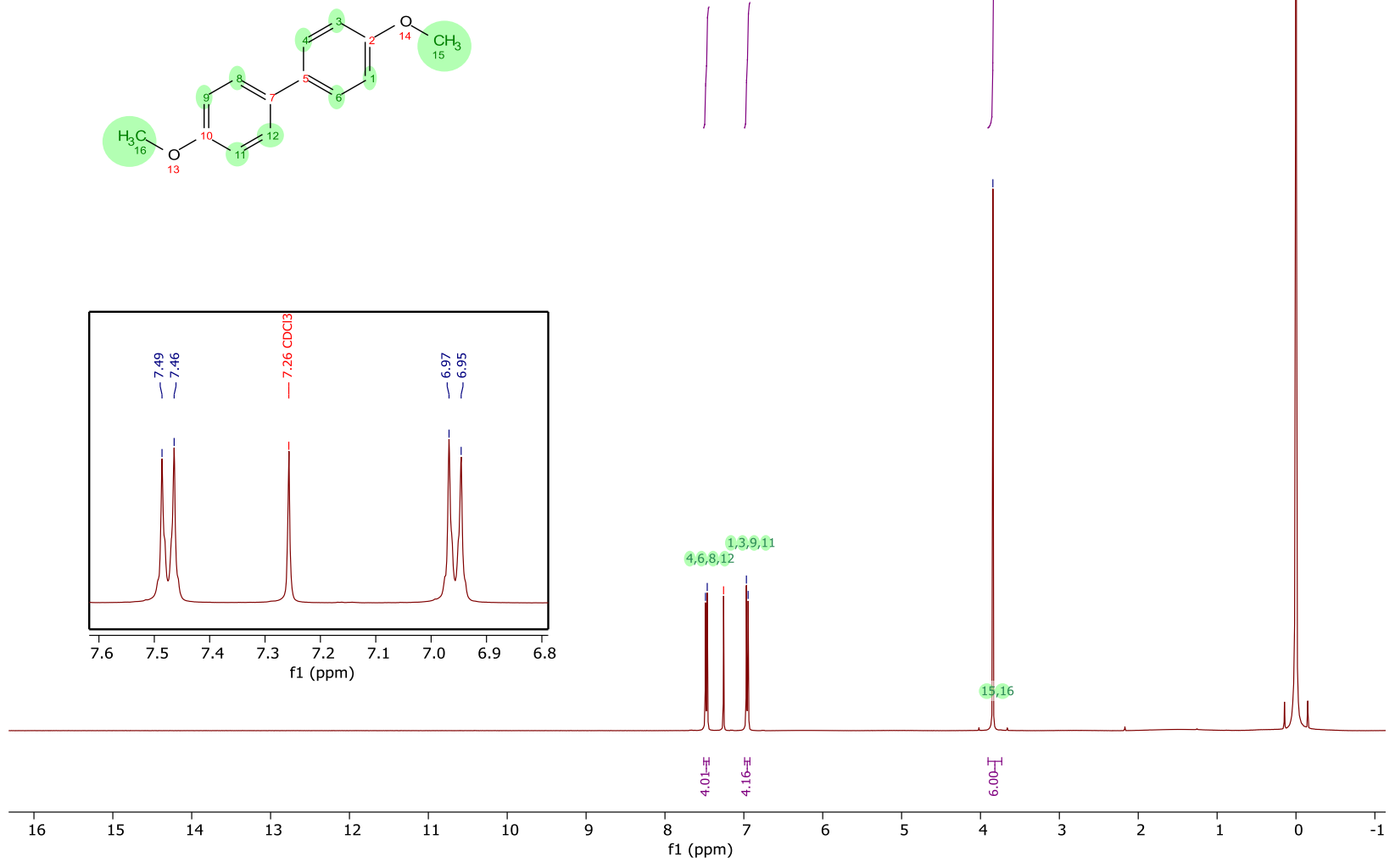

Supplementary Figure 31. ${ }^{1} \mathrm{H}$ NMR spectrum of isolated 4,4'-bianisyl. A crude product mixture was obtained according to the procedure of Supplementary Figure 30. To this end, a hot filtration was performed to remove the zeolite, followed by a cold filtration to isolate the precipitates. White, crystalline flakes of high-purity 4,4'-bianisyl $(198.0 \mathrm{mg})$ were obtained by recrystallization from diethyl ether with an isolated yield of $9.9 \%$. 


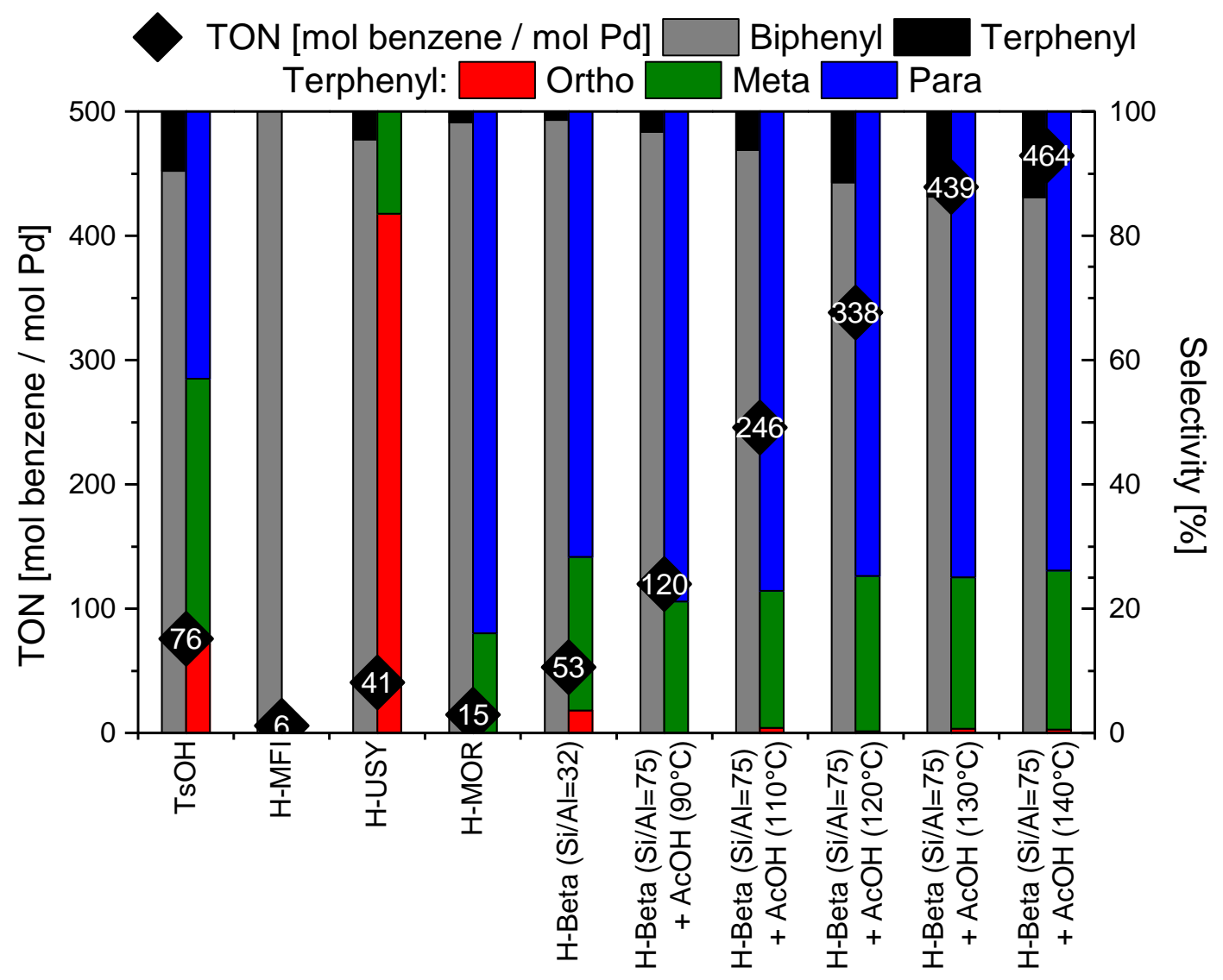

Supplementary Figure 32. Oxidative coupling of benzene. Reaction conditions: $15 \mu \mathrm{mol}$ $\mathrm{Pd}(\mathrm{OAc})_{2}, 2 \mathrm{ml}$ benzene, 16 bar $\mathrm{O}_{2}, 16$ hours, unless specified otherwise. The homogeneous reactions with $\mathrm{TsOH}$ were performed with $0.3 \mathrm{mmol}$ of $\mathrm{TsOH}$ and $1 \mathrm{ml}$ of acetic acid, while reactions with zeolites used $50 \mathrm{mg}$ of the solid without acetic acid. Zeolites with a Si/Al above 50 employed $100 \mathrm{mg}$ of the solid. In the examples ' $\mathrm{H}$-Beta $+\mathrm{AcOH}$ ', $3 \mathrm{mmol}$ of acetic acid was added. The first bar graph displays the obtained selectivites for the dimer and trimer, while the second bar graph shows the obtained selectivities for the different isomers in the trimer fraction. 


\section{Kinetic Study}

Our kinetic study focused on the apparent reaction order in Pd, since this criterion has been used by several researchers to discern between a mono- or bimetallic mechanism for the second arene activation ${ }^{53,54,55}$. Under the general reaction conditions we need to take the speciation of $\mathrm{Pd}$ in consideration. A $\mathrm{Pd}(\mathrm{OTf})(\mathrm{OAc})$ species was shown by Stahl et al. to be highly active in the oxidative coupling of $o$-xylene ${ }^{56}$. Therefore, we propose that under our optimal homogeneous conditions, a $\mathrm{Pd}(\mathrm{OTs})(\mathrm{OAc})$ species will be the active catalytic species. However, the $\mathrm{Pd}$ speciation will depend on both the acetic acid and $\mathrm{TsOH}$ concentration, and could be shifted towards an inactive $\mathrm{Pd}(\mathrm{OAc})_{2}$ or $\mathrm{Pd}(\mathrm{OTs})_{2}$ species (Supplementary Figure 33).

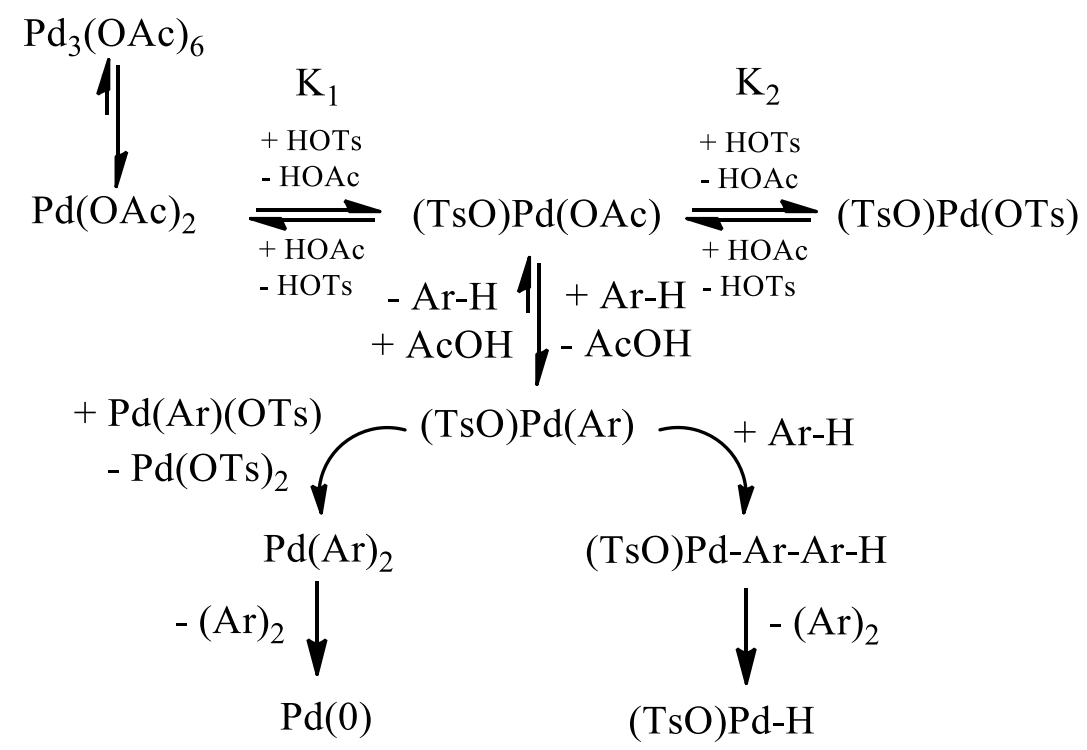

Supplementary Figure 33. Simplified reaction scheme under the homogeneous conditions. 
An equation for the fraction $F$ of active $\mathrm{Pd}(\mathrm{OTs})(\mathrm{OAc})$ was derived from Supplementary Figure 33. No mass balances for HOAc and HOTs were taken into account, due to the applied excess of both compounds compared to Pd.

$$
\frac{[P d(O T s)(O A c)]}{P d_{\text {Total }}}=F_{P d(O T s)(O A c)}=\left(\frac{H O A C}{K_{1} * H O T S}+1+\frac{K_{2} * H O T s}{H O A C}\right)^{-1}
$$

At low $\frac{K_{2} * \text { HOTs }}{\text { HOAC }}$ ratio,

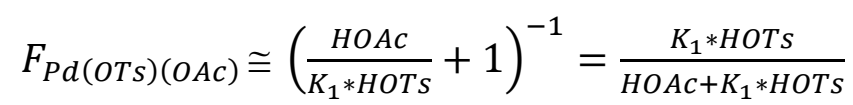

At low $\frac{H O A C}{K_{1} * \text { HOTS }}$ ratio,

$$
F_{P d(O T S)(O A C)} \cong\left(1+\frac{K_{2} * H O T S}{H O A C}\right)^{-1}=\frac{H O A C}{H O A C+K_{2} * H O T S}
$$

Initial rate measurements were initially determined as a function of the applied $\mathrm{Pd}(\mathrm{OAc})_{2}$ amount at a constant amount of acetic acid (Supplementary Figure 34A). An apparent second order in Pd at very low Pd concentrations was observed under the constant amount of acetic acid. The observed relation however fits perfectly with the derived Supplementary Equation 1 for the Pd(OAc)(OTs) speciation, multiplied with the applied Pd amount. Therefore this apparent second order at low Pd amounts could as well be attributed to a combined first order in both Pd and HOTs, according to Supplementary Equation 2. Subsequently, initial rate measurements were performed as a function of the applied Pd amount, while applying a constant ratio of acetic acid to Pd (Supplementary Figure 34B). An apparent first order in Pd is observed which declines at higher Pd concentrations of $12 \mathrm{mM}$ in which Pd black formation was visually observed. 

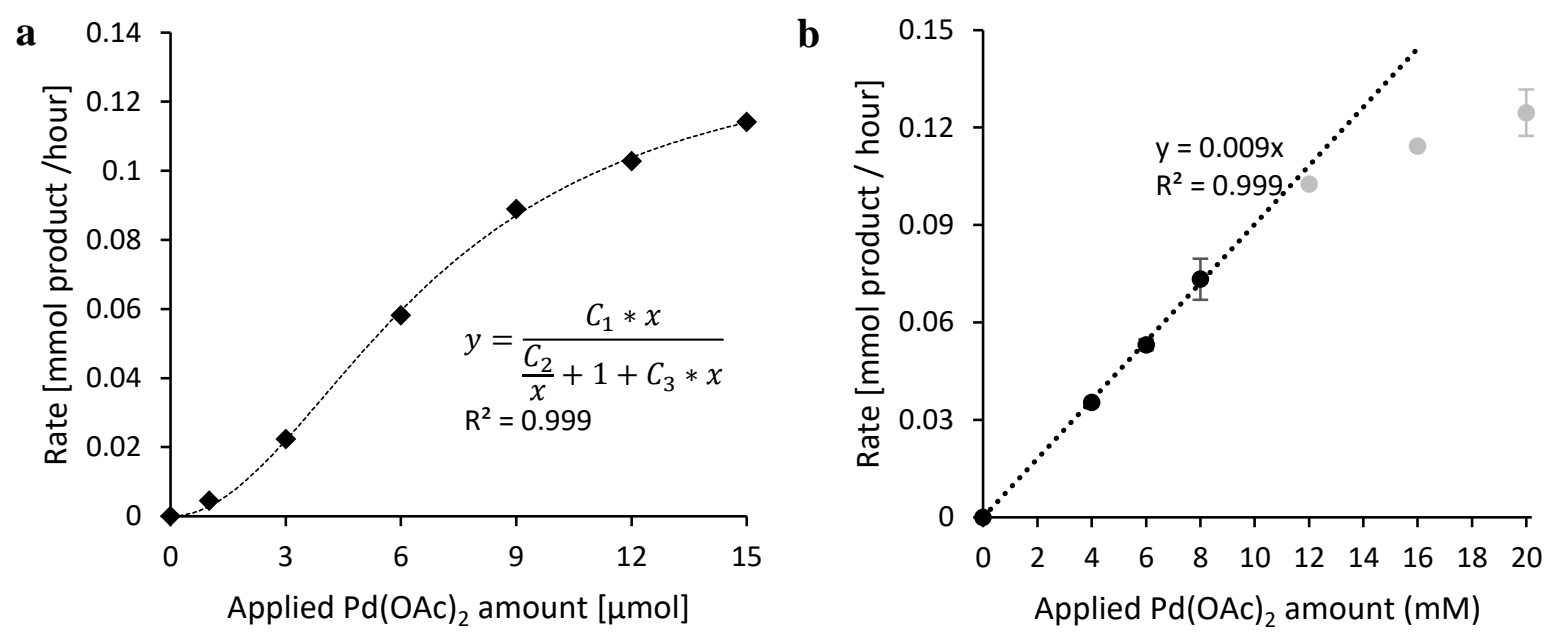

Supplementary Figure 34. Determination of the apparent reaction order in $\mathrm{Pd}$ for the homogeneous system. Reactions were carried out using different amounts of $\mathrm{Pd}(\mathrm{OAc})_{2}, \mathrm{TsOH}(20$ eq to $\mathrm{Pd}$ ), $2 \mathrm{ml}$ of toluene and 16 bar of $\mathrm{O}_{2}$ at $90^{\circ} \mathrm{C}$ for 30 to 60 minutes. a, A constant amount of acetic acid $(1 \mathrm{ml})$ was applied. $\mathbf{b}$, A constant ratio of acetic acid to $\mathrm{Pd}(1 \mathrm{ml} / 15 \mu \mathrm{mol} \mathrm{Pd})$ was applied. 
The initial rates seemingly depend strongly on the applied $\mathrm{AcOH}$ amount. The results of Supplementary Figure 34 can however be explained in two ways: either by the speciation of Pd or by assuming a positive second order in $\mathrm{Pd}$ and a negative order in acetic acid. Therefore, we varied the amount of acetic acid in the initial rate measurement at a constant amount of Pd to fully understand the role of acetic acid (Supplementary Figure 35). An amount of $3 \mu$ mol Pd was chosen to both avoid interference from Pd black formation, and since at this amount a change in regime from an apparent second order to first order in Pd was observed in Supplementary Figure 34A. Therefore, if the Pd speciation is pivotal, an increase in the initial rate up to a plateau of $1000 \mu 1$ of acetic acid is expected which decreases at higher amounts. If a negative order in acetic acid is operative, the initial rate should constantly decline over the whole range with an increase in the amount of acetic acid.

A clear plateau is observed around $1000 \mu \mathrm{l}$ of acetic acid (Supplementary Figure 35). Therefore, we have to conclude that the Pd speciation is pivotal in the apparent reaction order of $\mathrm{Pd}$. A true reaction order of 1 is ascribed to $\mathrm{Pd}$, which changes under the experimental conditions of Supplementary Figure 34A to an apparent reaction order of 2 at low Pd concentrations due to a combined first order in both $\mathrm{Pd}$ and $\mathrm{TsOH}$. We can therefore exclude a bimetallic mechanism through the parallel activation of two arenes. A monometallic mechanism is proposed, in which a single Pd consecutively activates two arenes.

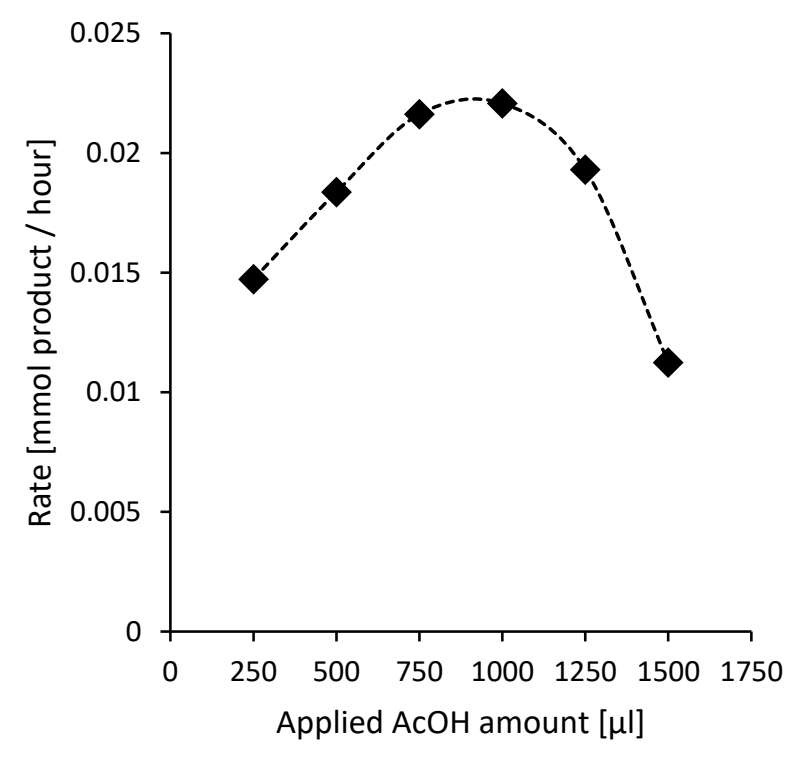

Supplementary Figure 35. Influence of acetic acid on the reaction rate for the homogeneous system at $3 \mu \mathrm{mol}$ of $\mathrm{Pd}(\mathrm{OAc})_{2}$. Reactions were carried out using different amounts of acetic acid, $3 \mu \mathrm{mol}$ of $\mathrm{Pd}(\mathrm{OAc})_{2}, 60 \mu \mathrm{mol} \mathrm{TsOH}, 2 \mathrm{ml}$ of toluene, 16 bar of $\mathrm{O}_{2}$ at $90^{\circ} \mathrm{C}$ for 30 to 60 minutes. 
Finally, we verified via similar initial rate measurements whether the observed phenomena in the homogeneous conditions are also applicable to the Pd-zeolites (Supplementary Figure 36). Pd was pre-loaded onto zeolite beta to avoid a rate-limiting dissociation of the $\mathrm{Pd}_{3}(\mathrm{OAc})_{6}$ trimer in the $\mathrm{Pd}(\mathrm{OAc})_{2}$ precursor as was proposed by Fernandez-Ibanez et al ${ }^{57}$. Similar trends were observed. However, due to the spatial separation of acidic sites in zeolites no double charge compensation of the framework can occur, and therefore also no sigmoidal trend was observed at a constant amount of acetic acid (Supplementary Figure 36A). A linear relation was observed in the initial rate measurement at a constant ratio of acetic acid to Pd-Beta (Supplementary Figure 36B), however this regression had an intercept at the $\mathrm{X}$-axis, indicative of an apparent second reaction order at lower Pd-Beta amounts. Indeed, an apparent reaction order of 2 was observed at lower PdBeta amounts (Supplementary Figure 36C), but attributed to an increased specificity for the adsorption of acetic acid at such low zeolite amounts (Supplementary Figure 37). Therefore, the local environment around Pd would feel a relatively higher acetic acid concentration in this region. Finally, we varied the applied amount of $\mathrm{Pd}(\mathrm{OAc})_{2}$ using a constant ratio of acetic acid:Pd, while using a constant amount of zeolite beta (Supplementary Figure 36D). In this experiment, no deviations arising from adsorption phenomena are expected. A linear relation is observed, indicative of a first reaction order in $\mathrm{Pd}$.

Therefore, we have to conclude that also a first reaction order in Pd is operative in the case of PdBeta. Therefore, also a monometallic mechanism is expected, which aligns well with both the heterogeneity of the catalyst and the beneficial effect of an increased dilution of $\mathrm{Pd}$ in the framework. A bimetallic mechanism would require Pd species that are mobile within the zeolite, and would benefit from increased loading of the Pd on the zeolite. 

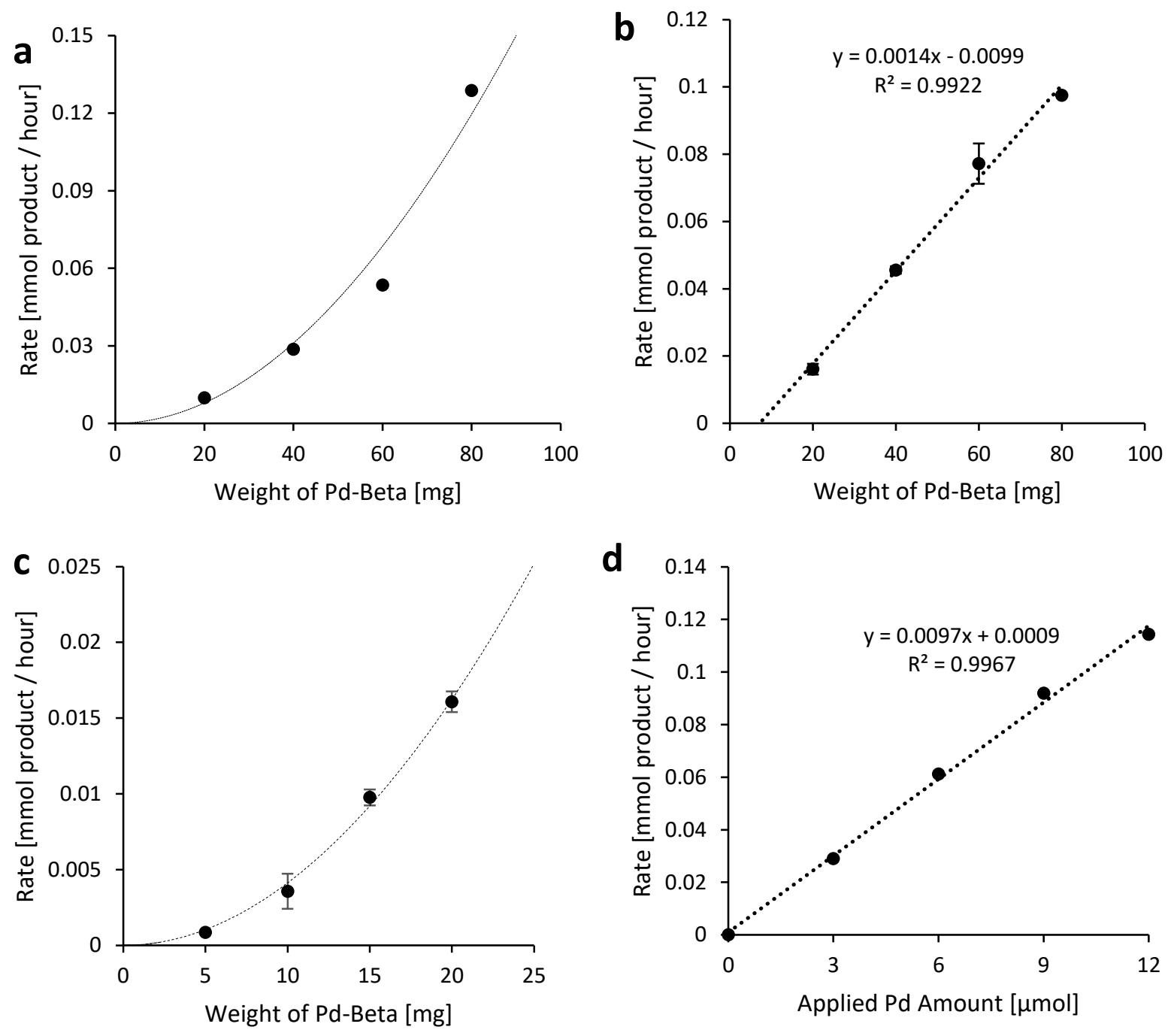

Supplementary Figure 36. Determination of the apparent reaction order in Pd in zeolite Betacatalyzed reactions. a,b,c, Reactions were carried out using different amounts of Pd,H-Beta 150 ( $\mathrm{Si} / \mathrm{Al}=75,15 \mu \mathrm{mol} / 100 \mathrm{mg}$, pre-loaded in $\mathrm{CHCl}_{3}$ ), $2 \mathrm{ml}$ of toluene, 16 bar of $\mathrm{O}_{2}$ at $90^{\circ} \mathrm{C}$ for 30 to 60 minutes. a, Different amounts of Pd,H-Beta and a constant amount of acetic acid (172 $\mu \mathrm{l})$ were applied. b, Different amounts of Pd,H-Beta and a constant ratio of acetic acid to Pd (172 $\mu 1 / 15$ $\mu$ mol Pd) were applied. c, Conditions of Supplementary Figure 36B at lower amounts. d, A constant amount of $\mathrm{H}$-Beta $(100 \mathrm{mg}, \mathrm{Si} / \mathrm{Al}=75)$ was employed, while the applied amount of $\mathrm{Pd}(\mathrm{OAc})_{2}$ was varied $\left(172 \mu \mathrm{AcOH} / 15 \mu \mathrm{mol} \mathrm{Pd}, 2 \mathrm{ml}\right.$ of toluene, 16 bar of $\mathrm{O}_{2}$ at $90^{\circ} \mathrm{C}$ for 30 to 60 minutes. 


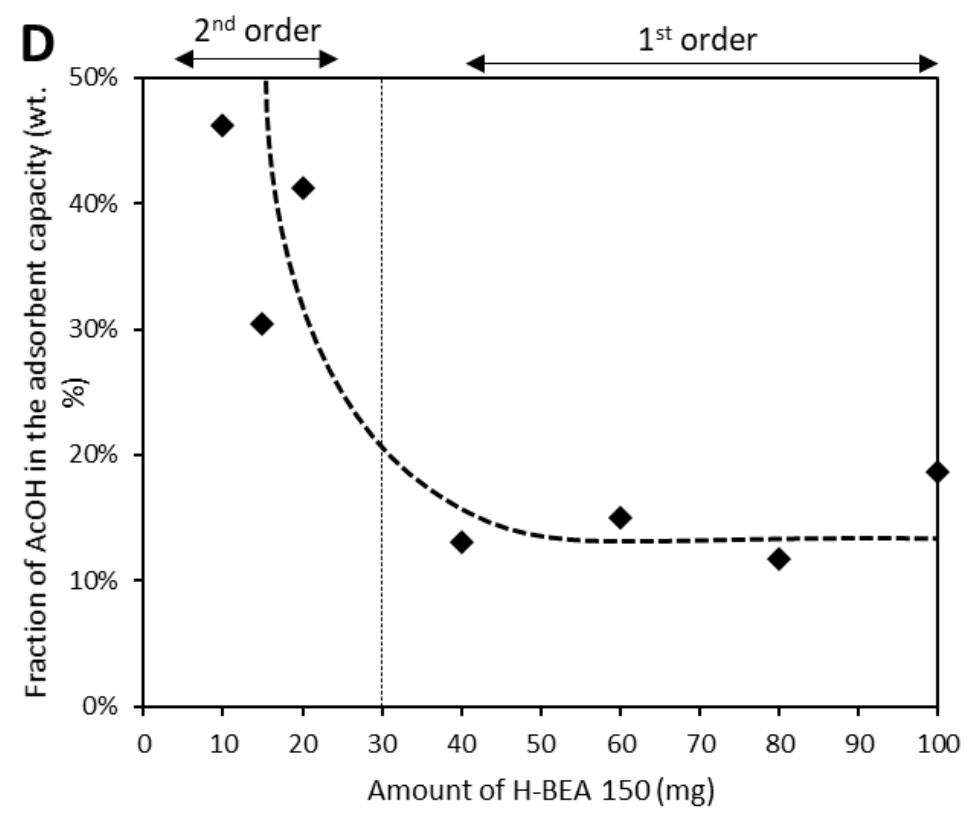

Supplementary Figure 37. Liquid phase adsorption of acetic acid in $\mathrm{H}$-Beta ( $\mathrm{Si} / \mathrm{Al}=75)$. Different amounts of $\mathrm{H}$-Beta $(\mathrm{Si} / \mathrm{Al}=75)$ were contacted with $172 \mu \mathrm{AcOH} / 100 \mathrm{mg}$ zeolite in $2 \mathrm{ml}$ toluene at $90^{\circ} \mathrm{C}$. After 24 hours, $250 \mu \mathrm{l}$ of the liquid phase was taken for analysis. The sample was silylated with BSTFA (1.5 eq to initial $\mathrm{AcOH}, 90^{\circ} \mathrm{C}, 1 \mathrm{~h}$ ), prior to analysis with GC-FID. The missing fraction of acetic acid was attributed to the zeolitic phase, and for clarity expressed as a fraction of the adsorbent capacity, which was assumed to be $20 \mathrm{wt} . \%$ of the initial zeolite weight. 
The apparent activation energy of the oxidative coupling of toluene with zeolite $\mathrm{Beta}(\mathrm{Si} / \mathrm{Al}=75)$ and additional acetic acid was determined experimentally by construction of the Arrhenius plot with obtained initial rates at various temperatures (Supplementary Figure 38). A convex Arrhenius plot was obtained in which the apparent activation energy changes from $86 \mathrm{~kJ} / \mathrm{mol}$ in the $70^{\circ} \mathrm{C}$ to $90^{\circ} \mathrm{C}$ region to $29 \mathrm{~kJ} / \mathrm{mol}$ in the $90^{\circ} \mathrm{C}$ to $150^{\circ} \mathrm{C}$ region. The data prove that in the $70-90^{\circ} \mathrm{C}$ temperature interval, the reaction is under chemical, rather than diffusional control.

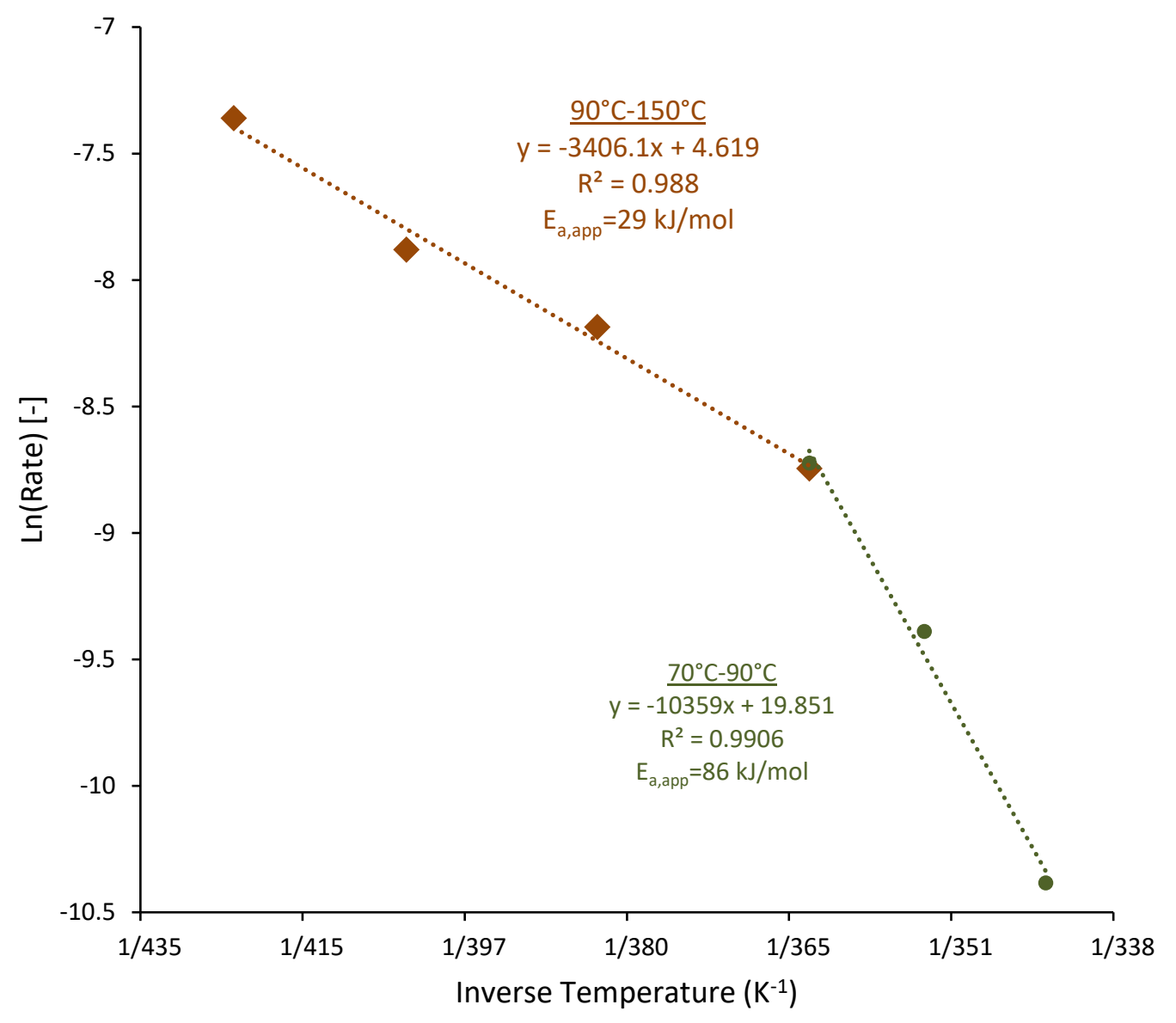

Supplementary Figure 38. Apparent activation energy for the oxidative coupling of toluene with zeolite beta $(\mathrm{Si} / \mathrm{Al}=75)$ and additional acetic acid. Reaction conditions: $100 \mathrm{mg}$ of Pd,H-Beta $\left(\mathrm{Si} / \mathrm{Al}=75\right.$, pre-loaded with $15 \mu \mathrm{mol} \mathrm{Pd}(\mathrm{OAc})_{2} / 100 \mathrm{mg}$ in $\left.\mathrm{CHCl}_{3}\right), 172 \mu \mathrm{AcOH}, 2 \mathrm{ml}$ toluene, 16 bar $\mathrm{O}_{2}, 30-60$ minutes. 


\section{Computational Study}

\section{H-Beta unit cell}

Each unit cell of zeolite Beta consists of one isolated Brønsted acid site (BAS), for which one Al substitution is required. In this case the $\mathrm{Si} / \mathrm{Al}$ ratio is 63 . The active site was positioned at the intersection of straight channels (on the T4 crystallographic position) as this location offers maximal available space in the BEA topology and results in minimal restrictions, even when bulky intermediates are involved.

In the static calculations the unit cell parameters (Supplementary Table 8) were kept constant and derived from the Birch Murnaghan equation of state ${ }^{58,59}$ fit with an optimal unit cell volume of $4253.88 \AA^{3}$.

Supplementary Table 8. Unit cell parameters used during the VASP simulations and used as reference cell in the $\mathrm{CP} 2 \mathrm{~K}$ simulations.

\begin{tabular}{|l|l|l|l|l|l|}
\hline $\mathrm{a}[\AA]$ & $\mathrm{b}[\AA]$ & $\mathrm{c}[\AA]$ & $\alpha\left[^{\circ}\right]$ & $\beta\left[^{\circ}\right]$ & $\gamma\left[^{\circ}\right]$ \\
\hline 12.64548 & 12.64447 & 26.60418 & 90.0171 & 89.9062 & 90.0447 \\
\hline
\end{tabular}

These unit cell parameters were used to optimize all configurations that are considered in the static calculations. The same unit cell parameters are also used for the reference unit cell in the MD simulations.

The proposed reaction pathway is described from step 0 to step 4, as shown in Figure 6.

Step 0: $\mathrm{Pd}(\mathrm{OAc})_{2}$ docking in H-Beta

\section{Structural analysis of $\mathrm{Pd}(\mathrm{OAc})_{2}$ in $\mathrm{H}$-Beta using $\mathrm{MD}$}

The initial interaction and possible docking of $\operatorname{Pd}(\mathrm{II})$ acetate with the BAS and the zeolite framework were investigated with a $60 \mathrm{ps}$ MD simulation. In the reaction mixture a toluene molecule was also present, to elucidate if any interaction between the free $\operatorname{Pd}(\mathrm{II})$ acetate and the reacting species is present. On Supplementary Figure 39 the snapshots of the first and last configurations are shown. When Pd(II) acetate is adsorbed in the H-Beta framework, it coordinates to the BAS with one oxygen atom, breaking the chelated coordination of acetate to Pd. Further, acetic acid might be formed and diffuse in the pores while Pd makes a square planar configuration with acetate as one ligand and the zeolite taking the role of the other ligand. In the simulation, we do not observe any interaction between toluene and the metal complex. The interaction of the BAS and the four oxygen atoms of Pd(II) acetate is shown in Supplementary Figure 39. 


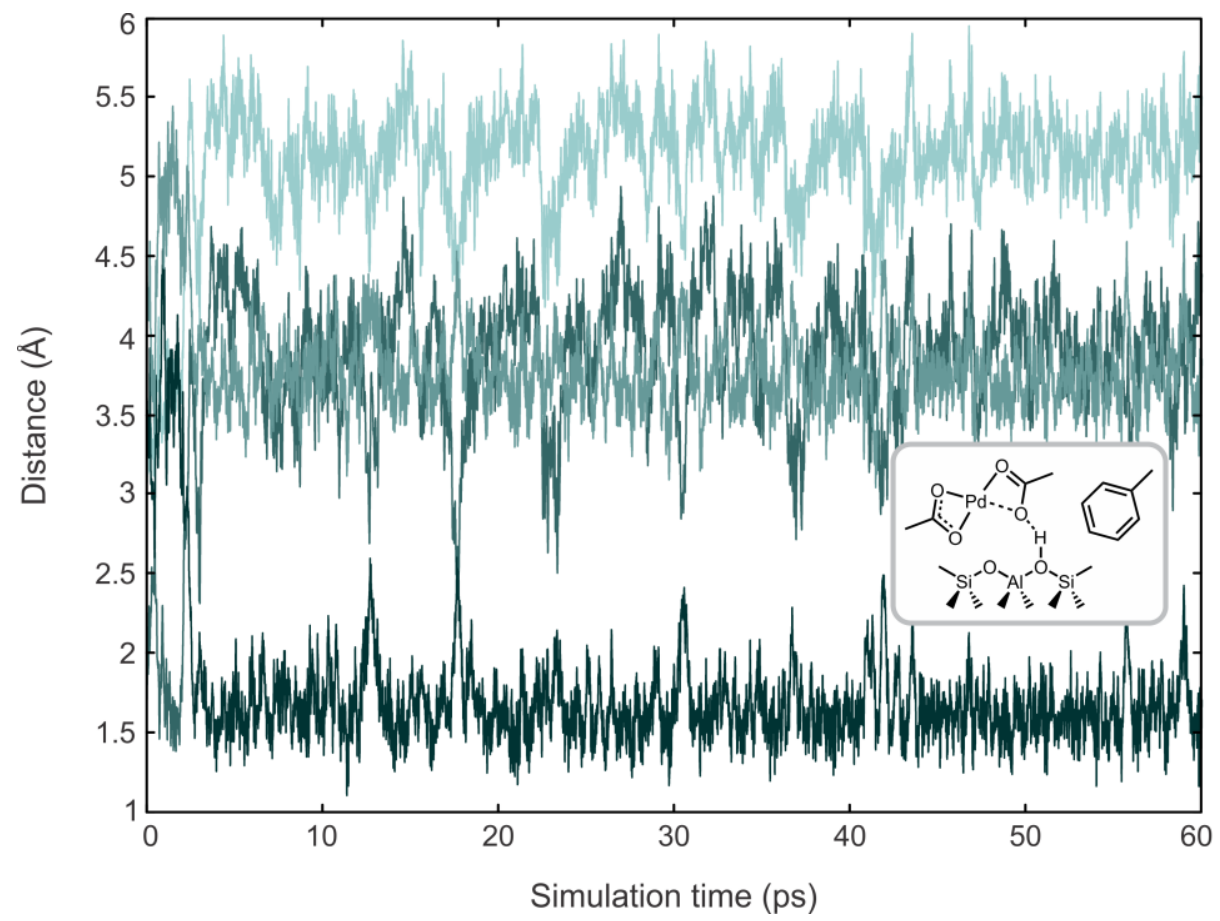

initial configuration

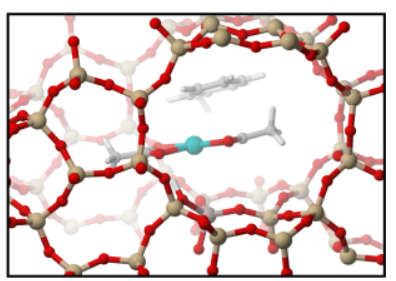

last configuration

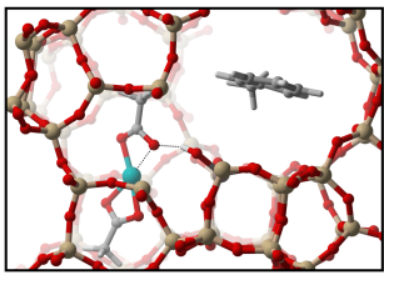

Supplementary Figure 39. Distances of the four $\mathrm{Pd}(\mathrm{OAc})_{2}$ oxygen atoms and the H-Beta BAS plotted as a function of the simulation time in the MD simulation (60 ps at $363 \mathrm{~K})$. The initial and last configurations are also shown. 
Step 1: Concerted metalation deprotonation (CMD)

\section{Static calculations}

Transition state, reactants and products for the CMD were fully optimized. The activation of all the five reactive toluene carbons was investigated. The optimized structures are shown in Supplementary Figure 41 (see also Supplementary Table 9). All the contributions to the final free energy values reported in the main text are listed in Supplementary Table 10 (enthalpic and entropic contributions to the free energy at a PBE-D3 LOT) and Supplementary Table 11 (singlepoint 0K B3LYP-D3 corrections). The final free energies for each of these processes are graphically summarized below in Supplementary Figure 40. As it can be seen, the energies of the two meta and ortho carbons are very similar (as expected due to the relatively symmetric nature of the zeolite channel), for this reason only the most stable transition state is reported in the main manuscript (Fig. 6b).

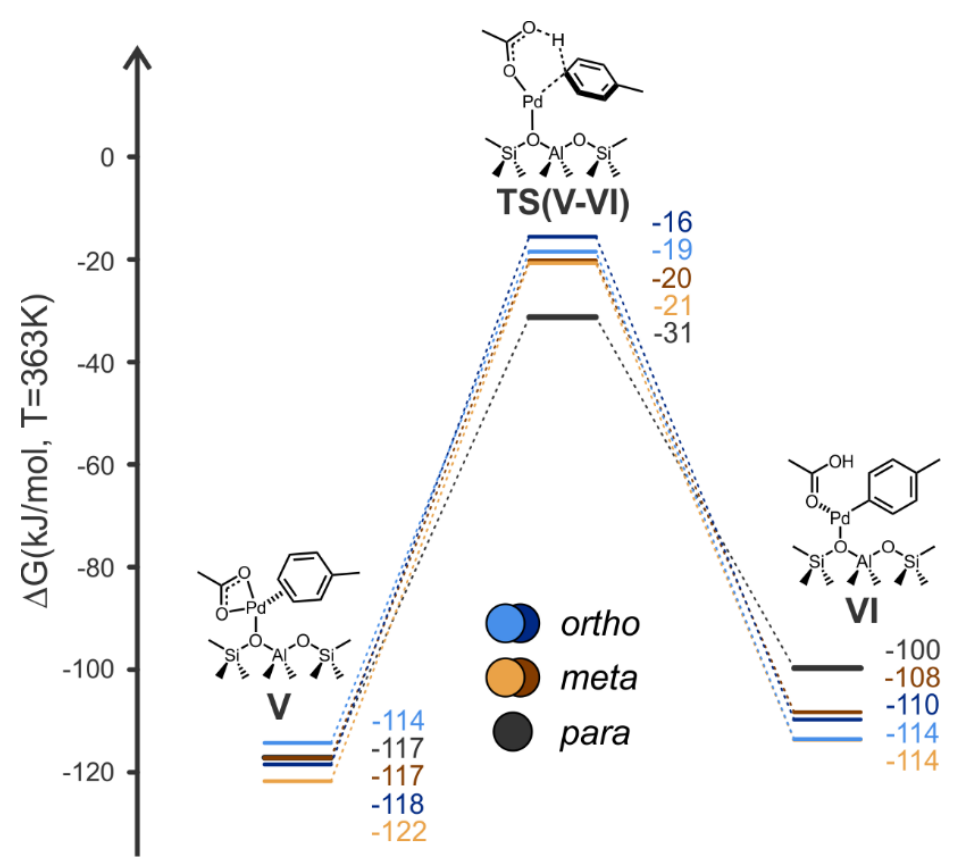

Supplementary Figure 40. Details of the CMD step on the free energy profile, reporting all the reactants, transition states and products that were analyzed (B3LYP-D3//PBE-D3 LOT). 

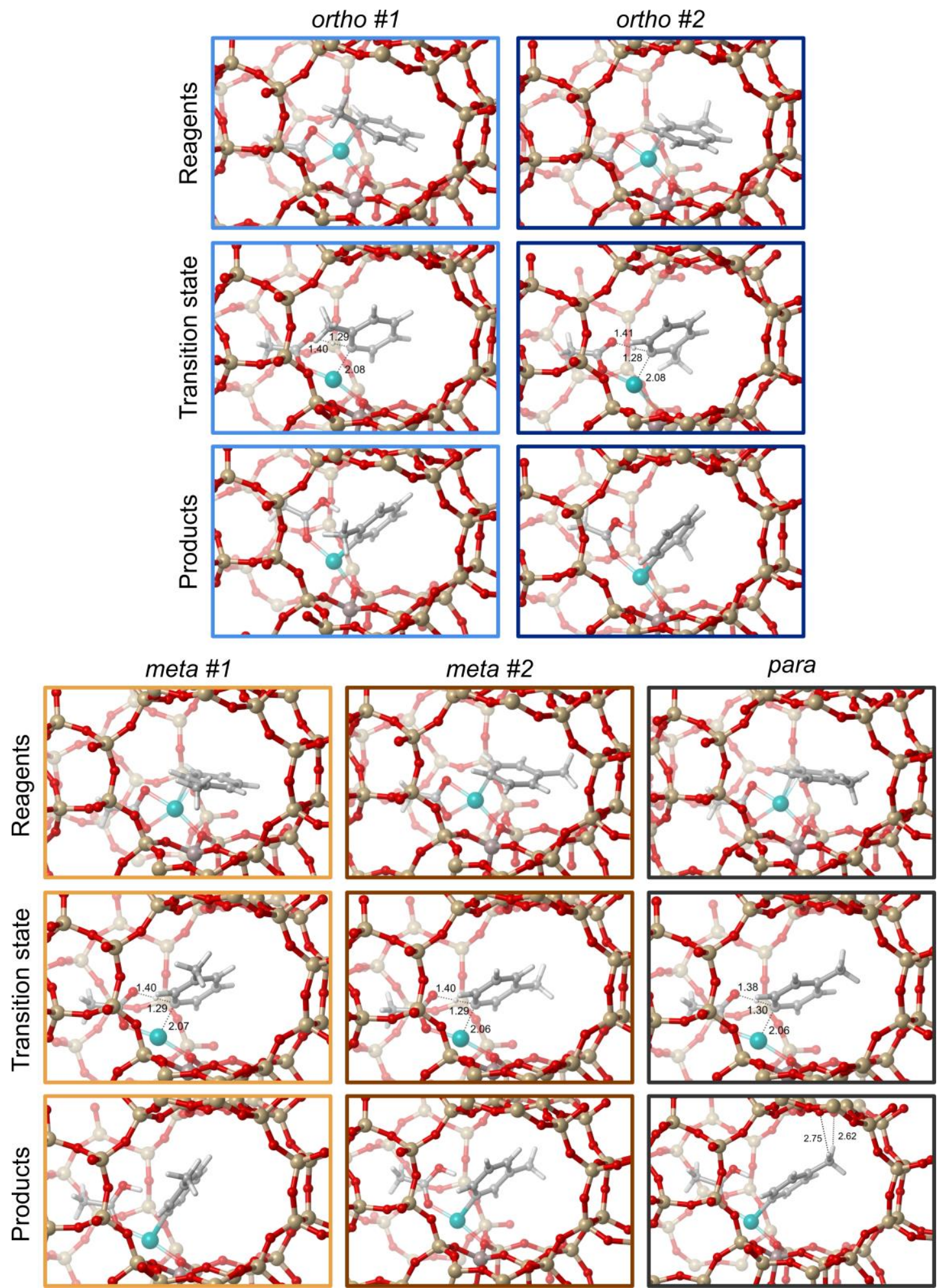

Supplementary Figure 41. Optimized structures for reactants, transition states and products in the concerted metalation-deprotonation reaction at the two ortho, two meta and para positions of the aromatic ring. The numbers in the figures refer to interesting distances, in $\AA$. 
Supplementary Table 9. Pd-O and Pd-C distances in the reactants of the CMD. ${ }^{\mathrm{a}}$

\begin{tabular}{|l|l|l|l|}
\hline & R para & R meta & R ortho \\
\hline Pd-O (framework) $[\AA]$ & 2.14 & 2.14 & 2.14 \\
\hline Pd-C (adsorbed toluene) $[\AA]$ & $2.30(\mathrm{~m}) ; 2.23(\mathrm{p})$ & $2.30(\mathrm{~m}) ; 2.22(\mathrm{p})$ & $2.34(\mathrm{i}) ; 2.24(\mathrm{~m})$ \\
\hline
\end{tabular}

${ }^{\mathrm{a}}$ The letter in brackets for the $\mathrm{Pd}-\mathrm{C}$ distances refers to the considered carbon atom (i=ipso, $\mathrm{m}=\mathrm{meta}$ and $\mathrm{p}=\mathrm{para}$ ).

Supplementary Table 10. Free energy $(\Delta \mathrm{G})$, enthalpy $(\Delta \mathrm{H})$ and entropy $(-\mathrm{T} \Delta \mathrm{S}) \mathrm{in} \mathrm{kJ} / \mathrm{mol}$ for the intermediates and transition states of Step 0 and Step 1 at $363 \mathrm{~K}$ and a PBE level of theory.

\begin{tabular}{|c|c|c|c|c|c|c|c|}
\hline & & \multicolumn{2}{|c|}{ Step 0} & \multicolumn{4}{|c|}{ Step 1} \\
\hline & & II & III & IV & V & $\mathrm{TS}(\mathrm{V}-\mathrm{VI})$ & VI \\
\hline \multirow{3}{*}{ para } & $\Delta \mathrm{G}$ & -62 & -51 & -81 & -98 & -21 & -66 \\
\hline & $\Delta \mathrm{H}$ & -140 & -122 & -149 & -165 & -94 & -136 \\
\hline & $-\mathrm{T} \Delta \mathrm{S}$ & 78 & 71 & 68 & 67 & 73 & 80 \\
\hline \multirow{3}{*}{ meta \#1 } & $\Delta \mathrm{G}$ & & & & -99 & -7 & -79 \\
\hline & $\Delta \mathrm{H}$ & & & & -168 & -82 & -144 \\
\hline & $-\mathrm{T} \Delta \mathrm{S}$ & & & & 69 & 75 & 65 \\
\hline \multirow{3}{*}{ meta \#2 } & $\Delta \mathrm{G}$ & & & & -97 & -12 & -76 \\
\hline & $\Delta \mathrm{H}$ & & & & -165 & -83 & -141 \\
\hline & $-\mathrm{T} \Delta \mathrm{S}$ & & & & 68 & 71 & 65 \\
\hline \multirow{3}{*}{ ortho \#1 } & $\Delta \mathrm{G}$ & & & & -90 & -4 & -79 \\
\hline & $\Delta \mathrm{H}$ & & & & -161 & -79 & -147 \\
\hline & $-\mathrm{T} \Delta \mathrm{S}$ & & & & 71 & 75 & 68 \\
\hline \multirow{3}{*}{ ortho \#2 } & $\Delta \mathrm{G}$ & & & & -97 & -3 & -79 \\
\hline & $\Delta \mathrm{H}$ & & & & -165 & -79 & -149 \\
\hline & $-\mathrm{T} \Delta \mathrm{S}$ & & & & 68 & 76 & 70 \\
\hline
\end{tabular}

Supplementary Table 11. 0K correction to the adsorption energy $(\mathrm{kJ} / \mathrm{mol})$ from a B3LYP-D3 single point on the PBE-D3 optimized structures. The values reported in Figure $6 \mathrm{~b}$ are the sum of the free energies listed in Supplementary Table 10 and the following corrections.

\begin{tabular}{|l|l|l|l|l|l|l|l|}
\hline & \multicolumn{3}{|c|}{ Step 0 } & Step 1 \\
\hline & & II & III & IV & V & TS(V-VI) & VI \\
\hline para & $\mathrm{E}$ & -14 & -29 & -36 & -19 & -11 & -34 \\
\hline meta \#1 & $\Delta \mathrm{E}$ & & & & -23 & -14 & -35 \\
\hline meta \#2 & $\Delta \mathrm{E}$ & & & & -20 & -8 & -33 \\
\hline ortho \#1 & $\mathrm{DE}$ & & & & -24 & -15 & -35 \\
\hline ortho \#2 & $\Delta \mathrm{E}$ & & & & -22 & -13 & -31 \\
\hline
\end{tabular}




\section{Molecular dynamic simulation}

To explore the dynamic behavior of the CMD reagents, two MD simulations were performed starting from the optimized geometry of the para activation for $100 \mathrm{ps}$. In the first, we simply used the optimized structure as such to allow an easy comparison with the conditions of the static calculations, while in the second we tried to be closer to the experimental conditions considering the co-adsorption of other molecules. As the reaction is performed in liquid toluene with acetic acid, we opted to add 4 more toluene molecules and an acetic acid molecule. This brings the total number of toluene molecules to 5, a value that has already been reported in the literature for Betatype frameworks ${ }^{60}$ and can also been deduced from some approximated calculations. The IZA database of zeolite structures reports indeed an accessible volume of $857 \AA^{3}$ for the BEA topology. Considering a density of $800.7 \mathrm{~kg} / \mathrm{m}^{3}$ for toluene at $363 \mathrm{~K}$ the volume per molecule results to be equal to $191 \AA^{3}$. This implies 4.5 molecules per unit cell. Despite already having the Pd(OAc) moiety in the unit cell, we still decided to insert a total of 5 toluene molecules as we noticed that the unit cell offered more than enough space to accommodate them (Supplementary Figure 42).

In both simulations we observed a largely predominant interaction between Pd and the para carbon of the toluene molecule adsorbed on the metal. In the low loading simulation, the toluene can occasionally rotate to expose other carbon atoms to the $\mathrm{Pd}$ while in the high loading simulation the constraints imposed by the surrounding toluene molecules restrict the movement of the interacting toluene and only interaction with the para carbon is observed (Supplementary Figure 43-44).
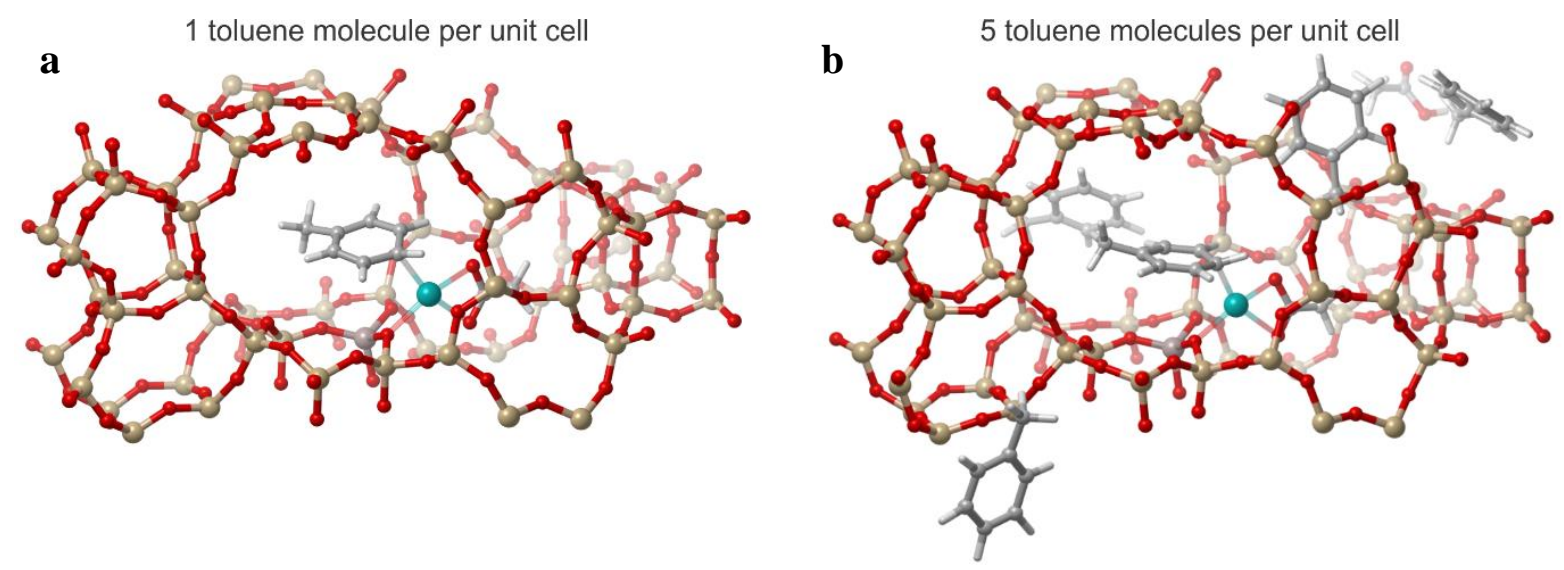

Supplementary Figure 42. H-Beta unit cell representative snapshot taken from the MD simulations of intermediate $\mathbf{V}$ with 1 (a) and 5 (b) toluene molecules per unit cell. 

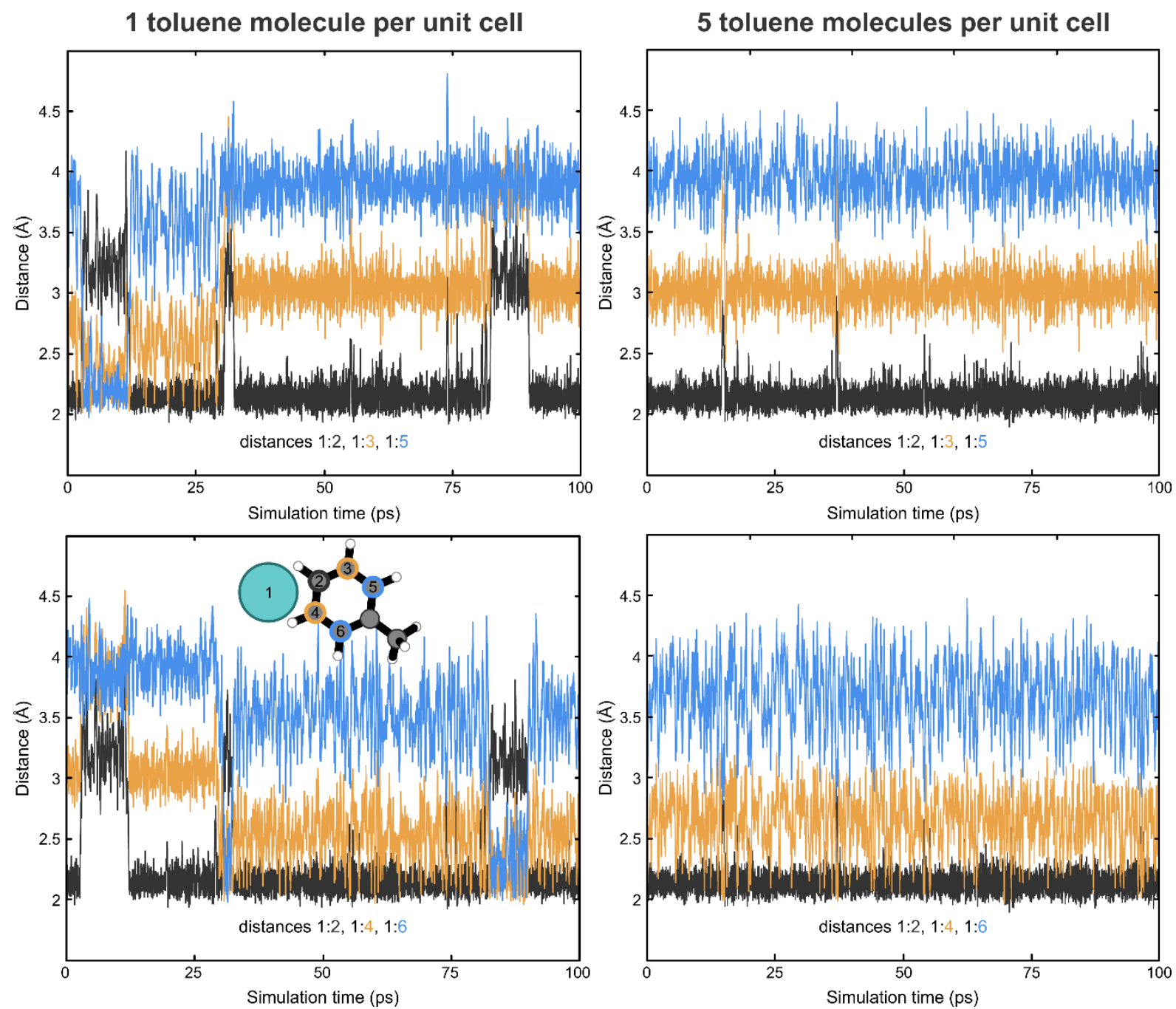

Supplementary Figure 43. Pd-C distances observed during the $100 \mathrm{ps}$ of MD simulation of $\mathbf{V}$ with one (left) and five (right) toluene molecules per unit cell. For the sake of clarity, distances to the two meta and two ortho carbon atoms are shown in different graphs.
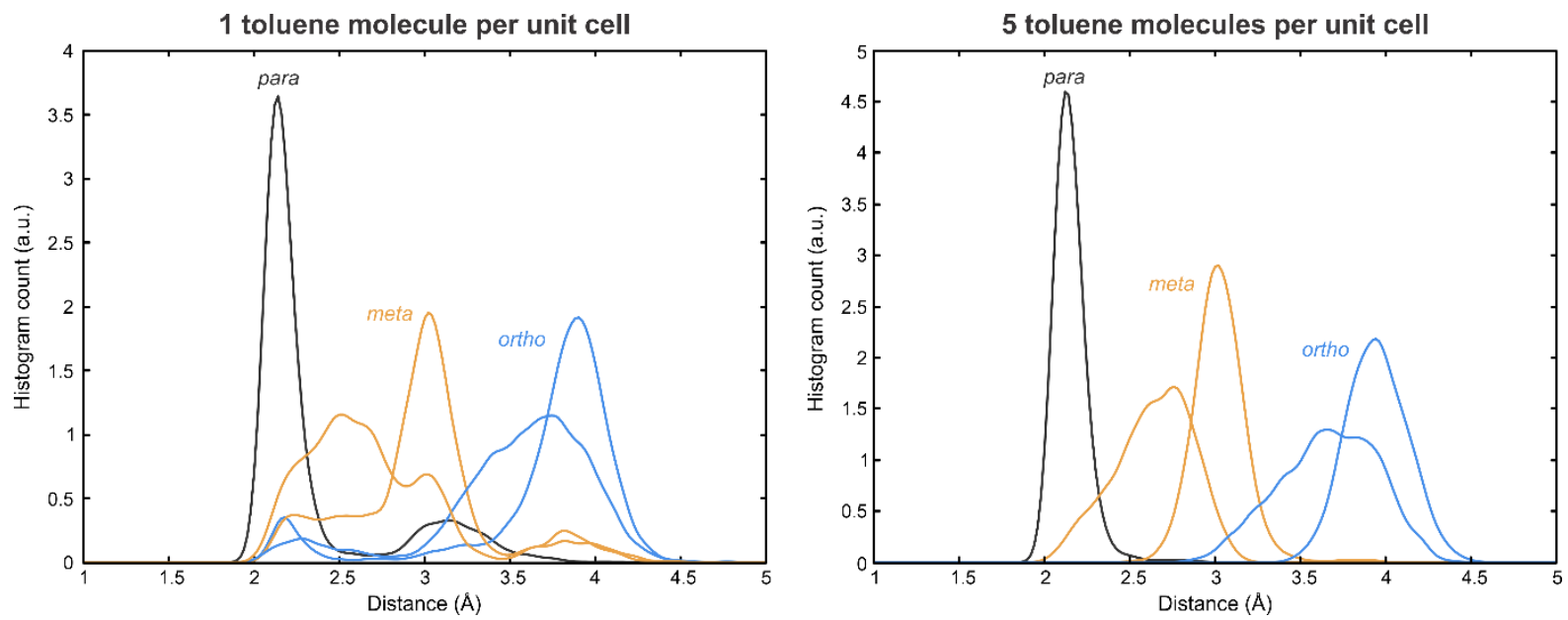

Supplementary Figure 44. Histogram analysis of the Pd-C bond distances explicitly shown in Supplementary Figure 43. 


\section{Step 2: Migratory insertion}

Formation of biarylated Pd intermediate: adsorption of the second toluene studied with MD

Two MD simulations of the Pd-para-tolyl complex, acetic acid and a second toluene molecule were performed. Again, we used a "low loading" condition, with two toluene molecules per unit cell (including the one bounded to Pd) and a "high loading" condition, with five toluene molecules per unit cell. We tracked the Pd-C distance but also C-C distance. Supplementary Figure 45 displays a snapshot of a representative configuration observed during the simulation while Supplementary Figure 46 shows a histogram analysis of the Pd-C and C-C distances. It can be seen how in both simulations the Pd interacts similarly with the para and meta carbon, while the interaction with the ortho carbons is very low. In the low loading simulation, moreover, there is also a significant interaction between the carbon bound to the Pd and the para carbon of the second aromatic ring. This interaction is mostly lost in the high loading simulation, in which all carbons interact similarly. We attribute this difference to the fact that the toluene adsorbed on Pd spontaneously rotated about $180^{\circ}$ on the ring plane in the high loading simulation.
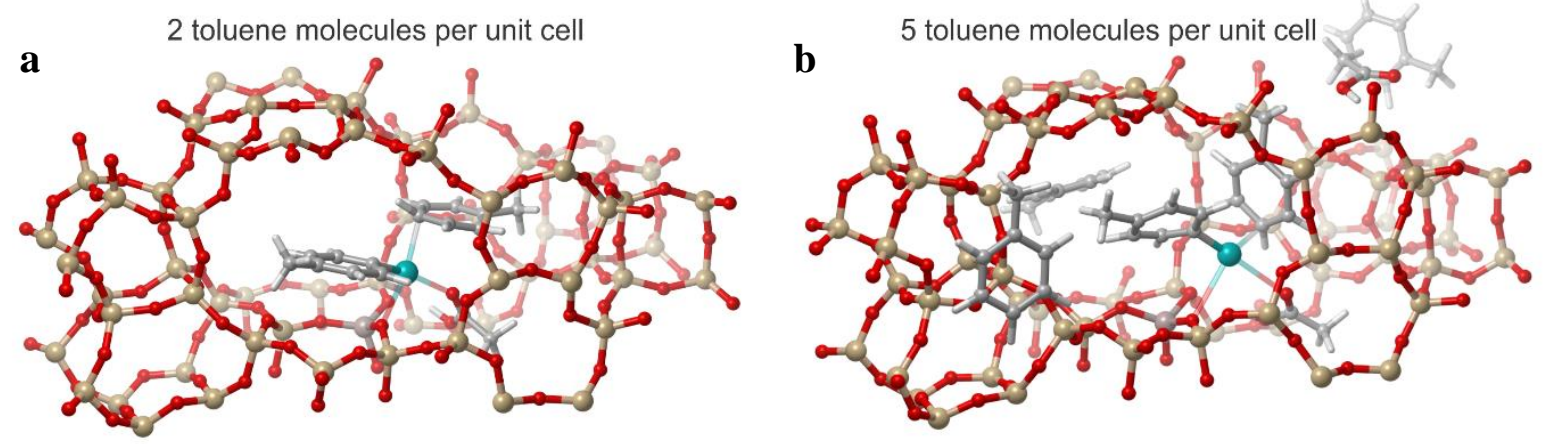

Supplementary Figure 45. H-Beta unit cell representative snapshot taken from the MD simulations of intermediate VII with 2 (a) and 5 (b) toluene molecules per unit cell. It can be noticed how the toluene adsorbed on Pd rotated about $180^{\circ}$ on the ring plane in the high loading simulation with respect to the low loading. 

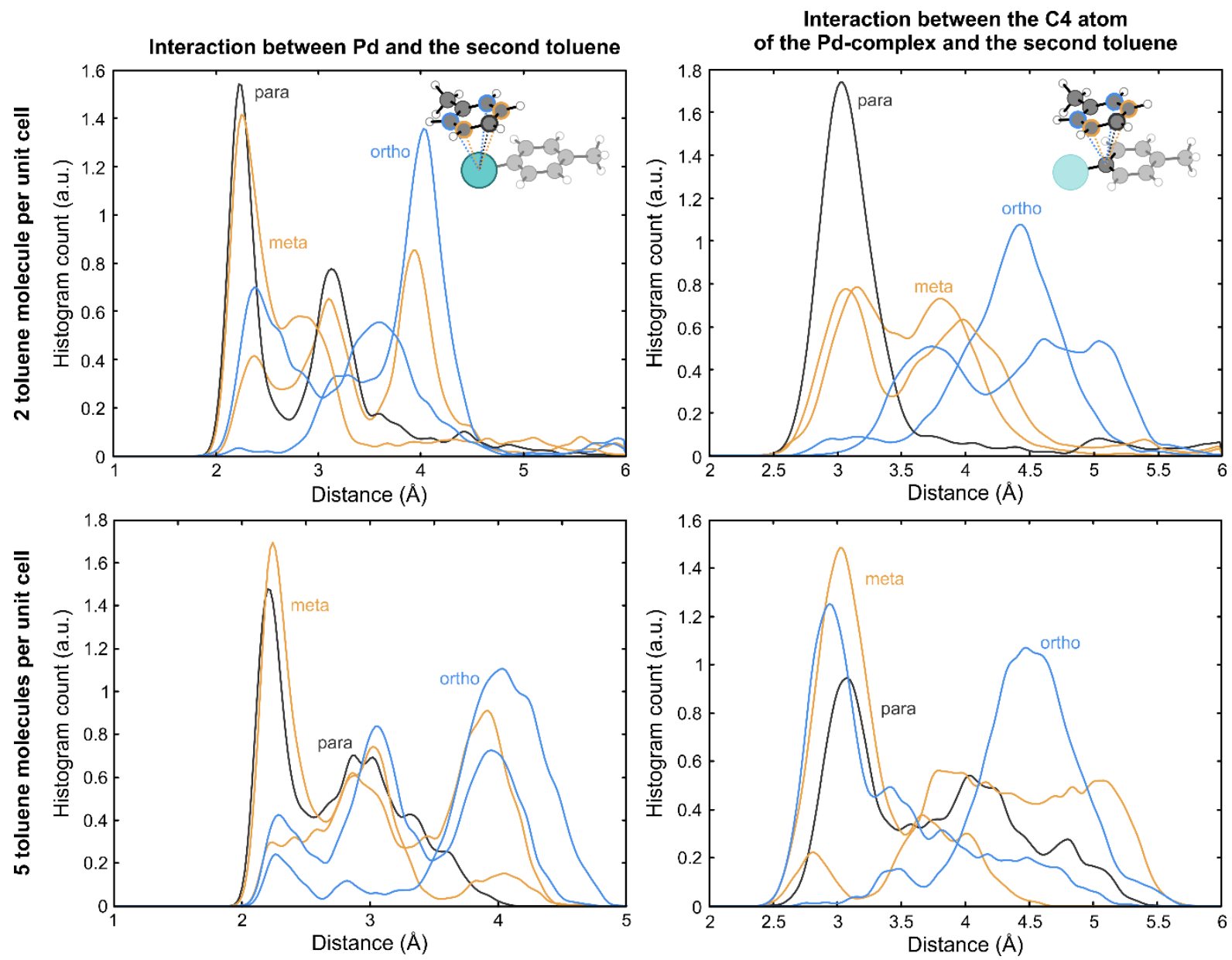

Supplementary Figure 46. Histograms analysis for the $\mathrm{Pd}-\mathrm{C}$ and $\mathrm{C}-\mathrm{C}$ distances for the MD simulations of intermediate VII (100 ps, $363 \mathrm{~K})$. The top graphs are referred to the low toluene loading (two toluene molecules per unit cell, including the one bound to $\mathrm{Pd}$ ) and the high toluene loading (five toluene molecules per unit cell, including the one bound to $\mathrm{Pd}$ ). 


\section{Reaction energies from static calculations}

Static calculations were used to determine the energy associated with the formation of $o, p$, $m, p^{\prime}$ and $p, p$ '-bitolyl products. As for the first step, only the most stable reactant state and transition states were reported in Fig. 6b. A complete free energy diagram with all the analyzed conformations is reported in Supplementary Figure 48. It is possible to notice how one of the $o, p$, transition states is particularly high in energy $(-40 \mathrm{~kJ} / \mathrm{mol})$, which is due to the substituted methyl carbon being significantly sterically clashing with the Pd centre. All the contributions to the final free energy values reported in the main text and Supplementary Figure 48 are listed in Supplementary Table 12 (enthalpic and entropic contributions to the free energy at a PBE-D3 LOT) and Supplementary Table 13 (single-point 0K B3LYP-D3 corrections). The optimized geometries are depicted in Supplementary Figure 49.

As it may be seen, the energetics of the transition states for the $m, p$ ' and $p, p$ ' activations are very close to each other.

At this point it is interesting to note that the typical selectivity obtained with Pd-Beta under optimal experimental conditions is about $77 \%$ of $p, p^{\prime}$ product and $18 \%$ of $m, p^{\prime}$ product. For step 1 we found that the barrier for the $p$ activation of toluene is about $10 \mathrm{~kJ} / \mathrm{mol}$ lower than the $m$ activation and $12 \mathrm{~kJ} / \mathrm{mol}$ lower than the $o$ activation. This would mean that, according to the simplest formulation of the Curtin-Hammett principle, step 1 accounts for:

$$
\left\{\begin{array} { l } 
{ \text { ortho } + \text { meta } + \text { para } = 1 } \\
{ \frac { \text { ortho } } { \text { para } } = e ^ { - \Delta \Delta G ^ { \neq } } / R T = 0 . 0 3 6 } \\
{ \frac { \text { meta } } { \text { para } } = e ^ { - \Delta \Delta G ^ { \neq } } / R T = 0 . 0 1 8 }
\end{array} \rightarrow \left\{\begin{array}{l}
\text { para }=0.948 \\
\text { meta }=0.034 \\
\text { ortho }=0.018
\end{array}\right.\right.
$$

To achieve a final $77 \%$ selectivity of the $p, p$ ' product we must have a para selectivity associated with the second step of $0.77 / 0.948=0.81$. Now, assuming that the $81 \%$ para selectivity for the second step is constant even for the meta product of the CMD, we have that the total $18 \%$ of observed $m, p$ ' product will be given by:

meta $=0.034 * 0.81+0.948 * x=0.18$

with $x$ the selectivity for meta arylation of step 2. In this case $x=0.16$. A graphical depiction of the product distributions going from step 1 to step 2 can be found in Supplementary Figure 47. We can now plug the obtained $m, p$ ' vs. $p, p$ ' selectivities back in the Curtin-Hammett equation to obtain an estimate of the expected $\Delta \Delta \mathrm{G}^{\ddagger}$ for step 2 :

$$
\Delta \Delta \mathrm{G}^{\neq} \approx-\mathrm{RT} \ln (0.16 / 0.81)=4.9 \mathrm{~kJ} / \mathrm{mol}
$$

This value is quite low, in the lower limit of DFT accuracy. It is then reasonable that our calculations cannot fully predict the experimentally observed $p, p$ ' vs. $m, p^{\prime}$ selectivity in the hypothesis that the reaction is under kinetic control. Despite starting from the assumption that the barriers related to step 1 are correct, the calculated $\Delta \Delta \mathrm{G}^{\ddagger}$ depends on the logarithm of the ratio between the meta and para selectivities and it is thus robust with respect to variations in the selectivity of the step 1. Finally, we show that the formation of the $o, p$ ' product should be limited, in good agreement with the experimental results. 


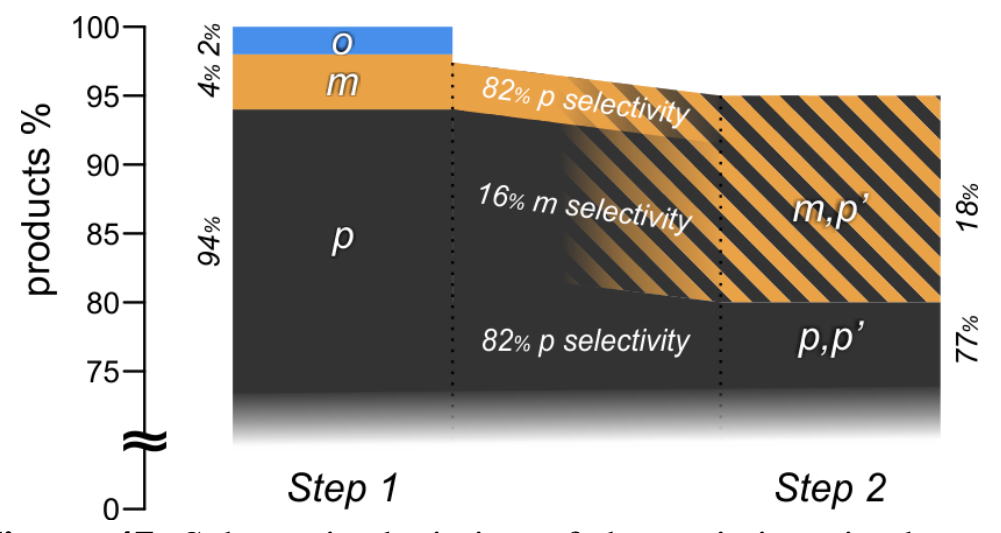

Supplementary Figure 47. Schematic depiction of the variations in the product distributions between step 1 and step 2 according to our model.

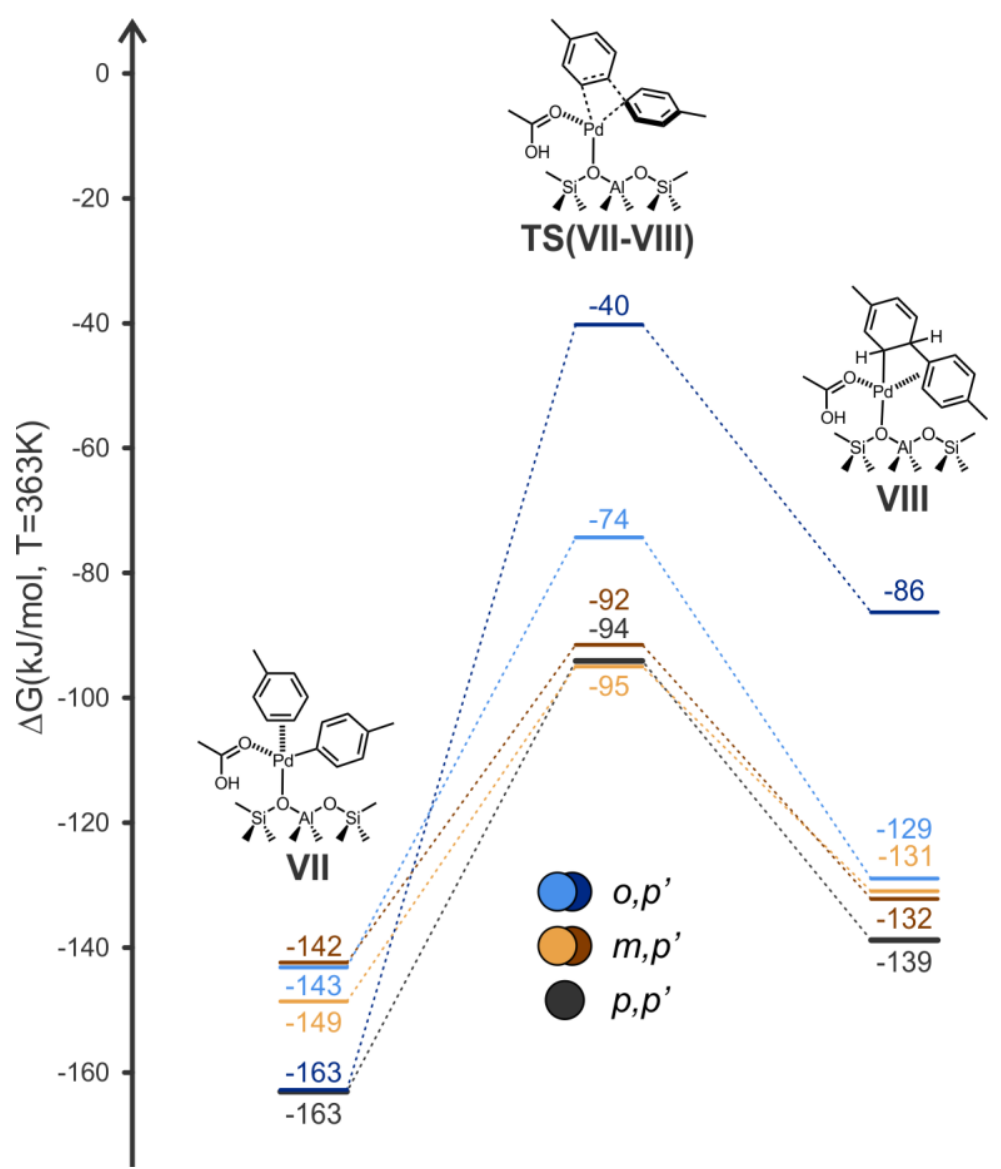

Supplementary Figure 48. Detail of the MI step on the free energy profile, reporting all the reactants, transition states and products that were analyzed. 

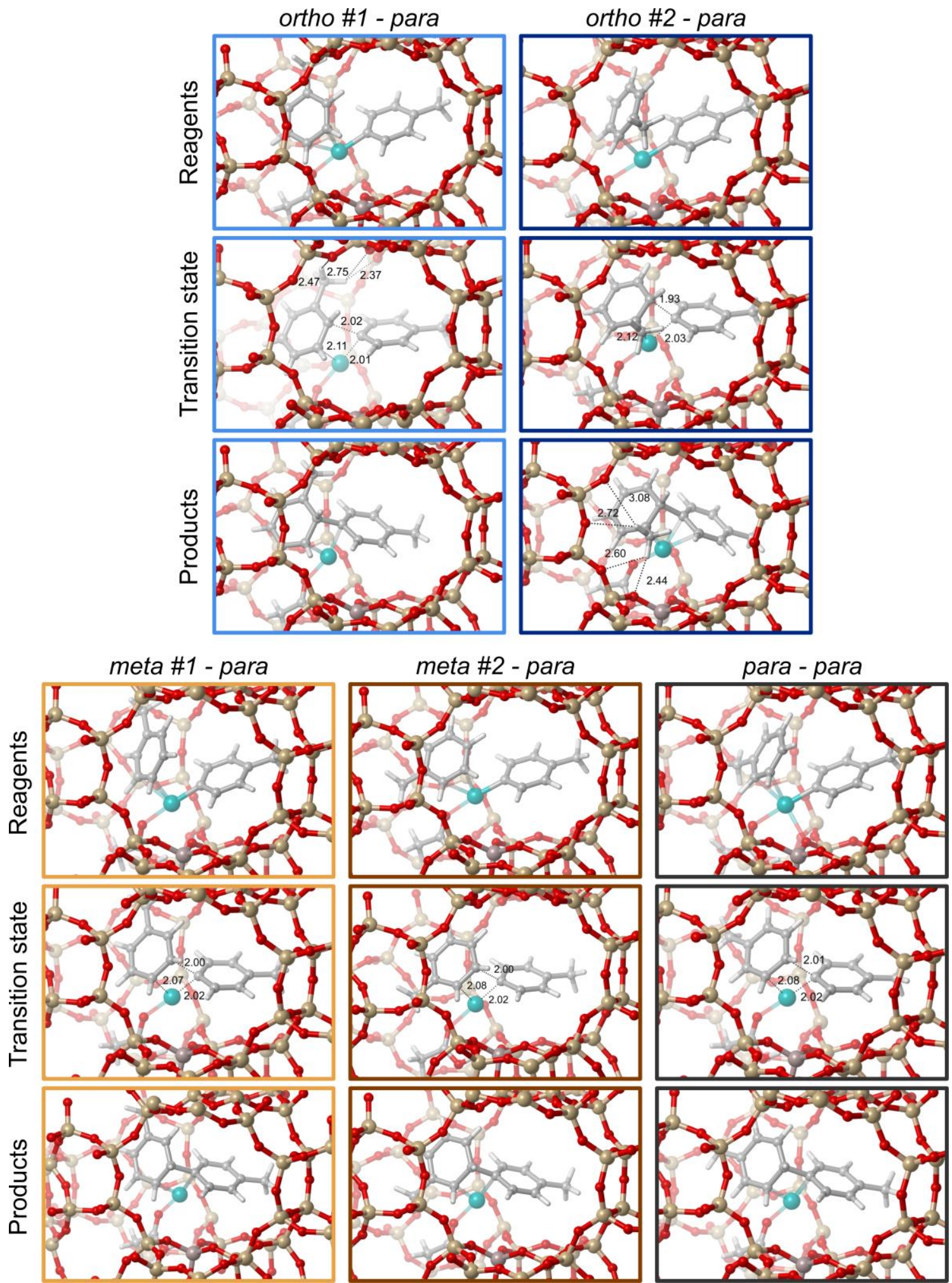

Supplementary Figure 49. Optimized structures for reactants, transition states and products in the migratory insertion reaction at the two ortho, two meta and para positions of the aromatic ring. The numbers in the figures refer to interesting distances, in $\AA$. 
Supplementary Table 12. Free energy $(\Delta \mathrm{G})$, enthalpy $(\Delta \mathrm{H})$ and entropy $(-\mathrm{T} \Delta \mathrm{S})$ in $\mathrm{kJ} / \mathrm{mol}$ for intermediate VII, TS(VII-VIII) and VII at $363 \mathrm{~K}$ and a PBE level of theory.

\begin{tabular}{|c|c|c|c|c|}
\hline & & \multicolumn{3}{|c|}{ Step 2} \\
\hline & & VII & TS(VII-VIII) & VIII \\
\hline \multirow{3}{*}{ para-para } & $\Delta \mathrm{G}$ & -120 & -69 & -113 \\
\hline & $\Delta \mathrm{H}$ & -248 & -202 & -249 \\
\hline & $-\mathrm{T} \Delta \mathrm{S}$ & 128 & 133 & 136 \\
\hline \multirow{3}{*}{ meta\#1-para } & $\Delta \mathrm{G}$ & -106 & -67 & -106 \\
\hline & $\Delta \mathrm{H}$ & -238 & -200 & -244 \\
\hline & $-\mathrm{T} \Delta \mathrm{S}$ & 132 & 133 & 138 \\
\hline \multirow{3}{*}{ meta\#2-para } & $\Delta \mathrm{G}$ & -104 & -61 & -103 \\
\hline & $\Delta \mathrm{H}$ & -236 & -196 & -241 \\
\hline & $-\mathrm{T} \Delta \mathrm{S}$ & 132 & 135 & 138 \\
\hline \multirow{3}{*}{ ortho\#1-para } & $\Delta \mathrm{G}$ & -104 & -45 & -102 \\
\hline & $\Delta \mathrm{H}$ & -233 & -181 & -238 \\
\hline & $-\mathrm{T} \Delta \mathrm{S}$ & 129 & 136 & 136 \\
\hline \multirow{3}{*}{ ortho\#2-para } & $\Delta \mathrm{G}$ & -112 & -20 & -55 \\
\hline & $\Delta \mathrm{H}$ & -245 & -156 & -195 \\
\hline & $-\mathrm{T} \Delta \mathrm{S}$ & 133 & 136 & 140 \\
\hline
\end{tabular}

Supplementary Table 13. 0K correction to the adsorption energy $(\mathrm{kJ} / \mathrm{mol})$ from a B3LYP single point on the PBE-optimized structures. The values reported in Supplementary Figure 48 are the sum of the free energies listed in Supplementary Table 12 and the following corrections.

\begin{tabular}{|l|l|l|l|l|}
\hline & & Step 2 & \\
\hline & & VII & TS(VII-VIII) & VIII \\
\hline para-para & $\Delta \mathrm{E}$ & -43 & -25 & -26 \\
\hline meta\#1-para & $\Delta \mathrm{E}$ & -43 & -28 & -25 \\
\hline meta\#2-para & $\Delta \mathrm{E}$ & -38 & -31 & -29 \\
\hline ortho\#1-para & $\Delta \mathrm{E}$ & -39 & -29 & -27 \\
\hline ortho\#2-para & $\Delta \mathrm{E}$ & -51 & -20 & -31 \\
\hline
\end{tabular}




\section{Step 3: Evidences for hydrogen transfer to $P d$}

As stated in the main text, in the absence of available base that might assist a reductive deprotonation, efforts turned to characterize a process in which $\mathrm{AcOH}$ is facilitating $\mathrm{C}-\mathrm{H}$ deprotonation, and concurrent hydrogen transfer to form a $\mathrm{Pd}-\mathrm{H}$ species. After various attempts, provisional regiodivergent transition states for the hydrogen transfer process for the $o, p^{\prime}, m, p^{\prime}$, and $p, p$ ' regioselectivities were located, i.e. TS(IX-X) (see Supplementary Figure 50 for the structure of the $p, p^{\prime}$ transition-state for reference). However, computed energetic spans (relative to VIII) for each selectivity were, while still more stable than the $2^{\text {nd }}$ CMD TSs, unusually large (where $\left.\Delta \mathrm{G}_{o, p^{\prime}}^{\sharp}=205 \mathrm{~kJ} / \mathrm{mol}, \Delta \mathrm{G}_{m, p^{\prime}}^{\sharp}=147 \mathrm{~kJ} / \mathrm{mol}, \Delta \mathrm{G}_{p, p^{\prime}}^{\sharp}=162 \mathrm{~kJ} / \mathrm{mol}\right)$.

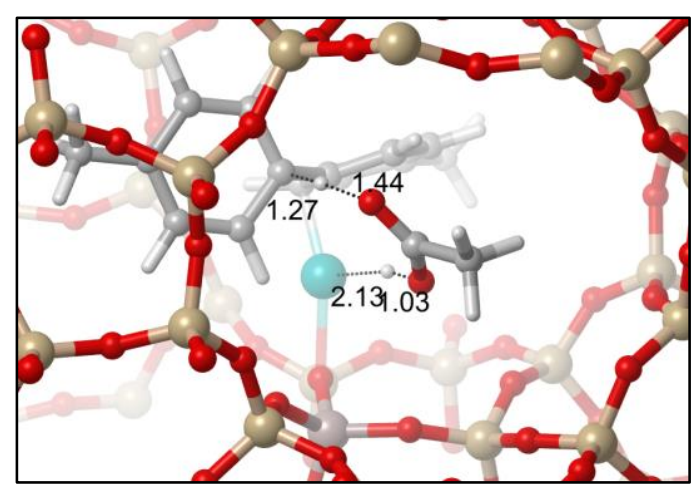

Supplementary Figure 50. Computed structure of TS(IX-X) with $p, p$ ' selectivity.

We must stress that these calculations suffered from unavoidable technical challenges. In particular, we are normally able to further relax the transition states obtained with the improved dimer method using a quasi-Newton algorithm. The results achieved by the latter are quite dependent on the chosen POTIM value, which scales the step size during the ionic relaxation process. Optimizing with higher values of POTIM can lead to a significant decrease in the energy, without the structure completely relaxing from the TS region. For the HT transition state, however, we were able to optimize the structures of the regiodivergent TSs only to half the POTIM value we normally consider sufficient to achieve a fully relaxed structure ( 0.1 vs 0.2$)$. Any attempt to increase the POTIM value led to the system diverging from the TS region, losing the imaginary mode corresponding to the reaction of interest. This does not allow us to exclude (in the limit of the accuracy of static calculations) with reasonable confidence that more stable structures can exist in the TS region of the PES. Moreover, we also speculate that this may not actually be the most energetically accessible route to finalize the coupling from the MI product species. For instance, further $\mathrm{AcOH}$ molecules could be involved to stabilize the transition-state via proton-shuttling networks, or preceding proton transfer to the Brønsted-Acid site could take place to allow for a formed OAc group to perform reductive deprotonation. We believe that further investigations of these types of transition states are beyond the scope of the current manuscript. 
Alternative $2^{\text {nd }} C M D / R C$ mechanism - free energies from static calculations

The mechanism of proton-transfer from $\mathrm{AcOH}$ to the Brønsted acid site, followed by second $\mathrm{C}-\mathrm{H}$ activation via CMD, was characterized to assess the accessibility of this pathway with respect to the MI/HT pathway. Subsequent reductive-coupling transition-states (TS(XI-XII)) were also computed. Transition states for all three regiodivergent $\mathrm{C}-\mathrm{H}$ activation / reductive coupling processes were located, and assuming facile conversion of low-lying intermediate VII (-163 $\mathrm{kJ} / \mathrm{mol}$ ) to form the respective reactants for each regiodivergent process, the following energetic spans for $2^{\text {nd }} \mathrm{C}-\mathrm{H}$ activation were obtained (Supplementary Figure 51):

$\Delta \mathrm{G}_{o, p^{\prime}}^{\ddagger}=206 \mathrm{~kJ} / \mathrm{mol}$

$\Delta \mathrm{G}_{m, p^{\prime}}^{\ddagger}=204 \mathrm{~kJ} / \mathrm{mol}$

$\Delta \mathrm{G}_{p, p^{\prime}}^{\ddagger}=187 \mathrm{~kJ} / \mathrm{mol}$

The most kinetically accessible is para activation $\left(\mathbf{T S}(\mathbf{V I I}-\mathbf{X I})_{\mathbf{p p}}, 24 \mathrm{~kJ} / \mathrm{mol}\right)$ to yield bis-metalated species $\mathbf{X I}_{\mathbf{p p}}-26 \mathrm{~kJ} / \mathrm{mol}$. It should be noted that reactant species in the $m, p$ ' pathway converged to a local minimum in which the proton remained at the Brønsted acid site, while the other regiodivergent reactant species $\left(o, p^{\prime}, p, p^{\prime}\right)$ afforded species in which concomitant proton transfer back to the acetate base took place. Enthalpic and entropic contributions to the free energy are reported in Supplementary Table 14, while the B3LYP single point corrections in Supplementary Table 15 .

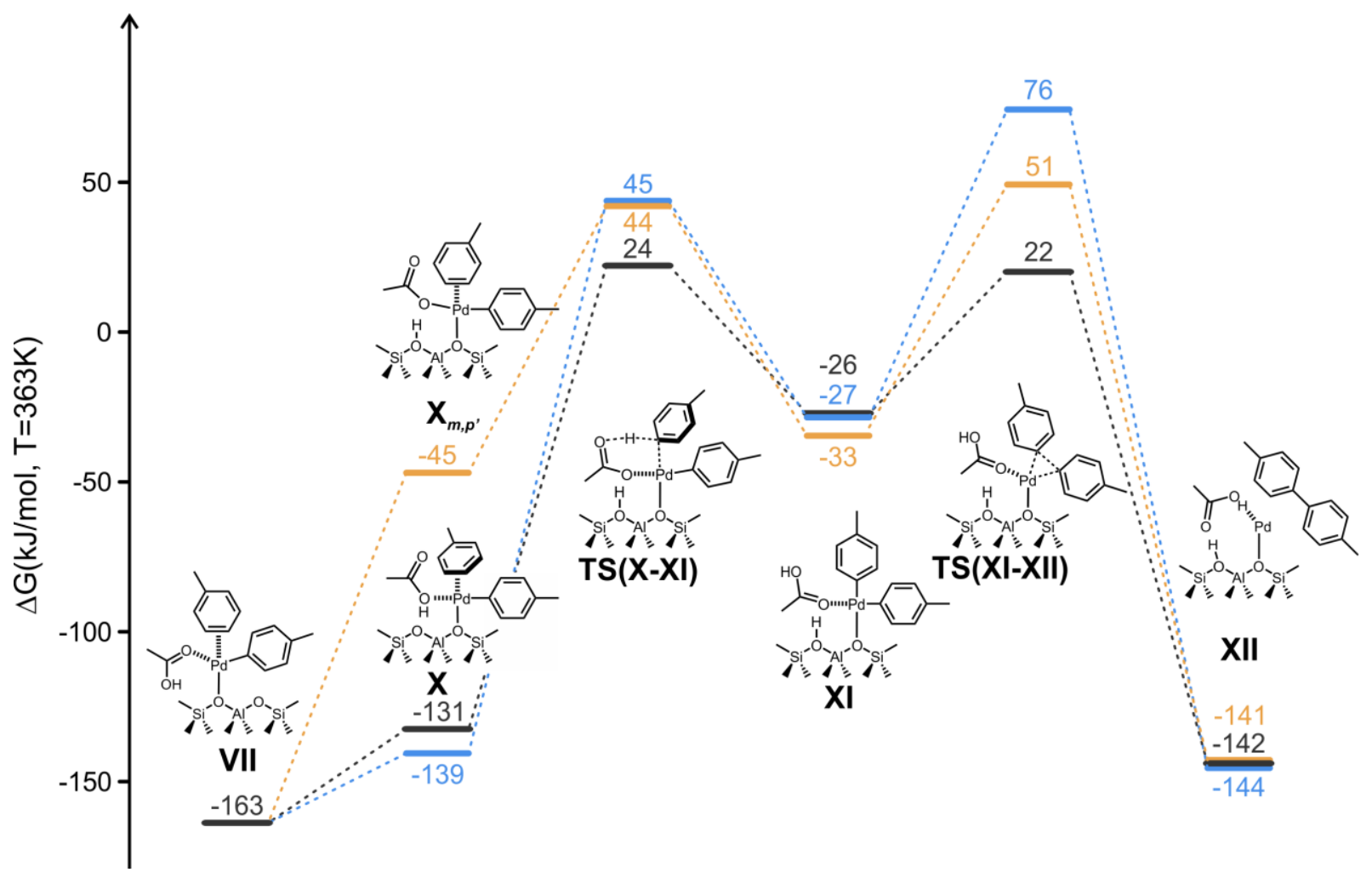

Supplementary Figure 51. Free energy profiles for $2^{\text {nd }} \mathrm{C}-\mathrm{H}$ activation, via CMD, followed by reductive coupling from species VII, for the following regioselective outcomes, at a B3LYPD3//PBE-D3 level of theory: $o, p^{\prime}$ (blue), $m, p^{\prime}$ (orange), p, p' (black). 
Supplementary Table 14. Free energy $(\Delta \mathrm{G})$, enthalpy $(\Delta \mathrm{H})$ and entropy $(-\mathrm{T} \Delta \mathrm{S})$ in $\mathrm{kJ} / \mathrm{mol}$ for intermediate X, TS(X-XI), XI, TS(XI-XII) and XII at 363K and a PBE-D3 level of theory.

\begin{tabular}{|l|l|l|l|l|l|l|}
\hline & & \multicolumn{3}{l}{$2^{\text {nd }} C M D$} & \multicolumn{2}{l|}{ Reductive elimination } \\
\hline & & $\mathrm{X}$ & $\mathrm{TS}(\mathrm{X}-\mathrm{XI})$ & $\mathrm{XI}$ & $\mathrm{TS}(\mathrm{XI}-\mathrm{XII})$ & $\mathrm{XII}$ \\
\hline \multirow{3}{*}{$p, p^{\prime}$} & $\Delta \mathrm{G}$ & -82 & 47 & 4 & 47 & -109 \\
\cline { 2 - 7 } & $\Delta \mathrm{H}$ & -214 & -87 & -130 & -82 & -238 \\
\cline { 2 - 7 } & $-\mathrm{T} \Delta \mathrm{S}$ & 132 & 134 & 134 & 129 & 129 \\
\hline \multirow{3}{*}{$m, p^{\prime}$} & $\Delta \mathrm{G}$ & 9 & 67 & 7 & 68 & -107 \\
\cline { 2 - 7 } & $\Delta \mathrm{H}$ & -115 & -67 & -124 & -69 & -242 \\
\cline { 2 - 7 } & $-\mathrm{T} \Delta \mathrm{S}$ & 124 & 134 & 131 & 137 & 135 \\
\hline \multirow{3}{*}{$o, p^{\prime}$} & $\Delta \mathrm{G}$ & -92 & 75 & 3 & 89 & -113 \\
\cline { 2 - 7 } & $\Delta \mathrm{H}$ & -220 & -68 & -127 & -50 & -251 \\
\cline { 2 - 7 } & $-\mathrm{T} \Delta \mathrm{S}$ & 128 & 143 & 131 & 139 & 137 \\
\hline
\end{tabular}

Supplementary Table 15. 0K correction to the adsorption energy $(\mathrm{kJ} / \mathrm{mol})$ from a B3LYP single point on the PBE-optimized structures. The values reported in Supplementary Figure 51 are the sum of the free energies listed in Supplementary Table 14 and the following corrections.

\begin{tabular}{|l|l|l|l|l|l|l|}
\hline & \multicolumn{3}{|c|}{$2^{\text {nd }} C M D$} & \multicolumn{2}{l|}{ Reductive elimination } \\
\hline & & $\mathrm{X}$ & $\mathrm{TS}(\mathrm{X}-\mathrm{XI})$ & $\mathrm{XI}$ & $\mathrm{TS}(\mathrm{XI}-\mathrm{XII})$ & $\mathrm{XII}$ \\
\hline$p, p^{\prime}$ & $\Delta \mathrm{E}$ & -49 & -23 & -29 & -25 & -33 \\
\hline$m, p^{\prime}$ & $\Delta \mathrm{E}$ & -55 & -24 & -30 & -13 & -30 \\
\hline$o, p^{\prime}$ & $\Delta \mathrm{E}$ & -44 & -29 & -40 & -17 & -35 \\
\hline
\end{tabular}


Step 4: Evaluation of $\mathrm{O}_{2}$-insertion pathways: characterization of hydrogen atom abstraction (HAA) and hydrogen metathesis-insertion (HMI)

The last step to complete the catalytic cycle is proposed to be insertion of $\mathrm{O}_{2}$ into the resulting $\mathrm{Pd}-$ $\mathrm{H}$ bond in species IX, and has been characterized with a 5T cluster model in Gaussian 09 (see the computational details). This protocol was chosen as opposed to the periodic model with VASP to allow for the efficient computation of minimum energy crossing points (MECPs) along the reaction pathway, given the spin-forbidden nature of the process as identified by Stahl et al. ${ }^{61,62}$ The two most favored pathways proposed by Stahl are hydrogen atom abstraction (HAA) and H$\mathrm{X}$ reductive elimination (HXRE), and so efforts began with attempting to characterize these analogous processes in the $5 \mathrm{~T}$ cluster model.

As the point in catalysis in which product dissociation and toluene re-coordination take place is unclear, HAA and HXRE were modelled from both an arene-bound state, in which bitolyl was replaced with toluene as the $\eta^{2}$-coordinated arene (species ${ }^{1} \mathbf{I}_{\mathbf{C}}$ in Supplementary Figure 52), and also from an arene-dissociated state (species ${ }^{1} \mathbf{X I}_{\mathbf{C}}$ in Supplementary Figure 53). This toluenebound model is presented in Supplementary Figure 52, while Supplementary Figure 53 describes an arene-desorbed pathway for $\mathrm{O}_{2}$ insertion. We must point out that, while the $\Delta \mathrm{G}$ between ${ }^{\mathbf{1}} \mathbf{I}_{\mathbf{C}}$ and ${ }^{1} \mathbf{X I} \mathbf{C}$ (and free toluene) is $-20 \mathrm{~kJ} / \mathrm{mol}$ in favor of the arene-dissociated state, we anticipate that the poor description of entropic contributions in this gas-phase cluster model is insufficiently capturing the thermodynamics of this process, and as it is unclear which starting species is favored, both states were modelled, and are reported in full.

\section{Toluene-bound pathway (from ${ }^{1} \boldsymbol{I}_{\boldsymbol{C}}$ )}

Beginning with HAA in the toluene-bound profile (Supplementary Figure 52a), addition of $\mathrm{O}_{2}$ takes place to yield weakly-bound adduct ${ }^{3} \mathbf{I I}_{\mathbf{C}}(+34 \mathrm{~kJ} / \mathrm{mol})$. Subsequent HAA can take place via ${ }^{3}$ TS(II-III)C $(+80 \mathrm{~kJ} / \mathrm{mol})$, in which hydrogen transfer onto oxygen is concomitant with rearrangement of the formed peroxide to form ${ }^{3} \mathrm{Pd}-\mathrm{OOH}$ adduct ${ }^{3} \mathbf{I I I}_{\mathbf{C}}(-25 \mathrm{~kJ} / \mathrm{mol})$. Subsequent facile spin-crossover via surface crossing point ${ }^{(3-1)}$ MECP(III)C $(-11 \mathrm{~kJ} / \mathrm{mol})$ takes place to afford singlet ${ }^{1} \mathrm{Pd}-\mathrm{OOH}$ adduct ${ }^{1} \mathbf{I I I}_{\mathbf{C}}(-41 \mathrm{~kJ} / \mathrm{mol})$. Rearrangement of the $\mathrm{AcOH}$ group can then take place via ${ }^{1} \mathbf{T S}(\mathbf{I I I}-\mathbf{I V}) \mathbf{C}(-36 \mathrm{~kJ} / \mathrm{mol})$ to afford ${ }^{1} \mathbf{I V}_{\mathbf{C}}(-69 \mathrm{~kJ} / \mathrm{mol})$, which results in a stabilizing hydrogen bond between $\mathrm{AcOH}$ and the $\kappa \mathrm{O}$ of the peroxide group (where $\mathrm{R}_{\mathrm{HO}}=1.41 \AA$ ). Finally, dissociation of toluene and coordination of another oxygen of the zeolite framework can exergonically take place to yield ${ }^{\mathbf{1}} \mathbf{V}_{\mathbf{c}}(-99 \mathrm{~kJ} / \mathrm{mol})$. From ${ }^{\mathbf{1}} \mathbf{V}_{\mathbf{c}}$, addition of AcOH can facilitate the dissociation of $\mathrm{H}_{2} \mathrm{O}_{2}$ to form ${ }^{1} \mathbf{V I}_{\mathrm{C}}$ (albeit mildly endergonically, where $\mathrm{G}=-57 \mathrm{~kJ} / \mathrm{mol}$ ), where $\mathrm{H}_{2} \mathrm{O}_{2}$ remains coordinated via hydrogen bonding with the pendant carboxylate arm. From this species, further dissociation is speculated to take place, where $\mathrm{H}_{2} \mathrm{O}_{2}$ can re-oxidize the palladium center at another stage in catalysis.

Efforts to characterize the HXRE pathway (Supplementary Figure 52b) began with modelling the reductive coupling of the Brønsted acid site and the hydride ligand. However, capturing a corresponding transition-state was unsuccessful, and we in turn speculated that a preceding proton transfer from $\mathrm{AcOH}$ to the Brønsted acid site must take place, which allows for a more efficient reductive coupling to instead take place between $\mathrm{H}^{-}$and the formed ${ }^{-} \mathrm{OAc}$ group. This process was successfully characterized, and takes place via transition-state ${ }^{1} \mathbf{T S}(\mathbf{I}-\mathbf{V I})_{\mathbf{C}}(+90 \mathrm{~kJ} / \mathrm{mol})$ to form species ${ }^{1} \mathbf{V I}_{\mathbf{C}}(+58 \mathrm{~kJ} / \mathrm{mol})$, where toluene is weakly coordinated to the Pd center. Inspection of the interatomic distances suggested that the re-protonated Brønsted acid site undergoes concomitant oxidative-addition to reinstate a hydride ligand at the Pd center, thus yielding no net change of the 
oxidation state of Pd (unlike the $\mathrm{Pd}^{\mathrm{II}} \rightarrow \mathrm{Pd}^{0}$ change in HXRE). To distinguish from HXRE we have named this process Hydrogen Metathesis-Insertion (HMI), as one cleaved $\mathrm{Pd}-\mathrm{H}$ bond is replaced with another in tandem. Subsequent dissociation of toluene and addition of $\mathrm{O}_{2}$ yields peroxo species ${ }^{3} \mathbf{V I I}_{\mathbf{C}}(+58 \mathrm{~kJ} / \mathrm{mol})$, which, upon identification that the $\mathrm{O}-\mathrm{O}$ bond is minimally perturbed upon coordination with the Pd center $(1.22 \AA)$ and comparison with the analogous intermediate in Stahl's work, is most likely a $\mathrm{Pd}(\mathrm{II})-\mathrm{O}_{2}$ species, with the unpaired spin-density distributed on the $\mathrm{O}$ atoms. However, a major difference between the $\mathrm{Pd}-\mathrm{O}_{2}$ species in this work and that in Stahl's, is that ${ }^{3} \mathbf{V I I} \mathbf{c}$ is computed to be an accessible intermediate. We expect that the lack of necessity to form a charge separated species (as Stahl identifies as a requirement to form the analogous $\mathrm{Pd}-\mathrm{O}_{2}$ intermediate in his work) allows this species to be energetically viable in the zeolite system.

Facile torsional rearrangement of $\mathrm{O}_{2}$ can then induce hydrogen transfer from the Brønsted acid site to the $\mathrm{O}_{2}$ ligand to afford ${ }^{3} \mathrm{Pd}-\mathrm{OOH}$ species ${ }^{3} \mathrm{VIIIC}(-16 \mathrm{~kJ} / \mathrm{mol})$. Further rearrangement of the AcOH ligand was also expected to take place to afford ${ }^{3} \mathbf{V}_{\mathbf{C}}(-18 \mathrm{~kJ} / \mathrm{mol})$ (although an explicit transition-state of this process could not be located). Subsequent spin-crossover from this species takes place via ${ }^{(3-1)} \mathbf{M E C P}(\mathbf{V})_{\mathbf{C}}(-1 \mathrm{~kJ} / \mathrm{mol})$ to afford square-planar species ${ }^{1} \mathbf{V}_{\mathbf{C}}(-99 \mathrm{~kJ} / \mathrm{mol})$, where subsequent exchange between $\mathrm{H}_{2} \mathrm{O}_{2}$ and $\mathrm{AcOH}$ affords ${ }^{1} \mathbf{V I}_{\mathbf{C}}(-57 \mathrm{~kJ} / \mathrm{mol})$, as previously outlined in the HAA pathway.

Comparing these two routes of $\mathrm{O}_{2}$ insertion into $\mathrm{Pd}-\mathrm{H}$, HAA is identified as the favored mechanism with a lower energetic span, $\Delta \mathrm{G}^{\ddagger}=+80 \mathrm{~kJ} / \mathrm{mol}$, over that of the HMI pathway $\left(\Delta \mathrm{G}^{\ddagger}=\right.$ $+90 \mathrm{~kJ} / \mathrm{mol})$. 
(a) Hydrogen Atom Abstraction (HAA)

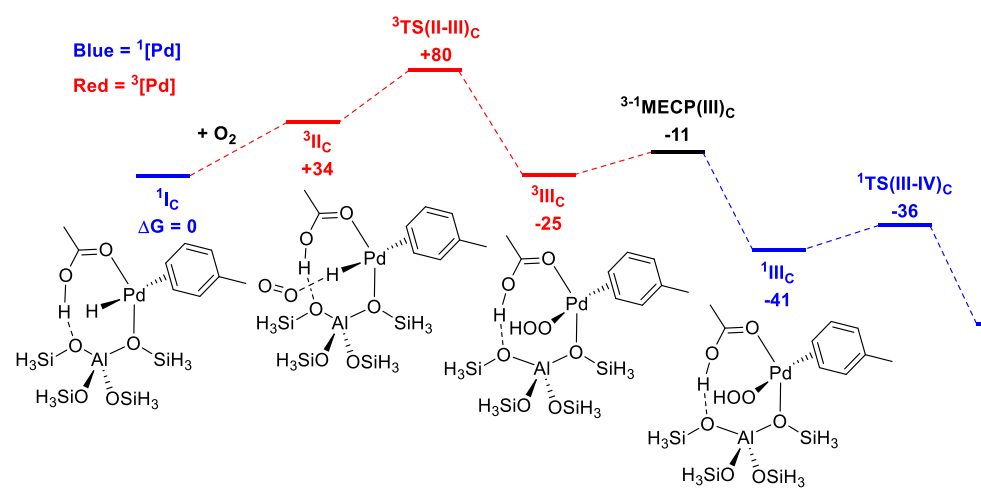

(b) Hydrogen Metathesis-Insertion (HMI)

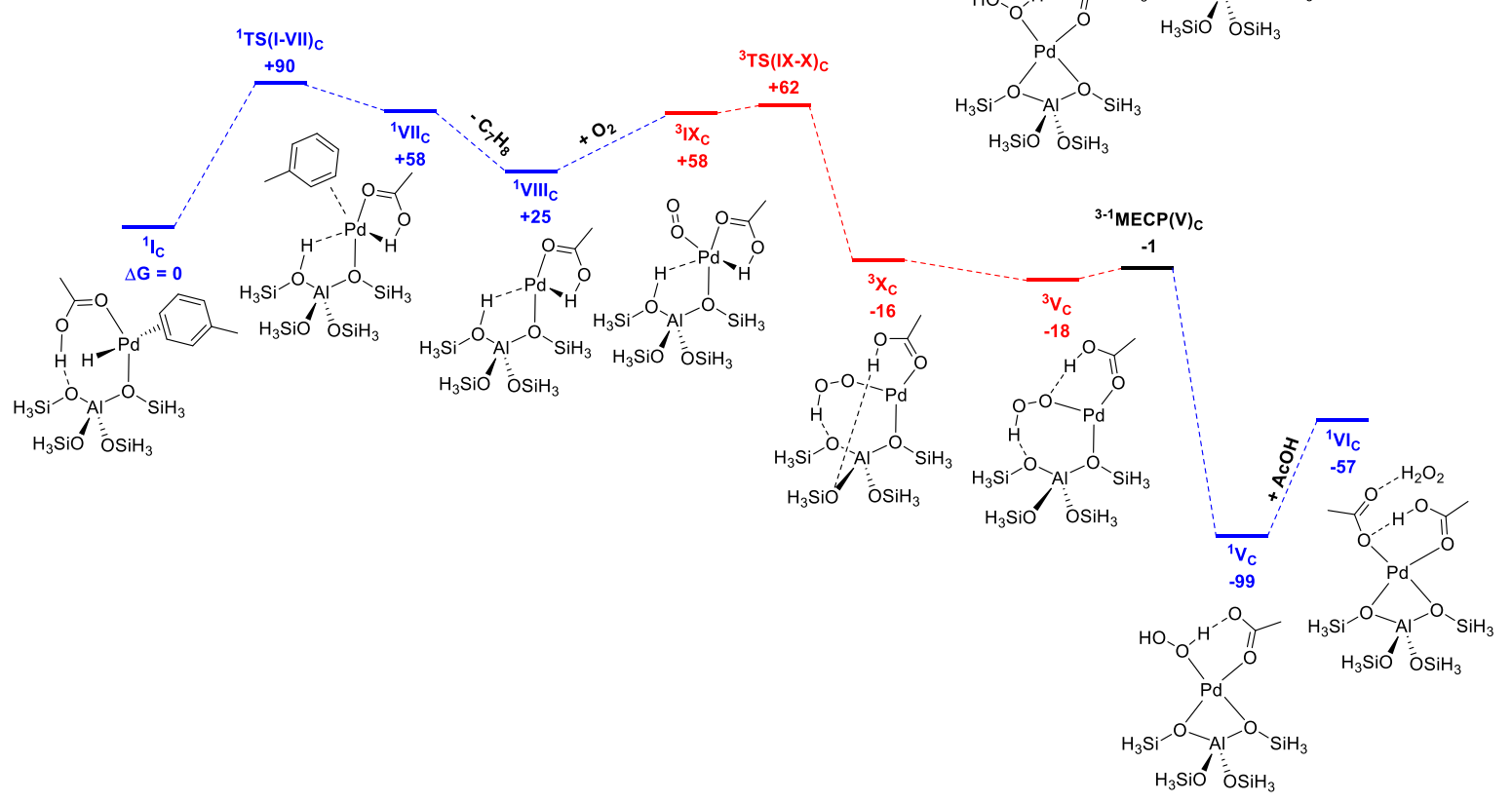

Supplementary Figure 52. Computed free-energy profile of the two modelled pathways of $\mathrm{O}_{2}$ insertion at the B3LYP-D3/Def2-TZVPPD//B3LYP/BS1 level. (a) Hydrogen atom abstraction (HAA). (b) Hydrogen Metathesis-Insertion (HMI). Energies are relative to toluene-bound state ${ }^{\mathbf{1}} \mathbf{I} \mathbf{C}$ and corresponding reactants. 


\section{Toluene-dissociated pathway (from ${ }^{1} \boldsymbol{X I}_{\boldsymbol{C}}$ )}

Unlike the toluene-bound state, no weakly bound $\mathrm{Pd}-\mathrm{H}^{\cdots} \mathrm{O}_{2}$ adduct was characterized from species ${ }^{1} \mathbf{X I} \mathbf{C}$, and instead, upon addition of $\mathrm{O}_{2}$, HAA takes place via ${ }^{3} \mathbf{T S}(\mathbf{X I}-\mathbf{X})_{\mathbf{C}}(+89 \mathrm{~kJ} / \mathrm{mol})$ to yield ${ }^{3} \mathrm{Pd}-\mathrm{OOH}$ adduct ${ }^{3} \mathbf{X}_{\mathbf{C}}(+1 \mathrm{~kJ} / \mathrm{mol})$, where the remaining steps to afford ${ }^{\mathbf{1}} \mathbf{V} \mathbf{I}_{\mathbf{C}}$ are identical to those outlined in the toluene-adsorbed profile.

The alternative HMI process from ${ }^{1} \mathbf{X I}_{\mathbf{C}}$ proceeds via ${ }^{1} \mathbf{T S}(\mathbf{X I}-\mathbf{V I I I})_{\mathbf{C}}(+89 \mathrm{~kJ} / \mathrm{mol})$ to afford intermediate ${ }^{1} \mathbf{V I C}(+43 \mathrm{~kJ} / \mathrm{mol})$. From here, the remaining steps to afford ${ }^{1} \mathbf{V I c}$ are identical to those outlined in the analogous toluene-adsorbed profile.

Comparing these two routes of $\mathrm{O}_{2}$ insertion into $\mathrm{Pd}-\mathrm{H}$, both $\mathrm{O}_{2}$-insertion processes, HAA and HMI, are isoenergetic, where $\Delta \mathrm{G}^{\ddagger}=+89 \mathrm{~kJ} / \mathrm{mol}$, while comparison with the toluene-bound pathway, HAA with an arene still $\eta^{2}$-coordinated to the $\mathrm{Pd}$ center, is identified to be the most kinetically accessible (via ${ }^{3} \mathbf{T S}(\mathbf{I I}-\mathbf{I I I})_{\mathbf{C}}$, where $\left.\Delta \mathrm{G}+=+80 \mathrm{~kJ} / \mathrm{mol}\right)$. 
(a) Hydrogen Atom Abstraction (HAA)

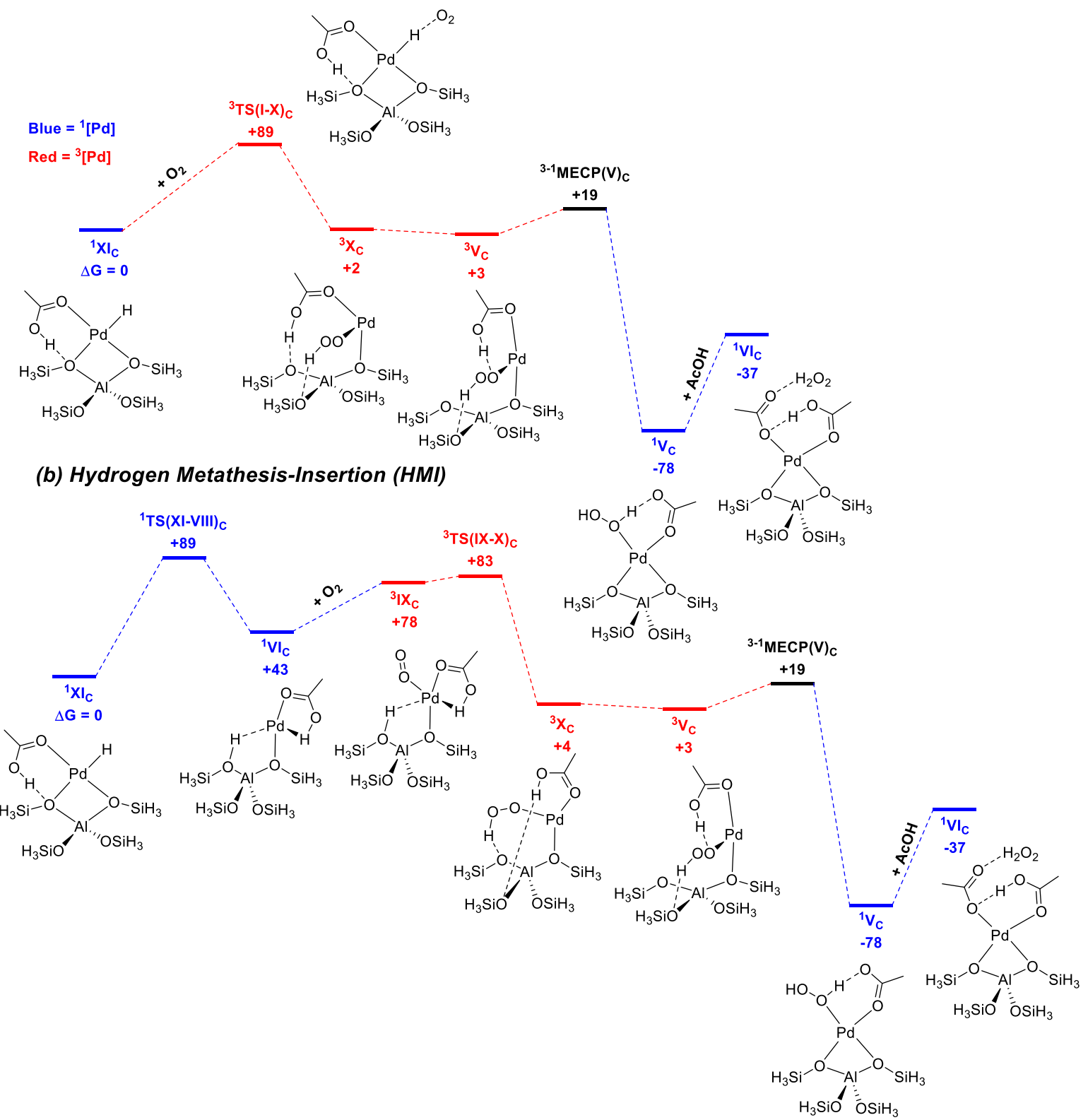

Supplementary Figure 53. Computed free-energy profile of the two modelled pathways of $\mathrm{O}_{2}$ insertion at the B3LYP-D3/Def2-TZVPPD//B3LYP/BS1 level. (a) Hydrogen atom abstraction (HAA). (b) Hydrogen metathesis-insertion (HMI). Energies are relative to toluene-dissociated state ${ }^{\mathbf{1}} \mathbf{X I}_{\mathbf{C}}$ and corresponding reactants. 
Supplementary Table 16: Reported optimized SCF energies (at the B3LYP/BS1 level), $\Delta \mathrm{G}$ corrections, and single-point SCF energies at the B3LYP-D3/Def2-TZVPPD level.

\begin{tabular}{|c|c|c|c|}
\hline Species & $\begin{array}{lr}\text { SCF } & \text { Energy } \\
\text { (B3LYP/BS1) } & \text { (a.u.) }\end{array}$ & $\Delta \mathbf{G}$ corr & $\begin{array}{l}\text { SCF } \quad \text { Energy } \\
\text { (B3LYP-D3/BS2) } \\
\text { (a.u.) }\end{array}$ \\
\hline $\mathbf{O}_{2}$ & -150.2048 & -0.0212 & -150.3902 \\
\hline $\mathrm{C}_{7} \mathrm{H}_{8}$ & -271.3734 & 0.0906 & -271.6954 \\
\hline AcOH & -228.9173 & 0.0274 & -229.1988 \\
\hline${ }^{1} \mathbf{I}_{\mathbf{C}}$ & -2337.1567 & 0.2303 & -2338.7527 \\
\hline${ }^{3} \mathbf{I I}_{\mathbf{C}}$ & -2487.3649 & 0.2237 & -2489.1446 \\
\hline${ }^{3}$ TS(II-III)C & -2487.3474 & 0.2223 & -2489.1258 \\
\hline${ }^{3}$ IIIC $_{1}$ & -2487.3963 & 0.2313 & -2489.1747 \\
\hline${ }^{3-1}$ MECP(III)C & -2487.3906 & 0.2333 & -2489.1713 \\
\hline${ }^{1}$IIIIC $_{C}$ & -2487.4055 & 0.2395 & -2489.1890 \\
\hline${ }^{1}$ TS $($ IIII-IV)C & -2487.4020 & 0.2393 & -2489.1866 \\
\hline${ }^{1} \mathbf{I V}_{\mathbf{C}}$ & -2487.4156 & 0.2385 & -2489.1987 \\
\hline${ }^{1} \mathbf{V}_{\mathbf{C}}$ & -2216.0477 & 0.1224 & -2217.4892 \\
\hline${ }^{1} \mathbf{V I} \mathbf{I}_{\mathbf{C}}$ & -2444.9705 & 0.1761 & -2446.6983 \\
\hline${ }^{1} \mathrm{TS}(\mathrm{I}-\mathrm{VII}) \mathrm{C}$ & -2337.1282 & 0.2263 & -2338.7146 \\
\hline${ }^{1}$ VIIC & -2337.1470 & 0.2276 & -2338.7278 \\
\hline${ }^{1}$ VIIIC & -2065.7710 & 0.1149 & -2067.0231 \\
\hline${ }^{3} \mathbf{I} \mathbf{X}_{\mathbf{C}}$ & -2215.9810 & 0.1099 & -2217.4169 \\
\hline${ }^{3}$ TS $(I X-X) C$ & -2215.9809 & 0.1115 & -2217.4169 \\
\hline${ }^{3} \mathbf{X}_{\mathbf{C}}$ & -2216.0131 & 0.1173 & -2217.4526 \\
\hline${ }^{3} \mathbf{V}_{\mathbf{C}}$ & -2216.0152 & 0.1175 & -2217.4534 \\
\hline${ }^{3-1} \mathrm{MECP}(\mathrm{V})_{\mathrm{C}}$ & -2216.0077 & 0.1171 & -2217.4468 \\
\hline${ }^{1} \mathbf{X I} I_{C}$ & -2065.7884 & 0.1178 & -2067.0423 \\
\hline${ }^{3} \mathrm{TS}(\mathrm{XI}-\mathrm{X})_{\mathrm{C}}$ & -2215.9727 & 0.1095 & -2217.4117 \\
\hline${ }^{1} \mathrm{TS}(\mathrm{XI}-\mathrm{VIII})_{\mathrm{C}}$ & -2065.7504 & 0.1140 & -2067.0046 \\
\hline
\end{tabular}




\section{Supplementary References}

1. Palacios-Grijalva L. N. et al., Sulphated Zirconia as an Eco-Friendly Catalyst in Acylal Preparation under Solvent-Free Conditions, Acylal Deprotection Assisted by Microwaves, and the Synthesis of Anhydro-Dimers of $o$-Hydroxybenzaldehydes. Molecules, 14, 4065-4078 (2009).

2. Jiang, J. et al., Superacidity in Sulfated Metal-Organic Framework-808. J. Am. Chem. Soc., 136, 12844-12847 (2014).

3. Senapati, S., Zimdars, J., Ren, J. \& Koller, H. Post-synthetic modifications of as-made zeolite frameworks near the structure-directing agents. J. Mater. Chem. A, 2, 10470-10484 (2014).

4. Reddy, K. S. N., Eapen, M. J., Joshi, P. N., Mirajkar, S. P. \& Shiralkar, V. P. Physicochemical characterization of boro- and gallo-silicate isomorphs of $\beta$-zeolite. J. Incl. Phenom. Mol. Recognit. Chem., 20, 197-210 (1995).

5. Kamimura, Y., Itabashi, K. \& Okubo, T. Seed-assisted, OSDA-free synthesis of MTW-type zeolite and "Green MTW" from sodium aluminosilicate gel systems. Micropor. Mesopor. Mat., 147, 149-156 (2012).

6. Ravel, B. \& Newville, M. ATHENA, ARTEMIS, HEPHAESTUS: data analysis for X-ray absorption spectroscopy using IFEFFIT. J. Synchrotron Radiat., 12, 537-541 (2005).

7. Guda, S.A. et al., Optimized finite difference method for the full-potential XANES simulations: Application to molecular adsorption geometries in MOFs and metal-ligand intersystem crossing transients. J. Chem. Theory Comput., 11, 4512-4521 (2015).

8. Martini, A. et al., PyFitit: the software for quantitative analysis of XANES spectra using machine-learning algorithms. Comput. Phys. Commun., 250, 107064 (2020).

9. Hohwy, M., Jakobsen, H. J., Edén, M., Levitt, M. H. \& Nielsen, N. C. Broadband dipolar recoupling in the nuclear magnetic resonance of rotating solids: A compensated C7 pulse sequence. J. Chem. Phys., 108, 2686-2694 (1998).

10. Bak, M., Rasmussen, J. T. \& Nielsen, N. C. SIMPSON: A General Simulation Program for Solid-State NMR Spectroscopy. J. Magn. Reson, 147, 296-330 (2000).

11. VandeVondele, J. et al., Quickstep: Fast and accurate density functional calculations using a mixed Gaussian and plane waves approach. Comput. Phys. Commun., 167, 103-128 (2005).

12. Nosé, S. A. A molecular dynamics method for simulations in the canonical ensemble. Mol. Phys., 52, 255-268 (1984).

13. Martyna, G. J., Klein, M. L. \& Tuckerman, M. Nosé-Hoover chains: The canonical ensemble via continuous dynamics. J. Chem. Phys., 97, 2635-2643 (1992).

14. Martyna, G. J., Tobias, D. J. \& Klein, M. L. Constant pressure molecular dynamics algorithms. J. Chem. Phys., 101, 4177-4189 (1994).

15. Perdew, J. P., Burke, K. \& Ernzerhof, M. Generalized Gradient Approximation Made Simple. Phys. Rev. Lett., 77, 3865-3868 (1996).

16. Yang, K., Zheng, J., Zhao, Y. \& Truhlar, D. G. Tests of the RPBE, revPBE, $\tau$-HCTHhyb, $\omega \mathrm{B} 97 \mathrm{X}-\mathrm{D}$, and MOHLYP density functional approximations and 29 others against representative databases for diverse bond energies and barrier heights in catalysis. J. Chem. Phys., 132, 164117 (2010).

17. Lippert, G., Hutter, J. \& Parrinello, M. The Gaussian and augmented-plane-wave density functional method for ab initio molecular dynamics simulations. Theor. Chem. Acc., 103, 124-140 (1999).

18. Lippert, G., Hutter, J. \& Parrinello, M. A hybrid Gaussian and plane wave density functional scheme. Mol. Phys., 92, 477-488 (1997). 
19. Goedecker, S., Teter, M. \& Hutter, J. Separable dual-space Gaussian pseudopotentials. Phys. Rev. B: Condens. Matter Mater. Phys., 54, 1703-1710 (1996).

20. VandeVondele, J. \& Hutter, J. Gaussian basis sets for accurate calculations on molecular systems in gas and condensed phases. J. Chem. Phys., 127, 114105 (2007).

21. Kresse, G. \& Hafner, J., Ab initio molecular-dynamics simulation of the liquid-metalamorphous-semiconductor transition in germanium. Phys. Rev. B: Condens. Matter Mater. Phys., 49, 14251-14269 (1994).

22. Kresse, G. \& Furthmüller, J. Efficiency of ab-initio total energy calculations for metals and semiconductors using a plane-wave basis set. Comput. Mater. Sci., 6,15-50 (1996).

23. Kresse, G. \& Furthmüller, J. Efficient iterative schemes for ab initio total-energy calculations using a plane-wave basis set. Phys. Rev. B: Condens. Matter Mater. Phys., 54, 11169-11186 (1996).

24. Perdew, J. P., Burke, K. \& Ernzerhof, M. Generalized Gradient Approximation Made Simple. Phys. Rev. Lett., 77, 3865-3868 (1996).

25. Grimme, S., Antony, J., Ehrlich, S. \& Krieg, H. A. consistent and accurate ab initio parametrization of density functional dispersion correction (DFT-D) for the 94 elements H-Pu. $J$. Chem. Phys., 132, 154104 (2010).

26. Kresse, G. \& Joubert, D. From ultrasoft pseudopotentials to the projector augmented-wave method. Phys. Rev. B: Condens. Matter Mater. Phys., 59, 1758-1775 (1999).

27. Blöchl, P. E. Projector augmented-wave method. Phys. Rev. B: Condens. Matter Mater. Phys., 50, 17953-17979 (1994).

28. Heyden, A., Bell, A. T. \& Keil, F. J. Efficient methods for finding transition states in chemical reactions: Comparison of improved dimer method and partitioned rational function optimization method. J. Chem. Phys., 123, 224101 (2005).

29. Pulay, P. Convergence acceleration of iterative sequences. the case of scf iteration. Chem. Phys. Lett., 73, 393-398 (1980).

30. Ghysels, A., Van Neck, D. \& Waroquier, M. Cartesian formulation of the mobile block Hessian approach to vibrational analysis in partially optimized systems. J. Chem. Phys., 127, 164108 (2007).

31. Reetz, M. T. et al., Why are BINOL-based monophosphites such efficient ligands in Rhcatalyzed asymmetric olefin hydrogenation? J. Am. Chem. Soc., 127, 10305-10313 (2005).

32. Donoghue, P. J., Helquist, P., Norrby, P.-O. \& Wiest, O. Development of a Q2MM Force Field for the Asymmetric Rhodium Catalyzed Hydrogenation of Enamides. J. Chem. Theory Comput., 4, 1313-1323 (2008).

33. Ghysels, A., Verstraelen, T., Hemelsoet, K., Waroquier, M. \& Van Speybroeck, V. TAMkin: A Versatile Package for Vibrational Analysis and Chemical Kinetics. J. Chem. Inf. Model., 50, 1736-1750 (2010).

34. De Moor, B.A. et al., Normal Mode Analysis in Zeolites: Toward an Efficient Calculation of Adsorption Entropies. J. Chem. Theory Comput., 7, 1090-1101 (2011).

35. Zhi, Y. et al.,. Dehydration Pathways of 1-Propanol on HZSM-5 in the Presence and Absence of Water. J. Am. Chem. Soc., 137, 15781-15794 (2015).

36. Herrmann, S. \& Iglesia, E. Elementary steps in acetone condensation reactions catalyzed by aluminosilicates with diverse void structures. J. Catal., 346, 134-153 (2017).

37. DeLuca, M., Kravchenko, P., Hoffman, A. \& Hibbitts, D. Mechanism and Kinetics of Methylating C6-C12 Methylbenzenes with Methanol and Dimethyl Ether in H-MFI Zeolites. ACS Catal., 9, 6444-6460 (2019). 
38. Becke, A.D. Density-functional thermochemistry. III. The role of exact exchange. J. Chem. Phys., 98, 5648-5652 (1993).

39. Lee, C., Yang, W. \& Parr, R. G. Development of the Colle-Salvetti correlation-energy formula into a functional of the electron density. Phys. Rev. B, 37, 785-789 (1988).

40. Dolg, M., Wedig, U., Stoll, H., Preuss, H. Energy-adjusted ab initio pseudopotentials for the first row transition elements. J. Chem. Phys., 86, 866-872 (1987).

41. Andrae, D., Häußermann, U., Dolg, M., Stoll, H., Preuß, H. Energy-adjusted ab initio pseudopotentials for the second and third row transition elements. Theor. Chim. Acta, 77, 123-141 (1990).

42. Weigend, F. \& Ahlrichs, R. Balanced basis sets of split valence, triple zeta valence and quadruple zeta valence quality for $\mathrm{H}$ to $\mathrm{Rn}$ : Design and assessment of accuracy. Phys. Chem. Chem. Phys., 7, 3297 (2005).

43. Luchini, G. et al. bobbypaton/GoodVibes: GoodVibes v3.0.0. (2019).

44. Harvey, J. N., Aschi, M., Schwarz, H. \& Koch. W. The singlet and triplet states of phenyl cation. A hybrid approach for locating minimum energy crossing points between non-interacting potential energy surfaces. Theor. Chem. Acc., 99, 95-99 (1998).

45. Gannon, K. L. et al., An experimental and theoretical investigation of the competition between chemical reaction and relaxation for the reactions of $1 \mathrm{CH} 2$ with acetylene and ethene: implications for the chemistry of the giant planets. Farad. Discuss., 147, 173-188 (2010).

46. Andrae, D., Häußermann, U., Dolg, M., Stoll, H. \& Preuß, H. Energy-adjusted ab initio pseudopotentials for the second and third row transition elements. Theor. Chim. Acta, 77, 123-141 (1990).

47. Rappoport, D. \& Furche, F. Property-optimized Gaussian basis sets for molecular response calculations. J. Chem. Phys., 133, 134105 (2010).

48. Weigend, F., Ahlrichs, R. Balanced basis sets of split valence, triple zeta valence and quadruple zeta valence quality for $\mathrm{H}$ to Rn: Design and assessment of accuracy. Phys. Chem. Chem. Phys., 7, 3297-3305 (2005).

49. Antony, J., Ehrlich, S., \& Krieg, H. A consistent and accurate ab initio parametrization of density functional dispersion correction (DFT-D) for the 94 elements H-Pu. J. Chem. Phys., 132, 154104 (2010).

50. Grimme, S., Ehrlich, S. \& Goerigk, L. Effect of the damping function in dispersion corrected density functional theory. J. Comput. Chem., 32, 1456-1465 (2011).

51. Pritchard, B. P., Altarawy, D., Didier, B., Gibson, T. D. \& Windus, T. L. New Basis Set Exchange: An Open, Up-to-Date Resource for the Molecular Sciences Community. J. Chem. Inf. Model., 59, 4814-4820 (2019).

52. Zhao, Z., Xu, S., Hu, M. Y., Bao, X., Peden, C. \& Hu, J. Investigation of Aluminum Site Changes of Dehydrated Zeolite H-Beta during a Rehydration Process by High-Field Solid-State NMR. J. Phys. Chem. C, 119, 3, 1410-1417 (2015).

53. Wang, D., Izawa, Y. \& Stahl, S. S. Pd-Catalyzed Aerobic Oxidative Coupling of Arenes: Evidence for Transmetalation between Two Pd(II)-Aryl Intermediates. J. Am. Chem. Soc., 136, 9914-9917 (2014).

54. Kim, J. \& Hong, S. H. Ligand-Promoted Direct C-H Arylation of Simple Arenes: Evidence for a Cooperative Bimetallic Mechanism. ACS Catal., 7, 3336-3343 (2017).

55. Wang, L. \& Carrow, B. P. Oligothiophene Synthesis by a General C-H Activation Mechanism: Electrophilic Concerted Metalation-Deprotonation (eCMD). ACS Catal., 9, 6821-6836 (2019). 
56. Wang, D. \& Stahl, S. S. Pd-Catalyzed Aerobic Oxidative Biaryl Coupling: Non-Redox Cocatalysis by $\mathrm{Cu}(\mathrm{OTf})_{2}$ and Discovery of $\mathrm{Fe}(\mathrm{OTf})_{3}$ as a Highly Effective Cocatalyst. J. Am. Chem. Soc., 139, 5704-5707 (2017).

57. Álvarez-Casao, Y. et al., Palladium-Catalyzed Cross-Dehydrogenative Coupling of $o$-Xylene: Evidence of a New Rate-Limiting Step in the Search for Industrially Relevant Conditions. ChemCatChem, 10, 2620-2626 (2018).

58. Birch, F. Finite Elastic Strain of Cubic Crystals. Phys. Rev., 71, 809-824 (1947).

59. Murnaghan, F. D. The Compressibility of Media under Extreme Pressures. PNAS, 30, 244-247 (1944).

60. Blasco, T. et al. Direct Synthesis and Characterization of Hydrophobic Aluminum-Free Ti-Beta Zeolite. J. Phys. Chem. B, 102, 1, 75-88 (1998).

61. Popp, B. V. \& Stahl., S. S. Insertion of Molecular Oxygen into a Palladium-Hydride Bond: Computational Evidence for Two Nearly Isoenergetic Pathways. J. Am. Chem. Soc., 129, 14, 44104422 (2007).

62. Konnick, M. M., Decharin, N., Popp, B. V. \& Stahl., S. S. $\mathrm{O}_{2}$ insertion into a palladium(II)hydride bond: Observation of mechanistic crossover between HX-reductive-elimination and hydrogen-atom-abstraction pathways. Chem. Sci., 2, 326-330 (2011).

63. Newville, M., Boyanov, B. I. \& Sayers, D. E. Estimation of measurement uncertainties in XAFS data. J. Synchrotron Rad., 6, 264-265 (1999). 